University of Louisville

ThinkIR: The University of Louisville's Institutional Repository

Electronic Theses and Dissertations

$5-2020$

\title{
Experimental evaluation of heat leak and convective heat transfer in a household freezer.
}

Catherine E. Berghuis

University of Louisville

Follow this and additional works at: https://ir.library.louisville.edu/etd

Part of the Heat Transfer, Combustion Commons

\section{Recommended Citation}

Berghuis, Catherine E., "Experimental evaluation of heat leak and convective heat transfer in a household freezer." (2020). Electronic Theses and Dissertations. Paper 3458.

https://doi.org/10.18297/etd/3458

This Master's Thesis is brought to you for free and open access by ThinkIR: The University of Louisville's Institutional Repository. It has been accepted for inclusion in Electronic Theses and Dissertations by an authorized administrator of ThinkIR: The University of Louisville's Institutional Repository. This title appears here courtesy of the author, who has retained all other copyrights. For more information, please contact thinkir@louisville.edu. 


\title{
EXPERIMENTAL EVALUATION OF HEAT LEAK AND CONVECTIVE HEAT TRANSFER IN A HOUSEHOLD FREEZER
}

\author{
By \\ Catherine E. Berghuis \\ B.A., Dartmouth College, 2016 \\ B.E., Dartmouth College, 2017

\begin{abstract}
A Thesis
Submitted to the Faculty of the University of Louisville

J.B. Speed School of Engineering

In Partial Fulfillment of the Requirements

for the Degree of

Master of Science

in Mechanical Engineering
\end{abstract} \\ Department of Mechanical Engineering \\ University of Louisville \\ Louisville, KY
}

May, 2020 



\title{
EXPERIMENTAL EVALUATION OF HEAT LEAK AND CONVECTIVE HEAT TRANSFER IN A HOUSEHOLD FREEZER
}

\author{
By \\ Catherine E. Berghuis \\ B.A., Dartmouth College, 2016 \\ B.E., Dartmouth College, 2017
}

A Thesis Approved On

March $13^{\text {th }}, 2020$

by the following Thesis Committee:

Dr. Ellen Brehob, Thesis Co-Advisor

Dr. Andrea Kelecy, Thesis Co-Advisor

Dr. R. Eric Berson, Committee Member 


\section{DEDICATION}

This thesis is dedicated to my parents, Jennifer and Harold Berghuis, who have afforded me countless opportunities in educational, athletic, and personal endeavors throughout my life. I would also like to dedicate this work to my advisor and mentor throughout this project, Carlos Herrera, who has shown me the true definition of work ethic and perseverance in the face of adversity. 


\section{ACKNOWLEDGMENT}

I would like to thank my advisors, Dr. Kelecy and Dr. Brehob for their support, encouragement and dedication to thorough examination of my work throughout this study. Additionally, I am thankful for management at GE Appliances, including Tim O'Connell, who have created the opportunities for this project to be sponsored and funded. 


\begin{abstract}
EXPERIMENTAL EVALUATION OF HEAT LEAK AND CONVECTIVE HEAT TRANSFER IN A HOUSEHOLD FREEZER
\end{abstract}

Catherine E. Berghuis

\begin{abstract}
March $13^{\text {th }}, 2020$
Heat leak into household refrigerated cabinets is a key driver affecting energy consumption and efficiency of the cooling system. Additionally, knowledge of heat transfer coefficients of internal surfaces is valuable in the development of cabinet and system level performance simulations. Several studies have examined heat leak of refrigeration units using heat flux sensors (HFS); however, no such studies have used heat flux measurements to derive convective heat transfer coefficients of the refrigerated unit walls. The goal of this study is to evaluate the use of HFS to quantify heat leak into a 490 -liter freezer and determine the wall convective heat transfer coefficients.
\end{abstract}

Cabinet heat leak was measured using thermopile heat flux transducers adhered to the interior walls of a household freezer. The expected heat leak was calculated from an evaporator energy balance with temperature and pressure measurements of refrigerant and compared to HFS measurements. Convective 
heat transfer coefficients were based on Newton's law of cooling using measured inner surface and air temperatures.

This investigation determined that for the 12 HFS used, the HFS underpredict heat flux by an average of $7 \%$ in a one-dimensional validation system. When mounted to the internal walls of the freezer, HFS underpredicted heat leak by approximately $16 \%$ when considering gasket heat leak, edge effects, evaporator fan watts and sensor underprediction. Convective heat transfer coefficients were calculated using the average and local heat flux value for a wall and the air and wall temperatures. The average heat transfer coefficient values of the walls were between 8.9 and $14.6 \mathrm{~W} / \mathrm{m}^{2} \mathrm{~K}$. The local convection coefficients were between 6.0 and $17.5 \mathrm{~W} / \mathrm{m}^{2} \mathrm{~K}$.

The results showed that HFS are not a reliable method of determining heat transfer coefficients due to their sensitivity to variation in wall and free stream temperatures. 
TABLE OF CONTENTS

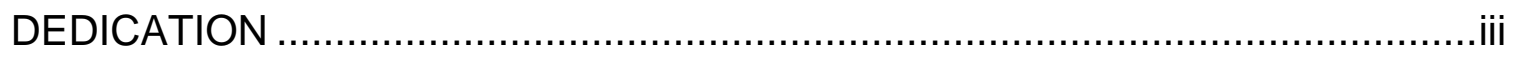

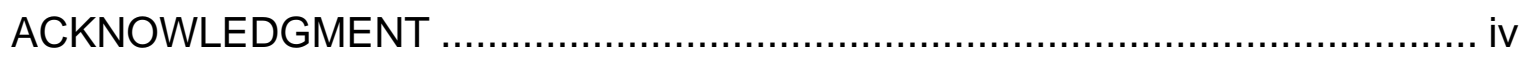

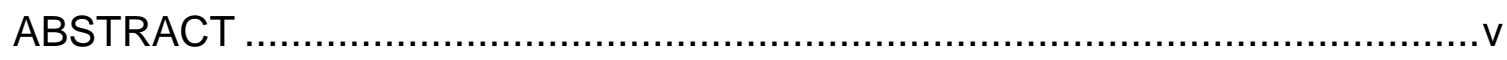

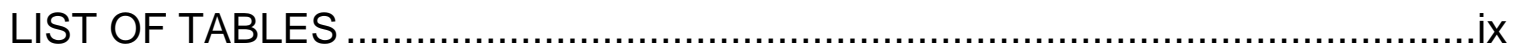

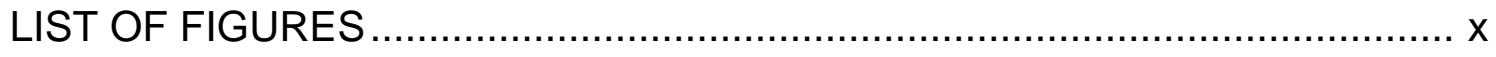

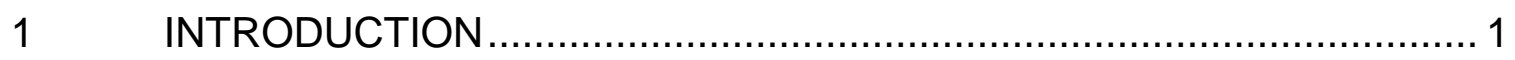

1.1 Previous Studies of Convective Heat Transfer in Refrigeration .............. 2

1.2 Previous Studies of Heat Leak Quantification in Refrigeration ............... 8

2 EXPERIMENTAL SETUP AND PROCEDURE …............................ 16

2.1 Forward Heat Leak Calorimeter ……............................................ 16

2.2 Sealed System Design and Construction ......................................... 19

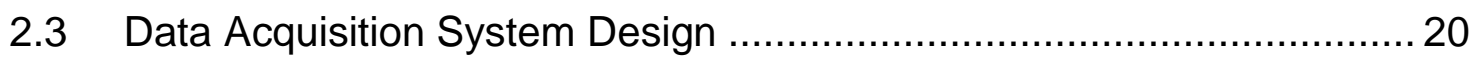

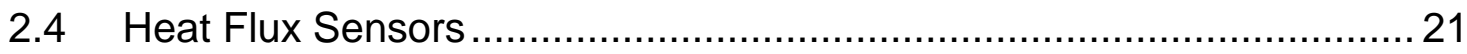

2.5 Heat Flux Sensor Measurement Validation ....................................... 23

2.6 Household Freezer Heat Flux Measurement..................................... 28

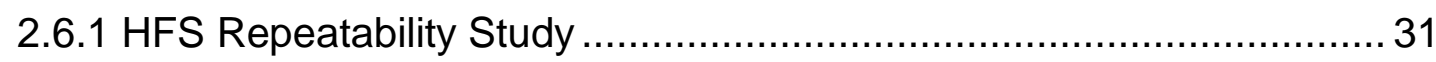

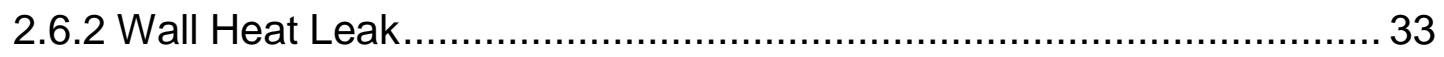


3 RESULTS

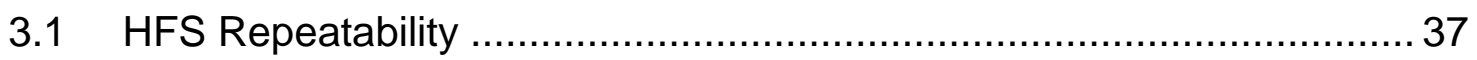

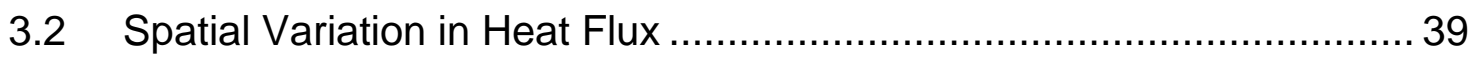

3.3 Wall to Wall Comparison of Heat Leak ............................................. 42

3.4 Calorimeter Heat Flux Compared to HFS Measurements .................... 43

3.4.1 Gasket Removal Testing to Quantify Gasket Heat Leak .................... 45

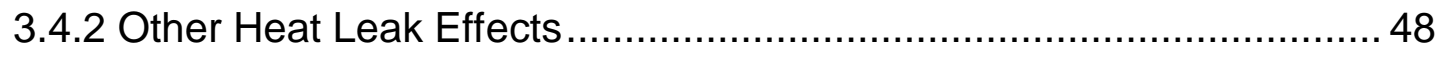

3.5 Convective Heat Transfer Coefficients ..............................................50

3.6 Uncertainty and Sensitivity Analysis ..............................................54

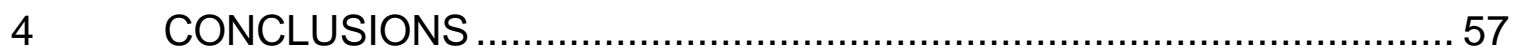

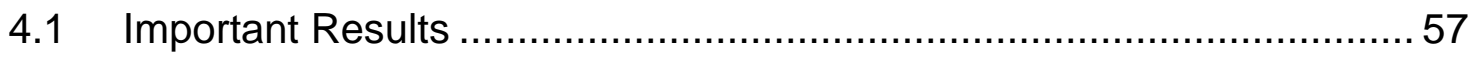

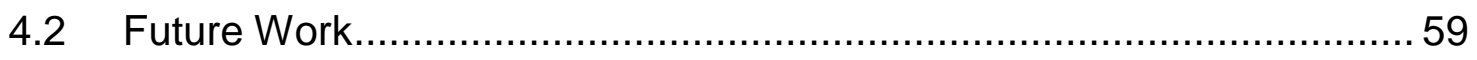

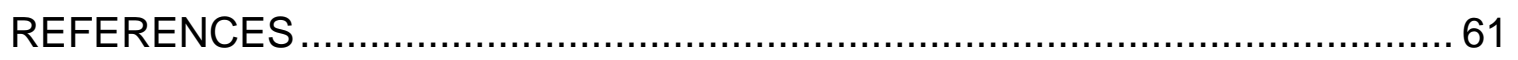

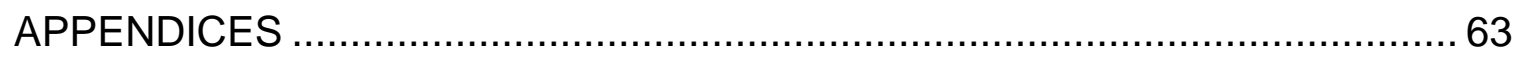

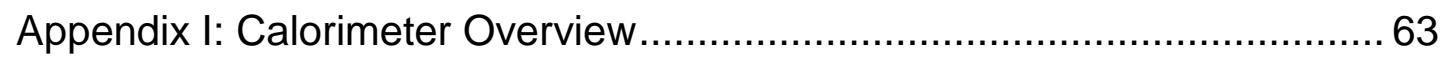

Appendix II: Heat Flux Sensor Technology ............................................. 75

Appendix III: Shape Factor Calculations …………................................. 79

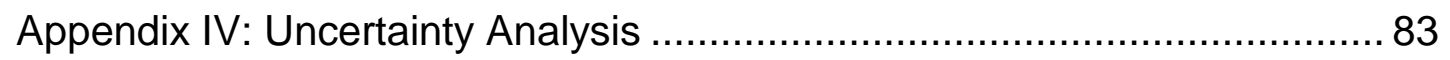

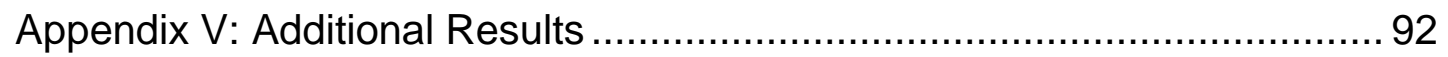




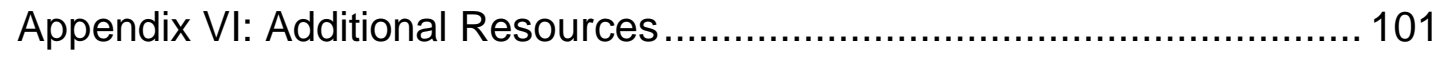

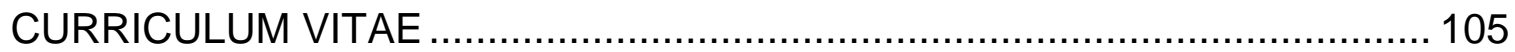




\section{LIST OF TABLES}

Table 1 Convective heat transfer coefficients for fresh food and freezer

compartments (Hasanuzzaman et al., 2009) ................................................ 3

Table 2 Heat flux and heat transfer rate distribution for each wall (Melo, 2000) . 12 Table 3 Summary of gasket heat leak, Nu correlations and convection coefficient estimates from the literature 14

Table 4 Data acquisition system measured variables described in Figure 2-1 and

$2-2$ 20

Table 5 HFS sensor models used for heat flux measurements ..... 22

Table 6 HFS validation experiment results for $0.5 \mathrm{~W}\left(29.4 \mathrm{~W} / \mathrm{m}^{2}\right.$ expected flux $)$

and $1 \mathrm{~W}\left(58.8 \mathrm{~W} / \mathrm{m}^{2}\right.$ expected flux) heater input 27

Table 7 Magnitude and standard deviation of percent error values of both sensor

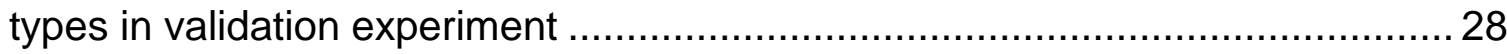

Table 8 Summary of heat leak testing with HFS ............................................. 36

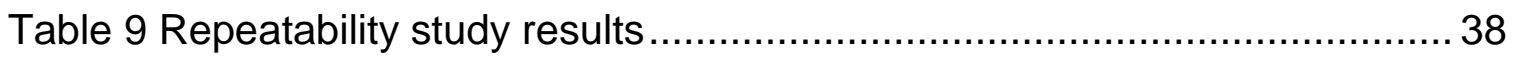

Table 10 Total heat leak into cabinet comparison to Melo et al. (2000).............. 42

Table 11 Comparison of HFS and calorimeter heat leak ................................. 45

Table 12 Heat leak values for different gasket conditions from calorimeter........ 45

Table 13 Average heat flux comparison between production gasket and foamed

gasket area for the left wall, right wall and door surfaces 
Table 14 Heat leak comparison between production gasket and foamed gasket area.

Table 15 Heat leak comparison between calorimeter measurement and all variations of HFS heat leak quantification 50 Table 16 Air and wall temperatures and local convection coefficients inside freezer compartment 51 Table 17 Average and local convective heat transfer coefficients for each internal wall of freezer 53

Table 18 Results of uncertainty analysis of calorimeter and HFS methods for typical calorimeter operating conditions. 55 Table 19 Convective heat transfer coefficient based on HFS and varying wall temperature with heat flux of $10 \mathrm{~W} / \mathrm{m}^{2}$ and air temperature of $-18.5^{\circ} \mathrm{C}\left(-1.3^{\circ} \mathrm{F}\right) 55$ Table 20 Convective heat transfer coefficient based on HFS and varying wall temperature with heat flux of $20 \mathrm{~W} / \mathrm{m}^{2}$ and air temperature of $-18.5^{\circ} \mathrm{C}\left(-1.3^{\circ} \mathrm{F}\right) 55$

Table A1 NI modules and their functionality ............................................. 74

Table A2 Thermopile heat flux sensors considered for study .......................... 78

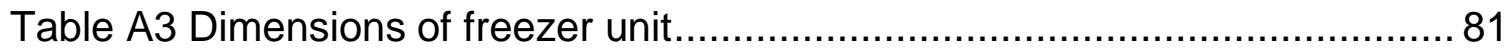

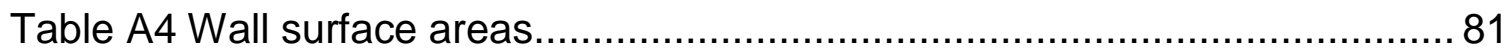

Table A5 Percentage of total heat leak attributed to walls, edges and corners of

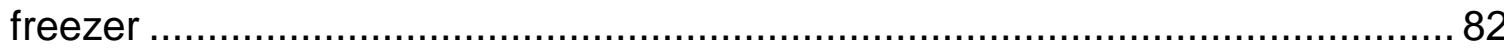

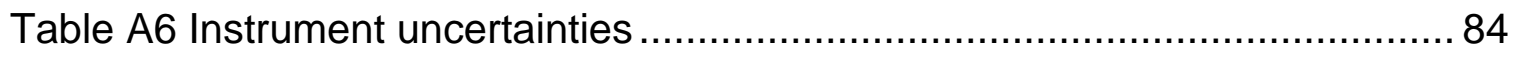


Table A7 Sequential perturbation results for overall heat leak, varying mass flow rate 85

Table A8 Sequential perturbation results for overall heat leak, varying inlet temperature 86

Table A9 Sequential perturbation results for overall heat leak, varying outlet temperature 86 Table A10 Convective heat transfer coefficient based on HFS and varying wall temperature with heat flux of $10 \mathrm{~W} / \mathrm{m}^{2}$ and air temperature of $-18.5^{\circ} \mathrm{C}$ 87 Table A11 Convective heat transfer coefficient based on HFS and varying wall temperature with heat flux of $20 \mathrm{~W} / \mathrm{m}^{2}$ and air temperature of $-18.5^{\circ} \mathrm{C}$ 87

Table A12: Air and wall temperatures inside freezer compartment for single test

Table A13 Average temperatures inside freezer and heat leak for stable and unstable mass flow conditions

Table A14 Additional reading on heat leak calorimetry and heat flux sensors.. 101 


\section{LIST OF FIGURES}

Figure 1-1 Comparison between experimental and predicted air temperatures with and without radiation: (a) empty refrigerator, (b) refrigerator fitted with glass

shelves, (c) refrigerator loaded with products (Laguerre, 2012) ........................ 4

Figure 1-2 Experimental setup of cabinet with cold contents and warm walls

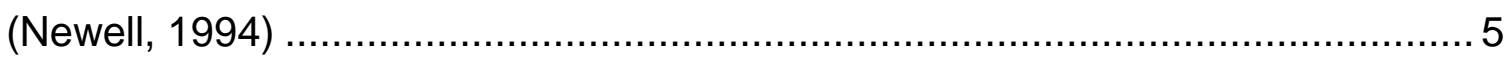

Figure 1-3 Thermocouple placement for Boughton's experiment (1992) ............. 8

Figure 1-4 Boughton's thermopile test apparatus (1992) …........................... 9

Figure 1-5 Refrigeration test facility built for Melo forward heat leak calorimeter

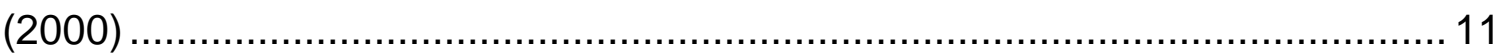

Figure 1-6 HFS distribution on refrigerator (Melo et al., 2000)........................ 11

Figure 2-1 Schematic of instrumented forward heat leak calorimeter ................ 17

Figure 2-2 Ideal P-h diagram of refrigeration cycle with numbers and letters

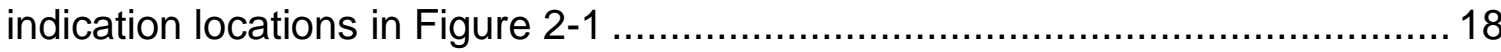

Figure 2-3 Schematic of differential temperature thermopile (Fluxteq, 2018) .....21

Figure 2-4 (a) $10 \mathrm{~mm}$ X $10 \mathrm{~mm}$ sensor (b) $4.4 \mathrm{~mm} \mathrm{X} 4.4 \mathrm{~mm}$ sensor. Dimension

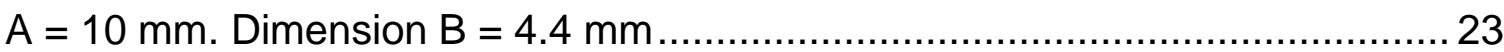

Figure 2-5 Aluminum plate with coil heater adhered to its bottom surface ......... 24

Figure 2-6 HFS validation test set-up. Vertical arrow indicates direction of heat

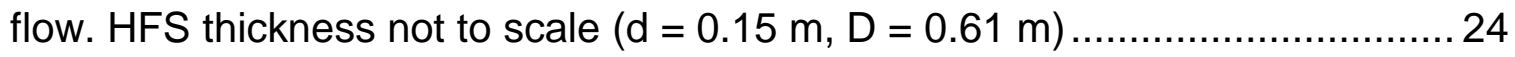

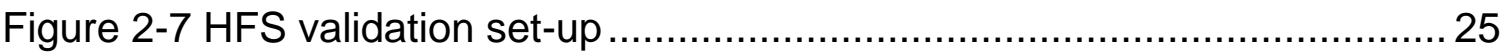


Figure 2-8 Inside of 490 -liter freezer with thermocouple brass weights installed in four locations. Back wall HFS mounted behind air tower cover 29 Figure 2-9 Moving average of heat flux approaching steady state when HFS was mounted to top wall of freezer 30 Figure 2-10 Freezer cabinet temperature pulling down to zero as measured by average of thermocouples embedded in brass weights. 31 Figure 2-11 Sensors mounted to left wall for repeatability study. Sensors are boxed in red...... 32 Figure 2-12 Left interior wall of unit. Numbers indicate grid location. Sensors not to scale 33

Figure 2-13 Grid areas for HFS mounting for each wall of the cabinet 34 Figure 3-1 Location of sensors on left wall for repeatability study. 39 Figure 3-2 (a) Left wall heat leak (12.3 W total) (b) Right wall heat leak (12.4 W total)

Figure 3-3 (a) Top wall heat flux (6.3 W total) (b) Bottom wall heat flux (5.1 W total) 40 Figure 3-4 (a) Door heat flux viewed from inside unit (12.5 W total) (b) Back wall heat flux (12.5 $\mathrm{W}$ total) 41 Figure 3-5 Heat leak components into refrigerated compartment of 490 -liter freezer 44

Figure 3-6 Freezer with gasket removed and insulating foam surrounding perimeter of door 46 
Figure 3-7 Cross section of 490-liter freezer with arrows indicating airflow pattern 52

Figure A1 Forward heat leak calorimeter fixture with (a) door closed and (b) open 63

Figure A2 Schematic of instrumented forward heat leak calorimeter. 64 Figure A3 Embraco VEGD 7H mounted to forward heat leak calorimeter fixture 65 Figure A4 Side panel of calorimeter with refrigerant charge ports, isolation valves and sight glasses. 66

Figure A5 (a) Alfa Laval AC16 connected to (b) filter dryer and mounted to forward heat leak calorimeter fixture. 67

Figure A6 (a) Liquid line receiver (b) suction line accumulator ......................... 68

Figure A7 Evaporator with refrigerant fittings installed ................................... 69

Figure A8 Front view of unit with TXV and evaporator cover installed............... 70

Figure A9 (a) Insulated copper tubes (b) Setra AccuSense pressure transducers installed on high and low side of sealed system ............................................. 71

Figure A10 Panel for thermocouple and fan quick connections........................ 72

Figure A11 Calorimeter with all instruments and power connected .................. 73

Figure A12 Cross sectional schematic of Gardon gauge (1953) ...................... 76

Figure A13 Schematic of thermopile heat flux sensor (Wikipedia, 2014) ............77

Figure A14 Conduction through corner of three perpendicular walls with a

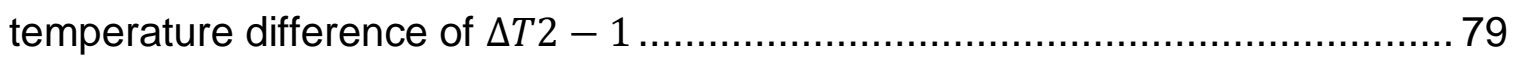

Figure A15 Conduction through the edge of adjoining walls............................. 80 
Figure A16 Temperature of left wall and air inside freezer .............................. 89

Figure A17 Temperature of right wall and air inside freezer ............................. 89

Figure A18 Temperature of top and bottom wall and air inside freezer .............. 90

Figure A19 Temperature of door and air inside freezer .................................. 90

Figure A20 Temperature of back wall and air inside freezer ...........................91

Figure A21 Left wall heat flux measurements............................................. 92

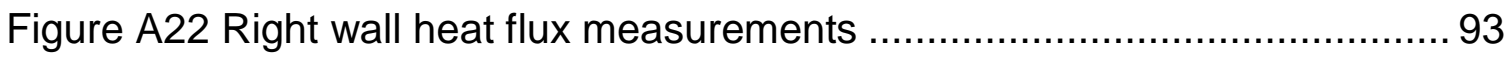

Figure A23 Top wall heat flux measurements …......................................... 93

Figure A24 Door heat flux measurements ................................................... 94

Figure A25 Bottom wall heat flux measurements ......................................... 94

Figure A26 Back wall heat flux measurements ............................................... 95

Figure A27 Heat flux measurements of locations that were previously missing

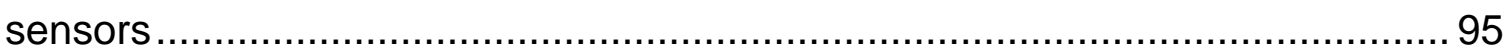

Figure A28 Left wall heat flux measurements with gasket foamed .....................96

Figure A29 Right wall heat flux measurements with gasket foamed..................96

Figure A30 Left wall heat flux measurements repeatability study first test .........97

Figure A31 Left wall heat flux measurements repeatability study second test....97

Figure A32 Heat leak into freezer with stable mass flow ................................ 99

Figure A33 Heat leak into freezer with unstable mass flow ........................... 100 


\section{INTRODUCTION}

Reducing energy consumption and maintaining safe and desirable temperatures is paramount when designing and optimizing the performance of household refrigerators. A traditional approach to improving refrigerator performance is to improve critical sealed system components such as the compressor and heat exchangers. Methods to determine the root cause of energy test failures are to troubleshoot these primary sealed system components. Refrigerated cabinets are prone to heat leak from the external environment to the inside of the case. Components like door gaskets and insulating foam help maintain the low temperatures; however, there are several ways thermal energy from the surrounding environment can transfer into the cabinet. As heat is transferred to the inside of the cabinet, the compressor must work harder to maintain desirable internal temperatures. This makes it difficult to meet energy standards since the compressor must utilize more energy to maintain low internal temperatures.

Two methods were used to quantify heat leak for a 490-liter upright freezer maintained at $-17.8^{\circ} \mathrm{C}\left(0^{\circ} \mathrm{F}\right)$ in a $32.2^{\circ} \mathrm{C}\left(90^{\circ} \mathrm{F}\right)$ room; calculating evaporator load from an energy balance using in line refrigerant property measurements and estimating heat leak using heat flux measurements. The primary objective was to determine if heat flux sensors (HFS) were able to accurately quantify heat leak into 
the cabinet. Additionally, the feasibility of using HFS to determine convective heat transfer coefficients of the internal walls of the freezer was examined.

\subsection{Previous Studies of Convective Heat Transfer in Refrigeration}

Hasanuzzaman, Saidur and Masjuki (2009) conducted experiments to investigate the effects of the ambient temperature, cabinet load and thermostat setting on the heat transfer and energy consumption of refrigerators. Cabinet load was modified by placing large containers of water inside the unit. Thermocouples and humidity sensors were placed in several locations in the fresh food and freezer compartments of a household refrigerator. The convective heat transfer was calculated for each operating condition and was based on the Nusselt number correlation of a closed rectangular cavity shown in Equation 1. Pr is the Prandtl number of the air circulating inside the cabinet. Ra is the Rayleigh number shown in Equation 2 where $L$ is the height of the cavity, $g$ is gravitational acceleration, $\beta$ is the thermal expansion coefficient, $v$ is the kinematic viscosity, $T_{w}$ is the vertical wall surface temperature and $T_{\infty}$ is the inside ambient temperature. The convective heat transfer coefficient $h$ is calculated with the unitless Nusselt number $\mathrm{Nu}$, thermal conductivity $k$, and the characteristic length $L$ (Equation 3 ).

$$
\begin{gathered}
N u=0.18\left(\frac{\operatorname{Pr}}{0.2+\operatorname{Pr}} R a\right)^{0.29} \\
R a=\operatorname{Pr}\left[\frac{g \beta}{v^{2}}\left|T_{\infty}-T_{w}\right| L^{3}\right] \\
h=\frac{N u * k}{L}
\end{gathered}
$$


The average convective heat transfer coefficients reported by Hasanuzzaman et al. for the fresh food and freezer compartments are shown in Table 1.

Table 1 Convective heat transfer coefficients for fresh food and freezer compartments (Hasanuzzaman et al., 2009)

\begin{tabular}{|c|c|}
\hline Compartment & $\begin{array}{c}\text { Average convective heat transfer } \\
\text { coefficient }\left[\mathrm{W} / \mathbf{m}^{2} \mathbf{K}\right]\end{array}$ \\
\hline Fresh food & 1.35 \\
\hline Freezer & 1.55 \\
\hline
\end{tabular}

Laguerre (2012) explored heat transfer and natural convection in refrigerators. Three configurations were studied to understand the three-dimensional airflow and heat transfer in a refrigerator that may cause warm temperatures: an empty refrigerator, an empty refrigerator fitted with glass shelves and a refrigerator loaded with products. The refrigerator unit was instrumented with thermocouples to measure internal temperatures. Experimental results were compared to a CFD model that predicted air temperatures and flow patterns. The authors achieved the best agreement between experimental and predicted values when radiative heat transfer was considered and the refrigerator was empty (Figure 1-1 (a)). 

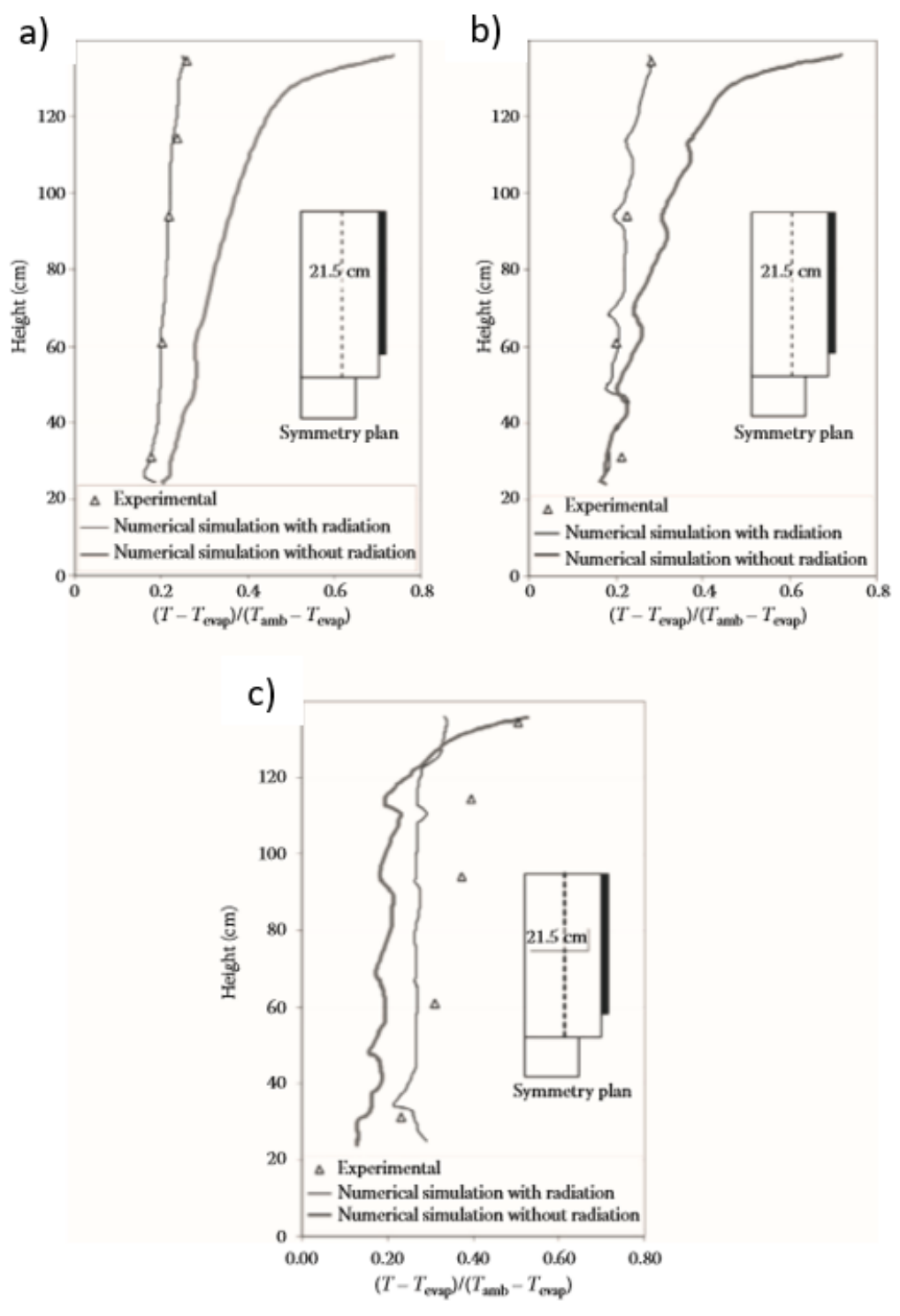

Figure 1-1 Comparison between experimental and predicted air temperatures with and without radiation: (a) empty refrigerator, (b) refrigerator fitted with glass shelves, (c) refrigerator loaded with products (Laguerre, 2012)

Laguerre found that adding shelves and a load significantly reduced air circulation in the cabinet and yielded higher temperatures compared to the unloaded refrigerator without shelves. This study compares a computational model 
to experimental data of airflow and heat transfer inside a refrigerator and no measurements of heat transfer coefficients were taken.

The convective heat transfer coefficient from the vertical, warm walls of a refrigerator with cold contents was explored in a study by Williams, Clausing and Newell (1994). The goal of their project was to experimentally determine the natural convection heat transfer coefficients as influenced by cabinet size, geometry and the load inside the refrigerator. Additionally, experimental data was compared to existing correlations for convection over a flat vertical plate, near corners, and between bodies and their enclosure. Ice in containers was placed inside the enclosure wrapped in aluminum to ensure a radiatively reflective surface (Figure 1-2).

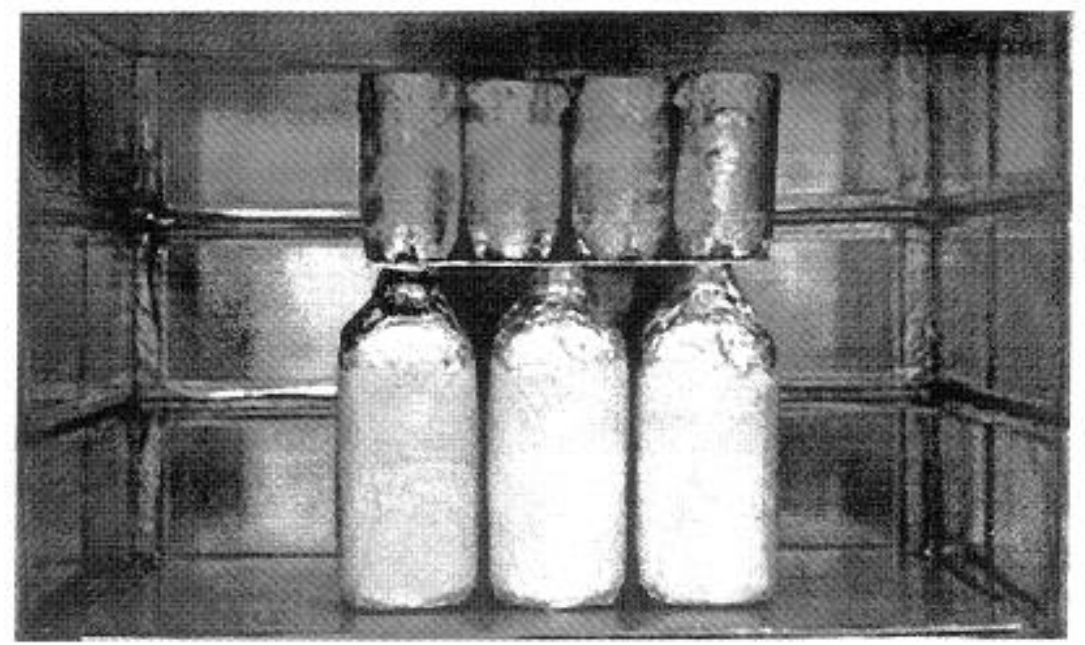

Figure 1-2 Experimental setup of cabinet with cold contents and warm walls (Newell, 1994)

Williams et al. (1994) assumed all walls were isothermal. This allowed for the calculation of average convective heat transfer coefficients for each internal wall of the refrigerator. The convection coefficient was extracted from the raw 
temperature and plate heater power data from inside the compartment. The total heat input to the enclosure is the combination of the radiative $h_{r}$ and convective $h_{c}$ heat transfer coefficients, the surface area of the plates $A_{\text {plate }}$, and the temperature difference between the plates and the ice inside the enclosure, as shown in Equation 4 and 5.

$$
\begin{gathered}
\dot{q}_{\text {in }}=\left(h_{c}+h_{r}\right) A_{\text {plate }}\left(T_{\text {plate }}-T_{\text {ice }}\right) \\
h_{r}=\sigma \varepsilon\left(T_{\text {plate }}{ }^{2}+T_{\text {ice }}{ }^{2}\right)\left(T_{\text {plate }}+T_{\text {ice }}\right)
\end{gathered}
$$

With known power input, surface area, emissivity $(\varepsilon)$, and ice and wall temperatures, the convective coefficient was backed out from Equation 4 for each experimental trial. It was found that the convective heat transfer coefficients for the vertical walls ranged from 1.47 to $3.13 \mathrm{~W} / \mathrm{m}^{2} \mathrm{~K}$. An area-weighted average convective heat transfer coefficient was calculated since there was little variation between walls. Increasing the cabinet height decreased the heat transfer coefficients. The authors suggest using low emissivity cabinet liners combined with low convective heat transfer coefficients in order to increase thermal resistance and reduce heat leak through the cabinet walls by approximately $10-20 \%$.

Several studies have explored convective heat transfer inside refrigerated and non-refrigerated enclosures. Equation 6 shows Clausing's (1983) correlation for the heating of air inside a rectangular cavity. 


$$
N u=0.082 * R a^{\frac{1}{3}}\left[-0.9+2.4\left(\frac{T_{\text {Wall }}}{T_{\infty}}\right)-0.5\left(\frac{T_{\text {Wall }}}{T_{\infty}}\right)^{2}\right]
$$

Typical wall and air temperatures inside the freezer compartment were $-18.9^{\circ} \mathrm{C}(-$ $\left.2^{\circ} \mathrm{F}\right)$ and $-17.8^{\circ} \mathrm{C}\left(0^{\circ} \mathrm{F}\right)$, respectively. The Rayleigh number was calculated using a characteristic length of $1 \mathrm{~m}$, equivalent to the height of the cabinet used for this study. Based on these values, the convection coefficient is approximately 5 $\mathrm{W} / \mathrm{m}^{2} \mathrm{~K}$.

Skok et. al (1991) looked at buoyancy driven flow in an open cavity. The cavity was modeled to represent a typical household refrigerator of $0.9 \mathrm{~m}$ height, $0.6 \mathrm{~m}$ depth and $0.75 \mathrm{~m}$ width. The cavity Nusselt number is shown in Equation 7.

$$
N u=0.087 R a^{\frac{1}{3}}
$$

Assuming typical freezer compartment temperatures $\left(-18.9^{\circ} \mathrm{C} \quad\left(-2^{\circ} \mathrm{F}\right)\right.$ wall temperature and $-17.8^{\circ} \mathrm{C}\left(0^{\circ} \mathrm{F}\right)$ free stream temperature $)$, the convection coefficient is approximately $2.4 \mathrm{~W} / \mathrm{m}^{2} \mathrm{~K}$.

Nellis and Klein (2012) describe a correlation for a smooth isothermal flat plate shown in Equation 8. Using the same properties described above that reflect the values seen in this study, the convective heat transfer coefficient is approximately $7 \mathrm{~W} / \mathrm{m}^{2} \mathrm{~K}$.

$$
N u=\frac{0.3387 \operatorname{Re}^{\frac{1}{2}} \operatorname{Pr}^{\frac{1}{3}}}{\left.1+(0.0486 / \operatorname{Pr})^{\frac{2}{3}}\right)^{\frac{1}{4}}}
$$




\subsection{Previous Studies of Heat Leak Quantification in Refrigeration}

Heat leak calorimetry has been the focus of several studies in the field of household refrigeration. Boughton (1992) investigated the thermal load on the cabinet during closed door conditions. This study was focused on the edge regions of the doors and walls where thermal losses are greatest. Thermocouples were mounted around the door gasket to determine the temperature difference across the seal. A schematic of the thermocouple placement is shown in Figure 1-3.

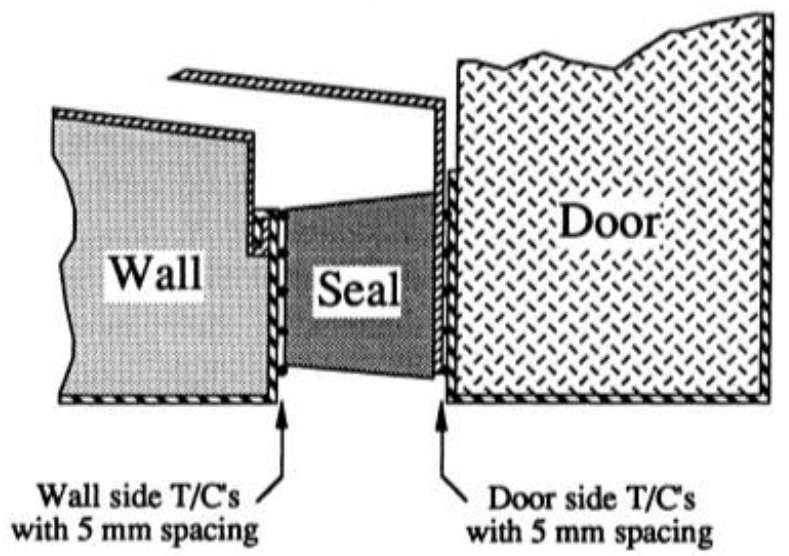

Figure 1-3 Thermocouple placement for Boughton's experiment (1992)

Boughton used thermopiles placed on the walls of the unit to measure temperature instead of heat flux (Figure 1-4). 


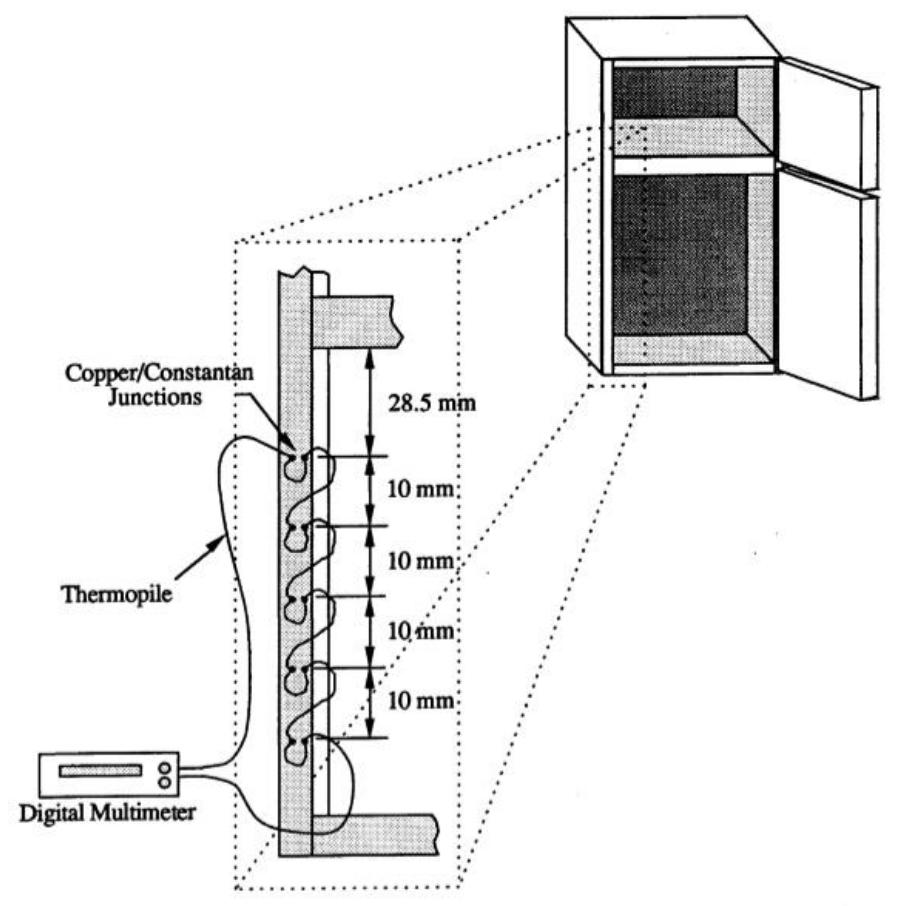

Figure 1-4 Boughton's thermopile test apparatus (1992)

The voltage output was divided by the number of thermocouple junctions in series to get the average temperature across a surface. Heat flux was calculated using thermal conductivities, convective heat transfer coefficients were derived from Nusselt correlations, and temperatures were measured with thermocouples and thermopiles. The convective heat transfer coefficients in this study were estimated from a flat plate natural convection correlation developed by Clausing (1983). The Nusselt number for laminar flow $\left(\mathrm{Ra}<10^{9}\right)$ is shown in Equation 9. Properties were evaluated at the film temperature $T_{f}$, as shown in Equation 10.

$$
\begin{gathered}
N u=0.52 * R a^{\frac{1}{4}} \\
T_{f}=\frac{T_{w}+T_{\infty}}{2}
\end{gathered}
$$


The internal convection coefficients for the fresh food and freezer compartments were found to be $6.70 \mathrm{~W} / \mathrm{m}^{2} \mathrm{~K}$ and $6.41 \mathrm{~W} / \mathrm{m}^{2} \mathrm{~K}$, respectively. The edge loading through the gaskets accounted for $17 \%$ of the total heat leak.

Gao, et al. (2017) used a combined experimental and computational approach to measure heat leak through the refrigerator gasket region. The authors built a structure that closely resembled the geometry of a household refrigerator and placed a heater inside to perform a reverse heat leak experiment. Reverse heat leak testing involves heating the inside of the unit and cooling the room such that the heat travels from the inside of the unit to the surrounding environment. Heat leak is quantified by supplying the heater inside the unit with a known power input. HFS and thermocouples were placed near the gasket to determine the gasket contribution to the overall heat leak of the unit. The results showed that the heat leak due to the door gasket was $17 \%$ and $14 \%$ of the total load in the fresh food and freezer compartments, respectively. Local heat leak values were determined using HFS. Convective heat transfer coefficients were not reported.

A study that closely resembles this current investigation was done by Melo, et al. (2000), who analyzed heat transfer paths from the surroundings to the interior food compartment of a 230-liter refrigerator under closed door conditions. An external sealed system shown in Figure 1-5 was built to maintain temperatures inside the unit and to measure refrigerant mass flow and temperatures without altering the construction of the unit. 


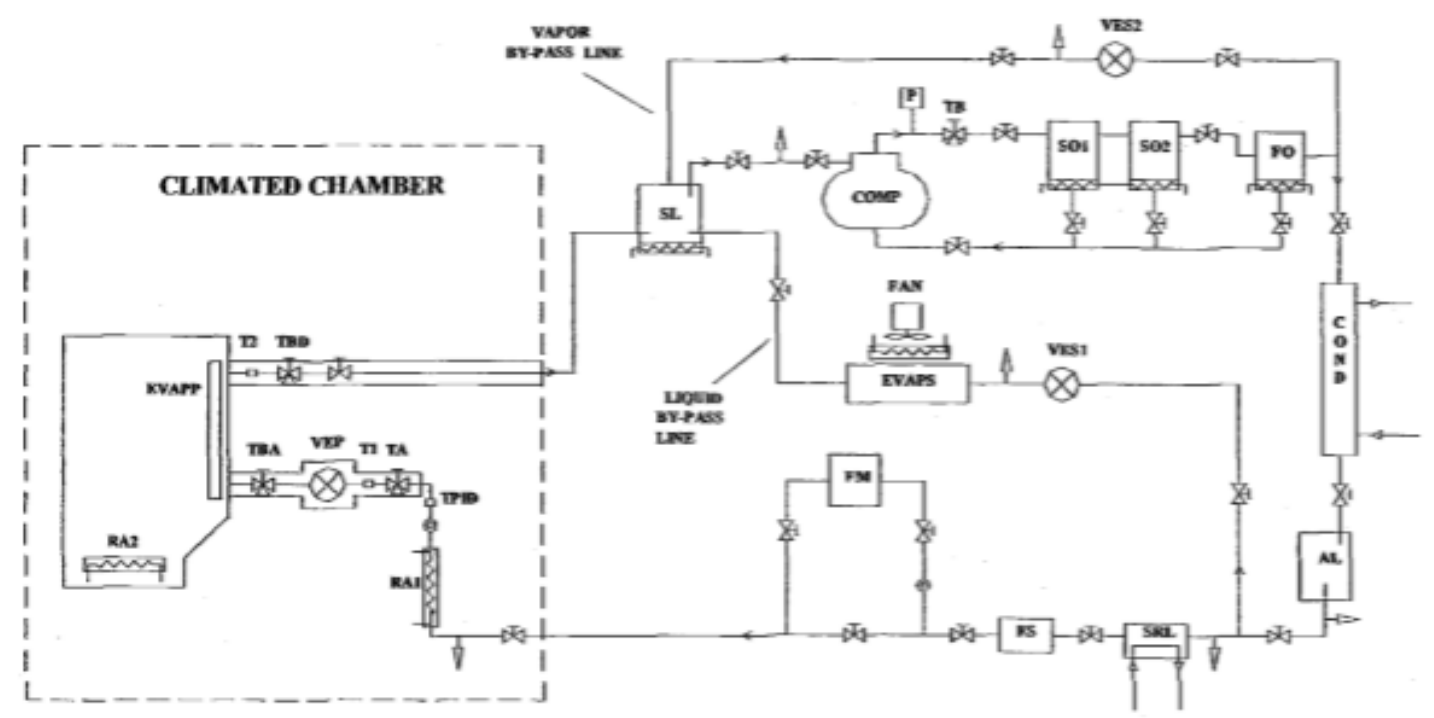

Figure 1-5 Refrigeration test facility built for Melo forward heat leak calorimeter (2000)

$31 \mathrm{HFS}$ were installed on the test unit (Figure 1-6). 25 HFS were placed on the external walls of the unit and six were placed on the gasket.
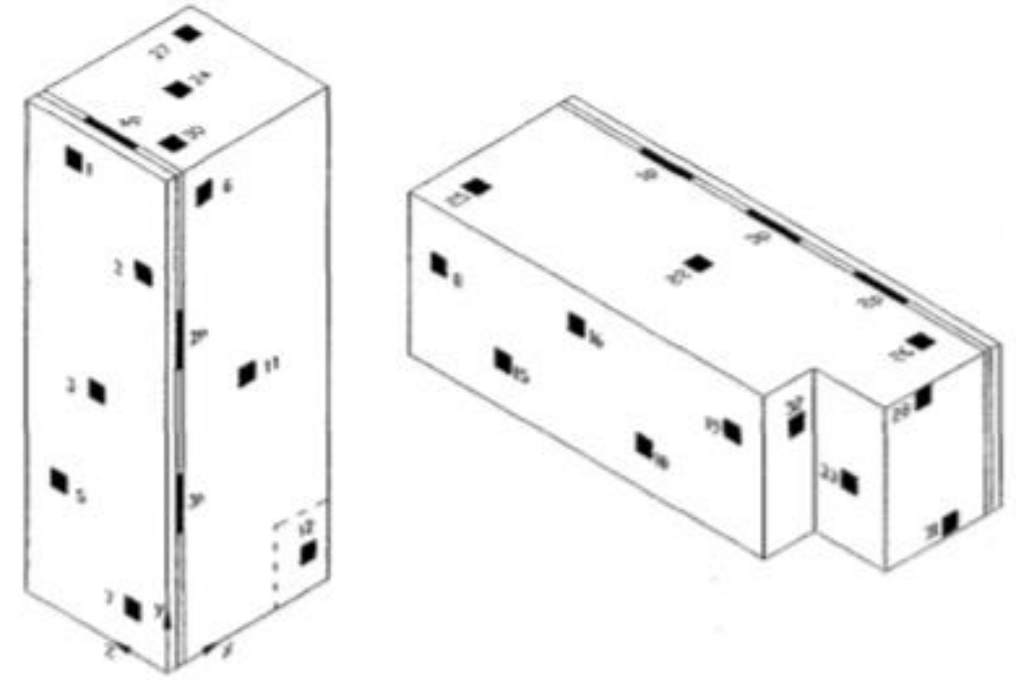

Figure 1-6 HFS distribution on refrigerator (Melo et al., 2000) 
The heat flux measurements were multiplied by the surface areas of each wall to determine the percentage of heat flow on each side of the unit. Similar to the current study, heat flux measurements were compared to the total heat transfer rate calculated using refrigerant mass flow rate and enthalpy change across the evaporator. The authors equated a $10 \%$ discrepancy between the heat flux measurements and the total heat transfer rate of the system to losses through the gaskets and door flanges. The internal temperature of the unit was $-0.4^{\circ} \mathrm{C}\left(31.2^{\circ} \mathrm{F}\right)$ and the ambient temperature outside of the unit was approximately $10^{\circ} \mathrm{C}\left(50^{\circ} \mathrm{F}\right)$. The heat leak measured with HFS was $41.93 \mathrm{~W}$ while the heat leak measured via in line mass flow and temperature and pressure measurements was $47 \mathrm{~W}$. Full results of the heat leak of each wall are shown in Table 2.

Table 2 Heat flux and heat transfer rate distribution for each wall (Melo, 2000)

\begin{tabular}{|c|c|c|c|c|}
\hline Heat transfer path & Area $\left[\mathbf{m}^{\mathbf{2}}\right]$ & $\mathbf{q}$ " $\left[\mathbf{W} / \mathbf{m}^{2}\right]$ & $\dot{\boldsymbol{q}}[\mathbf{W}]$ & $\begin{array}{c}\text { \% of } \\
\text { total }\end{array}$ \\
\hline Door & 0.67 & 12.92 & 8.68 & 20.7 \\
\hline Top wall & 0.24 & 10.10 & 2.42 & 5.8 \\
\hline Side wall & 0.69 & 13.34 & 9.18 & 21.9 \\
\hline Side wall & 0.69 & 13.34 & 9.18 & 21.9 \\
\hline Back wall & 0.56 & 15.18 & 8.49 & 20.2 \\
\hline $\begin{array}{c}\text { Bottom wall } \\
\text { compall [compressor }\end{array}$ & 0.16 & 7.05 & 1.13 & 2.7 \\
\hline $\begin{array}{c}\text { Bottom wall [compressor } \\
\text { compartment] }\end{array}$ & 0.08 & 11.70 & 0.93 & 2.2 \\
\hline Gasket & 0.09 & 7.00 & 0.79 & 1.9 \\
\hline Total & & 12.33 & 1.13 & 2.7 \\
\hline
\end{tabular}

The compressor compartment for the unit used for Melo's study was located on the bottom of the unit; however, the compressor and any other heat generating 
components were not operational during data collection since all sealed system and electronic components were located on the calorimeter fixture.

Numerous authors have referenced Nusselt correlations to estimate convective heat transfer coefficients inside a refrigerated cabinet. Table 3 summarizes the correlations and gasket contribution to overall heat leak reviewed for this study. Additionally, the gasket contribution to overall heat leak was investigated in the current study by insulating the door perimeter. Gasket leak was previously investigated by several authors but was determined by measuring heat flux in the gasket region. 
Table 3 Summary of gasket heat leak, Nu correlations and convection coefficient estimates from the literature

\begin{tabular}{|c|c|c|c|}
\hline Author(s) & $\begin{array}{c}\dot{q} \text { from } \\
\text { gasket [\% } \\
\text { of total } \\
\text { heat leak] }\end{array}$ & Nusselt Correlation & $\begin{array}{c}\text { Convective } \\
\text { Heat } \\
\text { Transfer } \\
\text { Coefficient } \\
{\left[\mathrm{W} / \mathrm{m}^{2} \mathrm{~K}\right]}\end{array}$ \\
\hline $\begin{array}{l}\text { Hasanuzzaman, } \\
2009\end{array}$ & - & $N u=0.18\left(\frac{\operatorname{Pr}}{0.2+\operatorname{Pr}} R a\right)^{0.29}$ & $\begin{array}{l}1.35 \text { fresh } \\
\text { food, } 1.55 \\
\text { freezer }\end{array}$ \\
\hline Williams, 1994 & - & $\begin{array}{c}\dot{q}_{\text {in }}=\left(h_{c}+h_{r}\right) A_{\text {plate }}\left(T_{\text {plate }}\right. \\
\left.-T_{\text {ice }}\right)\end{array}$ & 1.47 to 3.13 \\
\hline Clausing, 1983 & - & $\begin{array}{rl}N u=0.082 * & R a^{\frac{1}{3}}[-0.9 \\
& +2.4\left(\frac{T_{W}}{T_{\infty}}\right) \\
& \left.-0.5\left(\frac{T_{W}}{T_{\infty}}\right)^{2}\right]\end{array}$ & 4 \\
\hline Skok, 1991 & - & $N u=0.087 R a^{\frac{1}{3}}$ & 2.4 \\
\hline $\begin{array}{c}\text { Nellis and Klein, } \\
2012\end{array}$ & - & $N u_{x}=\frac{0.3387 \operatorname{Re}^{\frac{1}{2}} \operatorname{Pr}^{\frac{1}{3}}}{\left.1+(0.0486 / \operatorname{Pr})^{\frac{2}{3}}\right)^{\frac{1}{4}}}$ & 7 \\
\hline Boughton, 1992 & $17 \%$ & $N u=0.52 * R a^{\frac{1}{4}}$ & $\begin{array}{l}6.70 \text { fresh } \\
\text { food, } 6.41 \\
\text { freezer }\end{array}$ \\
\hline Gao, 2017 & $\begin{array}{l}17 \% \text { fresh } \\
\text { food, } 14 \% \\
\text { freezer }\end{array}$ & - & - \\
\hline Melo, 2000 & $2.7 \%$ & - & - \\
\hline
\end{tabular}

Although a substantial amount of research has been done on the use of HFS to measure heat leak in refrigerator units, there has been minimal research done on using HFS to derive convective heat transfer coefficients used for heat leak simulation models. This study will focus on quantifying heat leak with HFS, comparing HFS results to calorimeter heat leak quantities, determining local variation in heat flux and calculating convective heat transfer coefficients from 
average and local heat flux measurements on each wall. A list of additional references can be found in Appendix VI. 


\section{EXPERIMENTAL SETUP AND PROCEDURE}

This section outlines the experimental setup and procedure of the forward heat leak calorimeter. The forward heat leak calorimeter consists of a refrigeration sealed system capable of cooling a 490 -liter upright freezer to $-17.8^{\circ} \mathrm{C}\left(0^{\circ} \mathrm{F}\right)$ with very little temperature variation. The sealed system and data acquisition system are presented in the following sections as well as HFS technology used to estimate heat leak through the walls of the freezer. Finally, an experiment designed to determine the door gasket contribution to overall heat leak is described in detail.

\subsection{Forward Heat Leak Calorimeter}

A forward heat leak calorimeter with refrigeration sealed system was designed to maintain a 490 -liter upright freezer at $-17.8^{\circ} \mathrm{C}\left(0^{\circ} \mathrm{F}\right)$. The calorimeter was used to accurately quantify total heat leak $\dot{q}$ into the freezer compartment. Having an external sealed system connected to the freezer evaporator allowed for precise refrigerant flow control and in-line measurements without significant interference with the operation of the unit. Figure 2-1 shows a schematic of the forward heat leak calorimeter with instruments and components indicated. Circles with a "P" indicate pressure transducers. Circles with a " $T$ " indicate temperature sensors. Circle with " $\dot{m}$ " is where refrigerant mass flow is measured. Arrows indicate the direction of refrigerant flow. Figure 2-2 shows an ideal P-h diagram of the refrigeration cycle with the locations of each component indicated on the 
calorimeter diagram in Figure 2-1. Appendix I provides a detailed overview of the calorimeter construction and components.

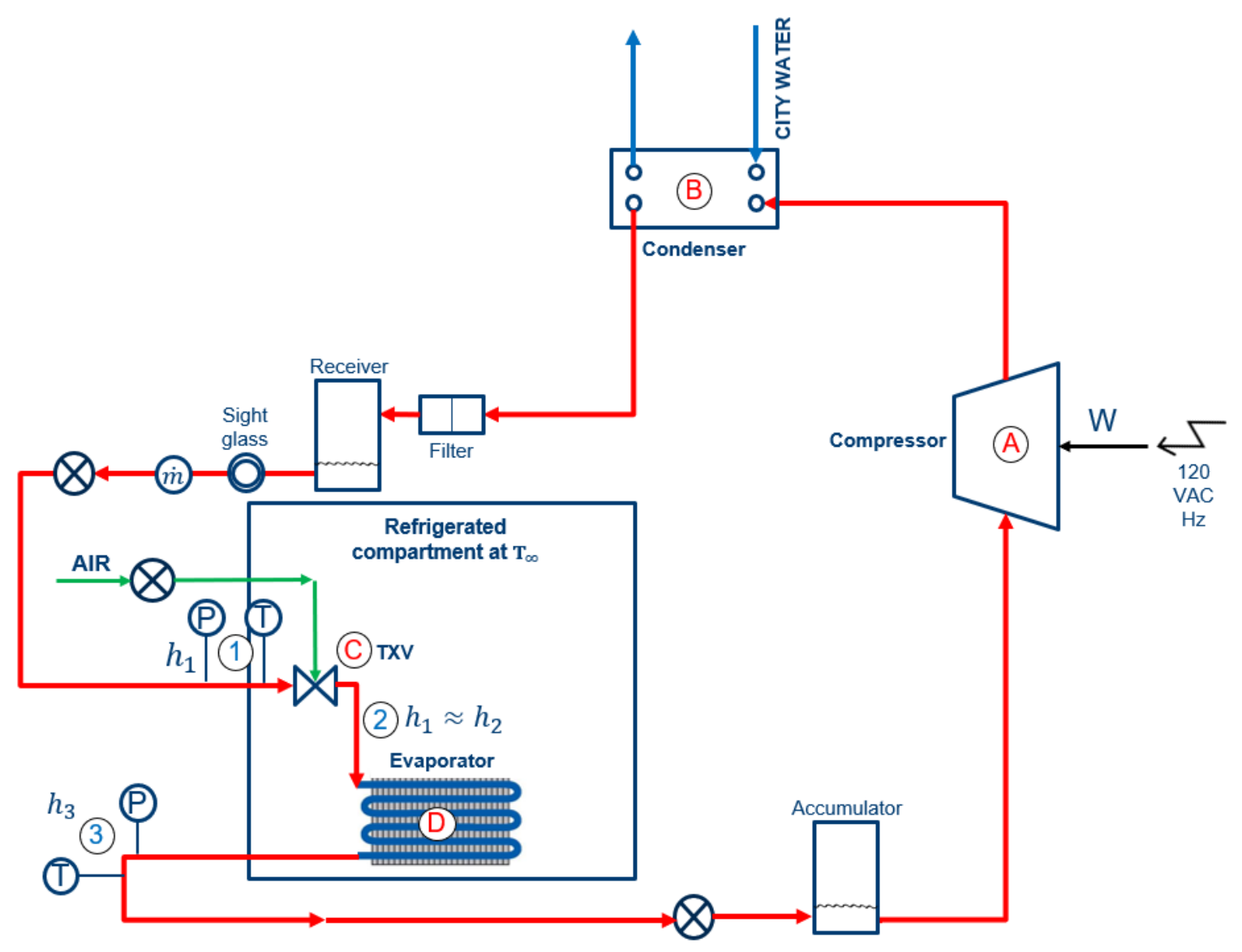

Figure 2-1 Schematic of instrumented forward heat leak calorimeter 


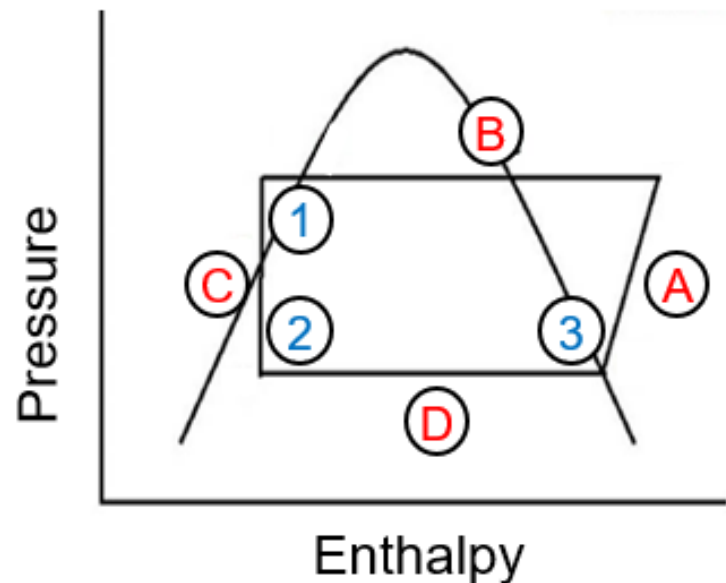

Figure 2-2 Ideal P-h diagram of refrigeration cycle with numbers and letters indication locations in Figure 2-1

Label A on Figure 2-2 indicates the Embraco variable speed compressor, B is the a water cooled brazed plate condenser, $C$ is the pneumatically controlled thermostatic expansion valve (TXV) and D is the evaporator located inside the freezer. The TXV was installed inside the refrigerated compartment to reduce heat transfer between the refrigerant flowing through the valve and the surrounding environment.

The calorimeter sealed system used R134a refrigerant and an Embraco VEGD7H variable speed compressor. The refrigerated compartment was controlled to $-17.8^{\circ} \mathrm{C}\left(0^{\circ} \mathrm{F}\right)$ by manually varying compressor speeds and the expansion valve setting. An accurate estimate of heat leak was determined via refrigerant flow through the system, as described later in this section. This heat leak was the standard to evaluate the accuracy of the heat leak calculated using HFS measurements. 


\subsection{Sealed System Design and Construction}

In addition to the typical refrigeration components, the forward heat leak calorimeter built for this experiment has several other components intended to improve the control of its cooling capacity. A TXV was used in place of a passive capillary tube in order to control superheat and temperature inside the cabinet. A filter dryer was installed to capture excess moisture and debris inside the system. A suction line accumulator was installed before the compressor inlet to ensure only superheated refrigerant entered the compressor. A liquid line receiver was installed before the mass flow meter to ensure only subcooled refrigerant entered the mass flow meter. Pressure and temperature sensors were placed in line with the refrigerant flow at the TXV inlet and evaporator outlet. These measurements allowed the inlet and outlet enthalpies to be calculated.

Heat leak into the refrigerator was quantified by performing an energy balance across the evaporator, as shown in Equations 11, and 12.

$$
\begin{gathered}
\dot{q}=\dot{m} \Delta h_{\text {evap }} \\
\Delta h_{\text {evap }}=h_{3}-h_{1}
\end{gathered}
$$

where $\dot{q}$ is the heat rate and $\dot{m}$ is mass flow rate of the refrigerant. $P_{1}$ is the inlet pressure measured at the expansion device inlet. $T_{1}$ is inlet temperature of the refrigerant into the expansion device. $P_{3}$ is the outlet pressure measured at the outlet of the evaporator. $T_{3}$ is outlet temperature of the refrigerant exiting the evaporator. Enthalpy $h_{1}$ and $h_{3}$ are determined with these temperature and pressure values via Reference Fluid Thermodynamic and Transport Properties 
software, which uses thermophysical property tables to determine enthalpy at a given temperature and pressure. Assuming isenthalpic expansion $\left(h_{2} \approx h_{1}\right), h_{1}$ measured prior to the TXV is used as the evaporator inlet enthalpy.

\subsection{Data Acquisition System Design}

The sealed system was controlled and operated with a National Instruments (NI) data acquisition system. A LabVIEW program was used to control and measure performance of the forward heat leak system. The primary controls that were modified to control the unit temperature were the compressor speed and the expansion valve setting. The variables measured by the data acquisition system are listed in Table 4. The high and low side safety pressures were monitored to allow for system shutdown if the high or low side of the sealed system experience unsafe pressure extremes. NI modules and their function for the experiment are detailed in Appendix I.

Table 4 Data acquisition system measured variables described in Figure 2-1 and $2-2$

\begin{tabular}{|c|c|c|}
\hline Variable & Description & Measurement tool \\
\hline$P_{1}$ & TXV inlet pressure & $\begin{array}{c}\text { Setra AccuSense pressure } \\
\text { transducer }\end{array}$ \\
\hline$P_{3}$ & Evaporator outlet pressure & $\begin{array}{c}\text { Setra AccuSense pressure } \\
\text { transducer }\end{array}$ \\
\hline$T_{1}$ & TXV inlet temperature & 4-wire RTD \\
\hline$T_{3}$ & $\begin{array}{l}\text { Evaporator outlet } \\
\text { temperature }\end{array}$ & 4-wire RTD \\
\hline V & HFS voltage & $\begin{array}{c}4.4 \mathrm{~mm} \times 4.4 \mathrm{~mm} \text { and } 10 \mathrm{~mm} \times 10 \\
\mathrm{~mm} \text { HFS }\end{array}$ \\
\hline$T_{\infty}$ & Cabinet temperatures & Thermocouples \\
\hline$\dot{m}$ & Mass flow & $\begin{array}{l}\text { Micro Motion CMF-10 Coriolis mass } \\
\text { flow meter }\end{array}$ \\
\hline$P_{L}$ & Low side safety pressure & Omega PT100 pressure transducer \\
\hline$P_{H}$ & High side safety pressure & Omega PT200 pressure transducer \\
\hline
\end{tabular}




\subsection{Heat Flux Sensors}

The most common and readily available heat flux measurement devices are thin film thermopile HFS. A thermopile is a passive electronic device that converts thermal energy to electrical energy and amplifies the voltage by using many thermocouples connected in series. The thermoelectric properties of thermocouples generate an electrical signal that is proportional to the temperature change applied to the thermocouple junction. A thin film thermopile HFS consists of a thermopile embedded in a material with a known thermal conductivity. The thermopile junctions are located on either side of the thermal resistance layer. Figure 2-3 shows a schematic of a thermopile heat flux sensor.

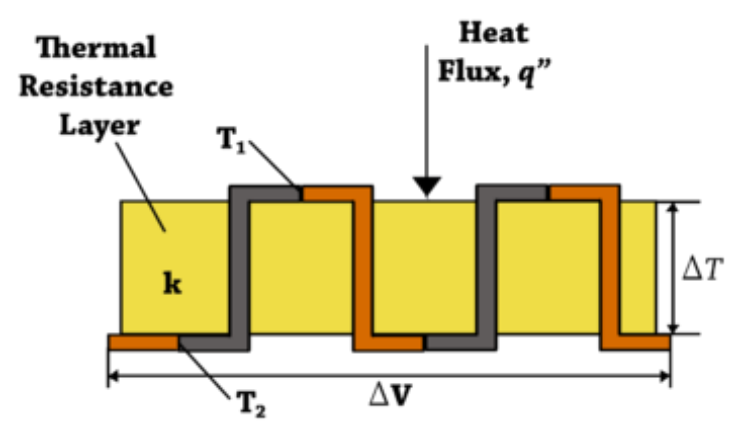

Figure 2-3 Schematic of differential temperature thermopile (Fluxteq, 2018)

The voltage output of the thermopile is proportional to the temperature difference across the thermal resistance layer. Equation 13 is the one-dimensional Fourier's Law equation used to calculate the heat flux $q$ " through the HFS.

$$
q^{\prime \prime}=k \frac{\Delta T}{\Delta x}
$$


where $\mathrm{k}$ is the thermal conductivity of the sensor, $\Delta T$ is the temperature difference across the sensor and $\Delta x$ is the sensor thickness. The sensitivity of the HFS is proportional to the number of thermocouple pairs embedded in the sensor. Due to their high sensitivity, low impact on flow conditions and relatively low cost, thin film thermopile HFS were chosen for this study. A detailed investigation of HFS technology and selection criteria can be found in Appendix II.

Two models of greenTEG HFS were purchased for this study. Four of the 14 sensors were $10 \mathrm{~mm} \times 10 \mathrm{~mm}$ and able to resolve $0.09 \mathrm{~W} / \mathrm{m}^{2}$. The remaining sensors were $4.4 \mathrm{~mm} \times 4.4 \mathrm{~mm}$ models and able to resolve $0.41 \mathrm{~W} / \mathrm{m}^{2}$. Sensor resolution was provided by the supplier. These sensors are detailed in Table 5.

Table 5 HFS sensor models used for heat flux measurements

\begin{tabular}{|c|c|c|}
\hline Sensor Dimensions [mm] & Resolution [W/m $\left.\mathbf{m}^{\mathbf{2}}\right]$ & Quantity \\
\hline $10 \times 10$ & 0.09 & 4 \\
\hline $4.4 \times 4.4$ & 0.41 & 10 \\
\hline
\end{tabular}

Images of both models are shown in Figure 2-4 . Although the larger HFS model was able to resolve low flux values, it was more expensive, and the uncertainty analysis of the experiment indicated that a $0.41 \mathrm{~W} / \mathrm{m}^{2}$ flux resolution would suffice for the level of accuracy required for these tests. As an example, the expected heat flux for the freezer walls was in the range of $10-30 \mathrm{~W} / \mathrm{m}^{2}$. Assuming flux through the freezer wall is on the low end of this range, the uncertainty of the sensor is only 4.1\%, therefore both sensor types were used in this study. See Appendix IV for a 
sensitivity study of flux sensors on convective heat transfer coefficients. See Appendix II for HFS model comparison.

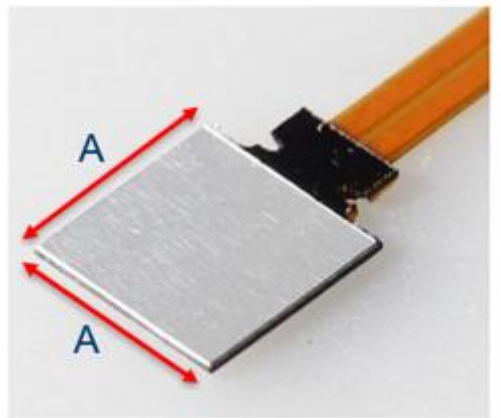

(a)

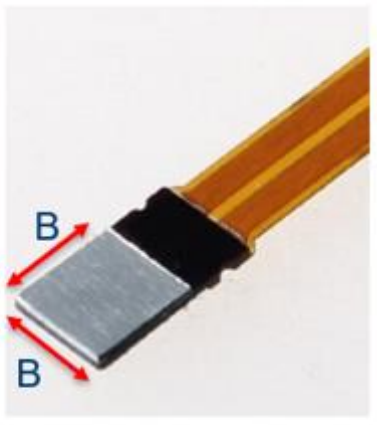

(b)

Figure 2-4 (a) $10 \mathrm{~mm} \times 10 \mathrm{~mm}$ sensor (b) $4.4 \mathrm{~mm} X 4.4 \mathrm{~mm}$ sensor. Dimension $A=10 \mathrm{~mm}$. Dimension $B=4.4 \mathrm{~mm}$

\subsection{Heat Flux Sensor Measurement Validation}

A HFS validation experiment based on a one-dimensional thermal conduction system was built to test the accuracy of the sensors. The validation experiment consisted of a round aluminum plate with a coil heater attached to the bottom surface. The coil heater was powered using a Kikusui PCR2000MS power supply and was attached to the base of the aluminum plate with thermally conductive aluminum tape, shown in Figure 2-5. 

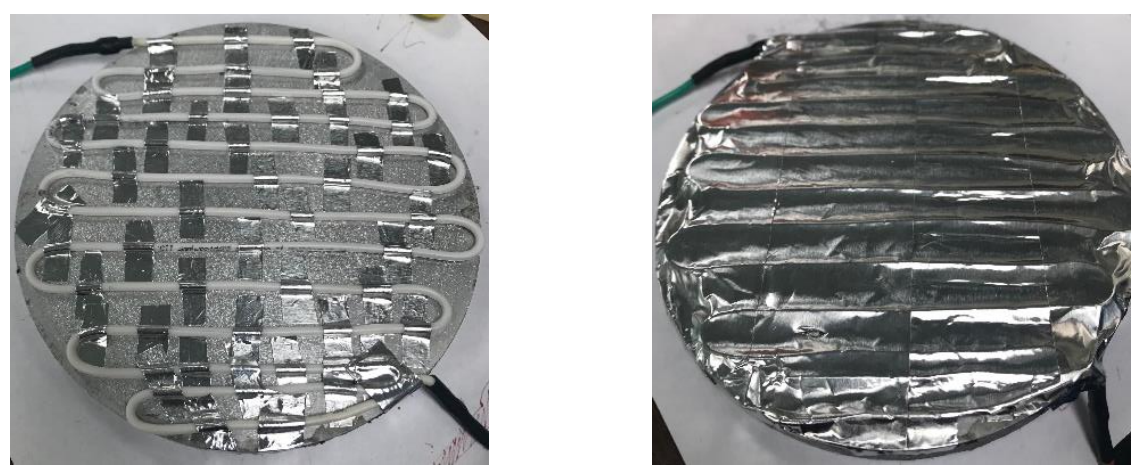

Figure 2-5 Aluminum plate with coil heater adhered to its bottom surface

The aluminum plate was installed flush with the top surface of insulating foam and secured with polyurethane expanding, insulating foam. The top surface of the aluminum plate was exposed to the environment. This created a one-dimensional conduction system since most thermal energy from the coil heater was driven towards the aluminum plate and through the HFS adhered to the aluminum surface. The 1-D conduction validation test set-up is shown in Figure 2-6. Variables "D" and "d" in Figure 2-6 are 0.61 and 0.15 m, respectively.

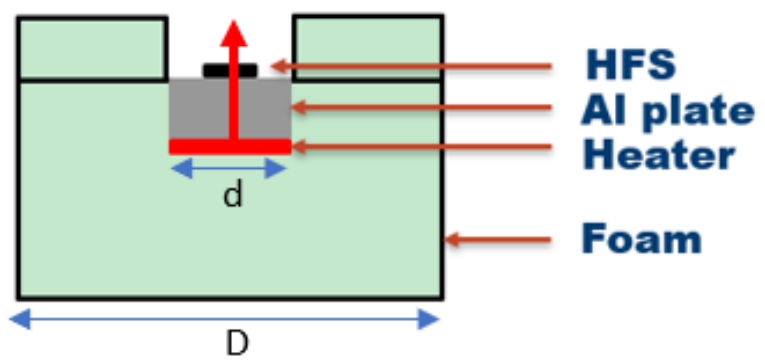

Figure 2-6 HFS validation test set-up. Vertical arrow indicates direction of heat flow. HFS thickness not to scale $(d=0.15 \mathrm{~m}, \mathrm{D}=0.61 \mathrm{~m})$

Two HFS were placed on the top of the aluminum plate and adhered with thermal grease for each validation test. Thermally conductive tape was placed on 
the sensor wire leads to provide strain relief. 10-pound weights were placed around the perimeter of the top layer of insulating foam to press the layers of foam together and prevent non-one-dimensional heat leak outside of the perimeter of the aluminum plate. A thermocouple was adhered to the aluminum plate surface with aluminum tape to measure the plate temperature, which is used to provide a temperature correction to heat flux readings. Each sensor was tested at two heater wattages, $0.5 \mathrm{~W}$ and $1.0 \mathrm{~W}$, resulting in expected heat fluxes of $29.2 \mathrm{~W} / \mathrm{m}^{2}$ and $58.8 \mathrm{~W} / \mathrm{m}^{2}$, respectively. Data was taken every minute. A constant ambient temperature of $32.2^{\circ} \mathrm{C}\left(90^{\circ} \mathrm{F}\right)$ was maintained for each test. An image of the fully instrumented HFS validation test set-up is shown in Figure 2-7 HFS validation setup.

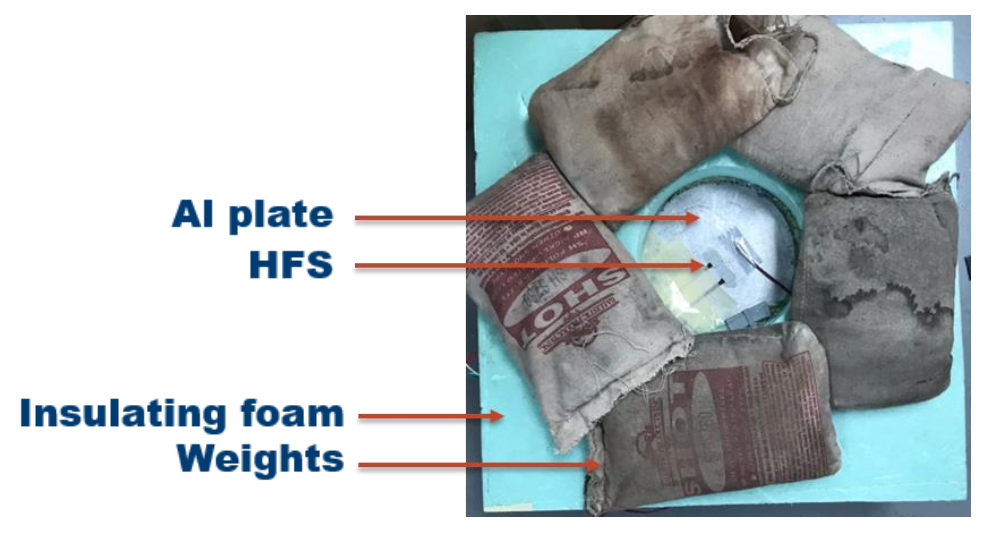

Figure 2-7 HFS validation set-up

Data from the HFS was collected with a NI 9213 thermocouple module that can resolve microvolt level voltages from the sensors. The time to achieve steady state heat flux was shorter than the time for the surface temperature of the aluminum plate to reach its steady state temperature. Therefore, once steady state 
for the of the aluminum plate surface thermocouple was achieved, the HFS were assumed to be at steady state. Time to steady state of the surface thermocouple was defined as the time when the temperature change over a one-minute time interval was less than $0.5^{\circ} \mathrm{C}$.

Equation 14 describes how heat flux q" was calculated by dividing the sensor output voltage $V$ by the sensitivity of the sensor $S$ at temperature $T$. The sensitivity as a function of temperature is calculated in Equation 15. Sensor specific sensitivity $\left(\mathrm{S}_{\mathrm{o}}\right)$ and correction factor $\left(\mathrm{S}_{\mathrm{c}}\right)$ were provided by the supplier.

$$
\begin{gathered}
q^{\prime \prime}=\frac{V}{S(T)} \\
S(T)=S_{o}+\left(T-22.5^{\circ} \mathrm{C}\right) * S_{c}
\end{gathered}
$$

The $10 \mathrm{~mm}$ sensor correction factors ranged from $0.0037 \mu \mathrm{V} / \mathrm{W} / \mathrm{m}^{2} /{ }^{\circ} \mathrm{C}$ and 0.0049 $\mu \mathrm{V} / \mathrm{W} / \mathrm{m}^{2} /{ }^{\circ} \mathrm{C}$. The $4.4 \mathrm{~mm}$ sensor correction factors ranged from 0.0194 $\mu \mathrm{V} / \mathrm{W} / \mathrm{m}^{2} /{ }^{\circ} \mathrm{C}$ and $0.0277 \mu \mathrm{V} / \mathrm{W} / \mathrm{m}^{2} /{ }^{\circ} \mathrm{C}$. Since these values were extremely small, the heat flux calculation did not have a strong sensitivity to temperature. Expected heat flux was calculated by dividing the heater power by the surface area of the aluminum plate $\left(\mathrm{W} / \mathrm{m}^{2}\right)$. Expected heat flux was compared to measured heat flux for each sensor at several coil heater settings.

The results of the HFS validation experiment are shown in Table 6. Sensors S13 and S14 were deemed unusable because their measurements underpredicted expected heat flux by over $20 \%$ for the $1 \mathrm{~W}$ power input validation test. Sensors S13 and S14 were tested several times to determine if the experimental setup was 
impacting the measurements; however, all tests run with these sensors had a percentage error much higher than values typically seen with other sensors.

Table 6 HFS validation experiment results for $0.5 \mathrm{~W}\left(29.4 \mathrm{~W} / \mathrm{m}^{2}\right.$ expected flux $)$ and $1 \mathrm{~W}\left(58.8 \mathrm{~W} / \mathrm{m}^{2}\right.$ expected flux $)$ heater input

\begin{tabular}{|c|c|c|c|c|c|}
\hline & & 0.5 W (29.4 & $\left./ \mathrm{m}^{2}\right)$ & $1.0 \mathrm{~W}-(58.8$ & $\left.\mathrm{N} / \mathrm{m}^{2}\right)$ \\
\hline $\begin{array}{l}\text { Sensor } \\
\text { Number }\end{array}$ & $\begin{array}{c}\text { Sensor } \\
\text { Width and } \\
\text { Length } \\
{[\mathrm{mm}]}\end{array}$ & $\begin{array}{c}\text { Steady State } \\
\text { Average Flux } \\
\text { Measurement } \\
{\left[\mathrm{W} / \mathrm{m}^{2}\right]}\end{array}$ & $\begin{array}{c}\text { Percent } \\
\text { Error } \\
{[\%]}\end{array}$ & $\begin{array}{c}\text { Steady State } \\
\text { Average Flux } \\
\text { Measurement } \\
{\left[\mathrm{W} / \mathrm{m}^{2}\right]}\end{array}$ & $\begin{array}{c}\text { Percent } \\
\text { Error } \\
\text { [\%] }\end{array}$ \\
\hline S1 & 10 & 28.5 & $-3.2 \%$ & 54.8 & $-6.9 \%$ \\
\hline S2 & 10 & 26.4 & $-10.4 \%$ & 56.1 & $-4.7 \%$ \\
\hline S3 & 10 & 30.2 & $2.7 \%$ & 54.4 & $-7.5 \%$ \\
\hline S4 & 10 & 28.5 & $-3.2 \%$ & 51.7 & $-12.2 \%$ \\
\hline S5 & 4.4 & 28.5 & $-3.0 \%$ & 55.8 & $-5.1 \%$ \\
\hline S6 & 4.4 & 24.8 & $-15.8 \%$ & 48.2 & $-18.1 \%$ \\
\hline S7 & 4.4 & 27.7 & $-5.8 \%$ & 54.8 & $-6.9 \%$ \\
\hline S8 & 4.4 & 27.6 & $-6.2 \%$ & 62.5 & $6.2 \%$ \\
\hline S9 & 4.4 & 31.9 & $8.2 \%$ & 61.3 & $4.2 \%$ \\
\hline S10 & 4.4 & 31.8 & $8.4 \%$ & 61.5 & $4.6 \%$ \\
\hline S11 & 4.4 & 27.0 & $-8.3 \%$ & 54.4 & $-7.3 \%$ \\
\hline S12 & 4.4 & 26.8 & $-9.0 \%$ & 52.9 & $-10.1 \%$ \\
\hline $\mathrm{S} 13$ & 4.4 & 24.4 & $-17.0 \%$ & 44.2 & $-24.9 \%$ \\
\hline S14 & 4.4 & 23.8 & $-19.0 \%$ & 45.1 & $-23.3 \%$ \\
\hline
\end{tabular}

The largest discrepancy between expected and measured heat flux was 3.1 $\mathrm{W} / \mathrm{m}^{2}$. Most sensors underpredicted heat flux for both the $0.5 \mathrm{~W}$ and $1 \mathrm{~W}$ validation tests. Table 7 summarizes the validation results for both sensor models at each heater power input. 
Table 7 Magnitude and standard deviation of percent error values of both sensor types in validation experiment

\begin{tabular}{|c|c|c|c|c|}
\hline $\begin{array}{c}\text { Sensor Width } \\
\text { and Length [mm] }\end{array}$ & $\begin{array}{c}\text { Average } \\
\text { Percent } \\
\text { Error [\%] }\end{array}$ & $\begin{array}{c}\text { Standard } \\
\text { Deviation of } \\
\text { Percent } \\
\text { Error [\%] }\end{array}$ & $\begin{array}{c}\text { Average } \\
\text { Percent } \\
\text { Error [\%] }\end{array}$ & $\begin{array}{c}\text { Standard } \\
\text { Deviation of } \\
\text { Percent } \\
\text { Error [\%] }\end{array}$ \\
\cline { 2 - 5 } & \multicolumn{2}{|c|}{$\mathbf{0 . 5}$ W Heater Input } & \multicolumn{2}{|c|}{$\mathbf{1}$ W Heater Input } \\
\hline 10 & $-4.9 \%$ & $5.4 \%$ & $-7.8 \%$ & $3.2 \%$ \\
\hline 4.4 & $-8.9 \%$ & $8.4 \%$ & $-7.8 \%$ & $8.5 \%$ \\
\hline
\end{tabular}

The results in Table 7 show that the larger, higher sensitivity sensor had lower standard deviation, but comparable percent error compared to the smaller $4.4 \mathrm{~mm}$ sensor. The underprediction of heat flux could be a result of non-one-dimensional heat transfer occurring in the validation experiment.

\subsection{Household Freezer Heat Flux Measurement}

Once the HFS were validated the sensors were placed on the internal walls of the 490-liter upright freezer investigated in this study. The HFS were mounted using $3 \mathrm{M}$ double sided thermally conductive tape to ensure uniform thermal contact with the walls of the unit. Tape was placed on the wire lead of the sensor at multiple locations for strain relief. The wire leads of the HFS were routed outside of the refrigerated compartment via a 1" diameter hole drilled through the upper left wall of the unit. The hole was covered with fiberglass insulation to prevent additional heat leak. U-type copper-copper thermocouple connectors were used to connect the HFS to the NI DAQ modules. Tests were performed with the sensors mounted to the inside walls of the freezer with an internal freezer temperature of $17.8^{\circ} \mathrm{C}\left(0^{\circ} \mathrm{F}\right)+/-1^{\circ} \mathrm{C}$ in a $32.2^{\circ} \mathrm{C}\left(90^{\circ} \mathrm{F}\right)$ room. The back wall was instrumented with 
sensors behind the air tower cover shown in Figure 2-8. Internal temperature was determined by averaging the temperature of four thermocouples embedded in brass weights, which were hung in the interior of the unit at various heights (Figure 2-8). Brass weights were used to reduce transient fluctuation of temperature. Discrepancies in the temperature of each brass weight was not analyzed; however, there may have been differences between each measurement based on airflow conditions and proximity to the evaporator. The room temperature was controlled with an HVAC system and monitored during each test to ensure the ambient temperature remained stable.

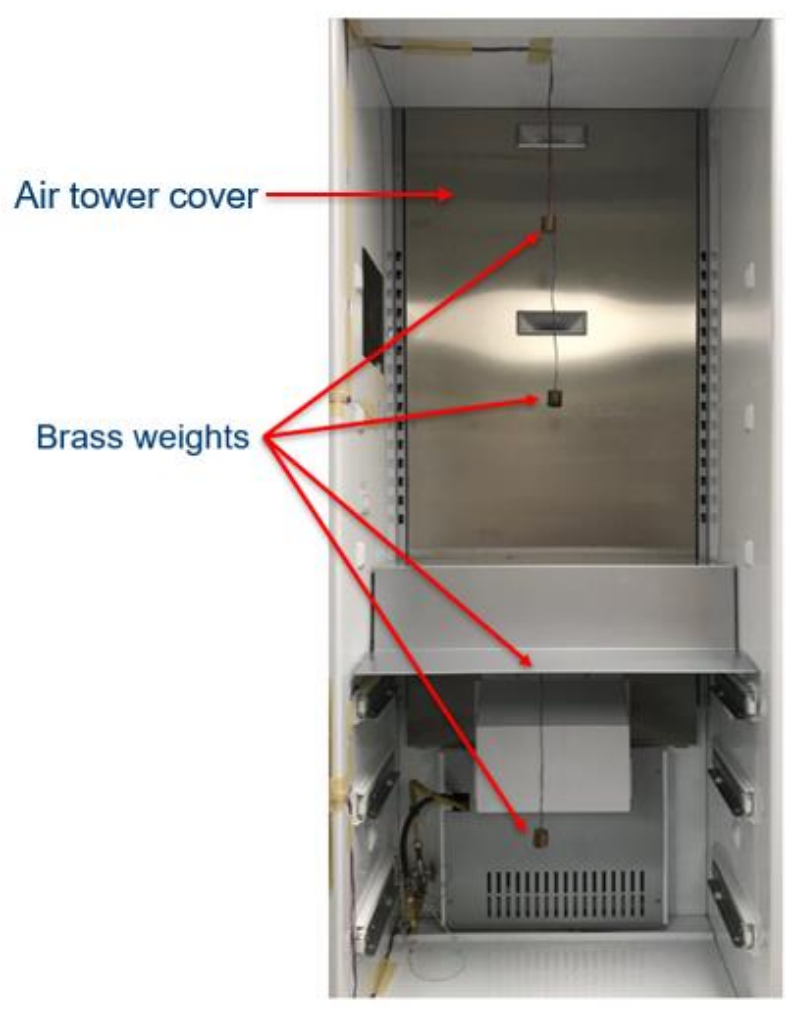

Figure 2-8 Inside of 490-liter freezer with thermocouple brass weights installed in four locations. Back wall HFS mounted behind air tower cover 
Time to achieve steady state varied from test to test. The heat flux traces show a moving average of the raw data over an interval of 180 minutes due to the noisy data obtained from the sensors. Data was collected every minute. Typical time for the unit to reach $-17.8^{\circ} \mathrm{C}\left(0^{\circ} \mathrm{F}\right)$ was approximately 10 hours. The time to achieve steady state heat flux was much shorter than the time for the brass weights to reach their steady state temperature. Therefore, once steady state for the brass weights was achieved the HFS were assumed to be at steady state. Time to steady state of the brass weight temperature was defined as the time needed for the brass weight average temperature to reach $-17.8^{\circ} \mathrm{C}\left(0^{\circ} \mathrm{F}\right) \mathrm{F}+/-1^{\circ} \mathrm{F}$ with a change in temperature over one-minute interval of less than $0.5^{\circ} \mathrm{C}$. Figure $2-9$ shows the moving average of heat flux mounted to the top wall of the freezer.

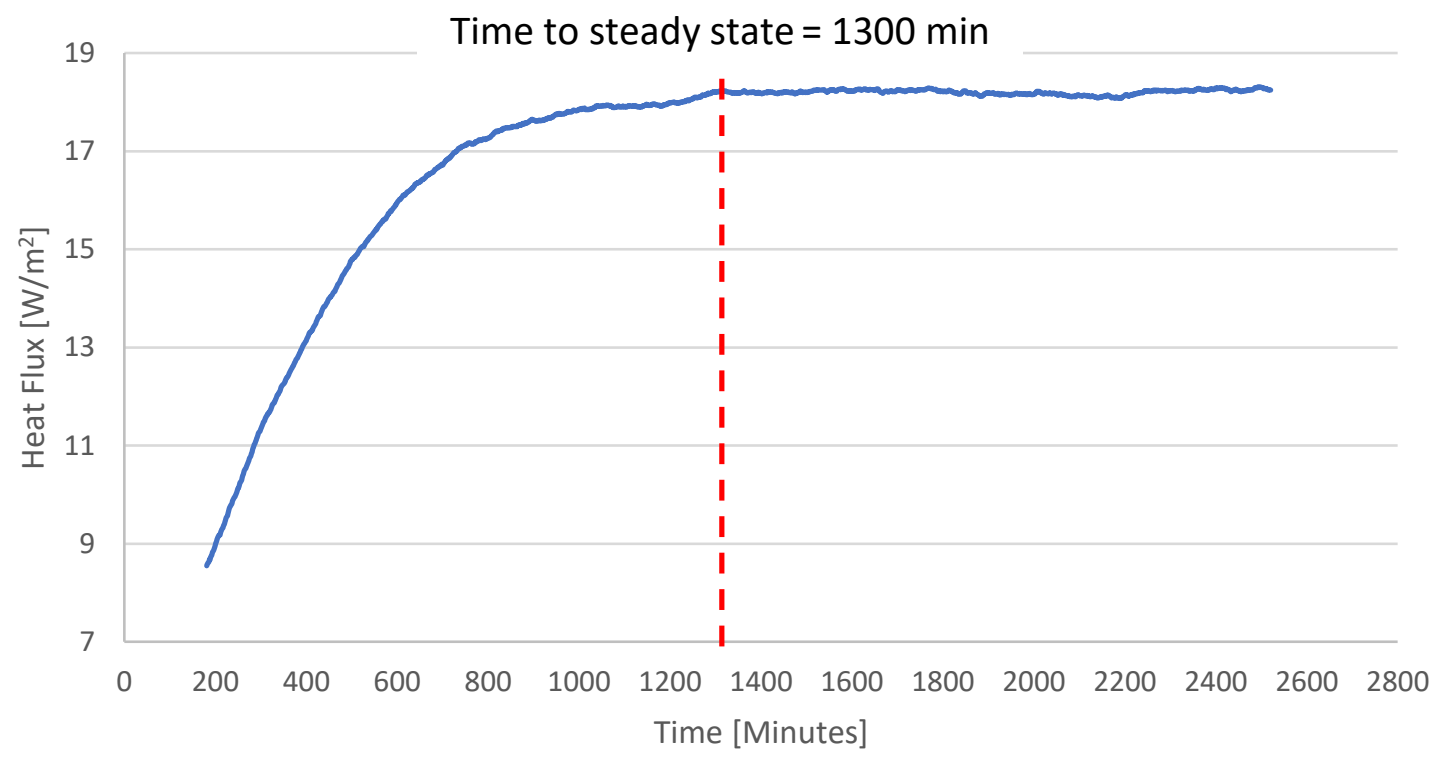

Figure 2-9 Moving average of heat flux approaching steady state when HFS was mounted to top wall of freezer 
Figure 2-9 and 2-10 are from the same experiment. Approximately 180 -minutes of data is absent from the start of each heat flux plot since that time period was used to calculate the first moving average datapoint.

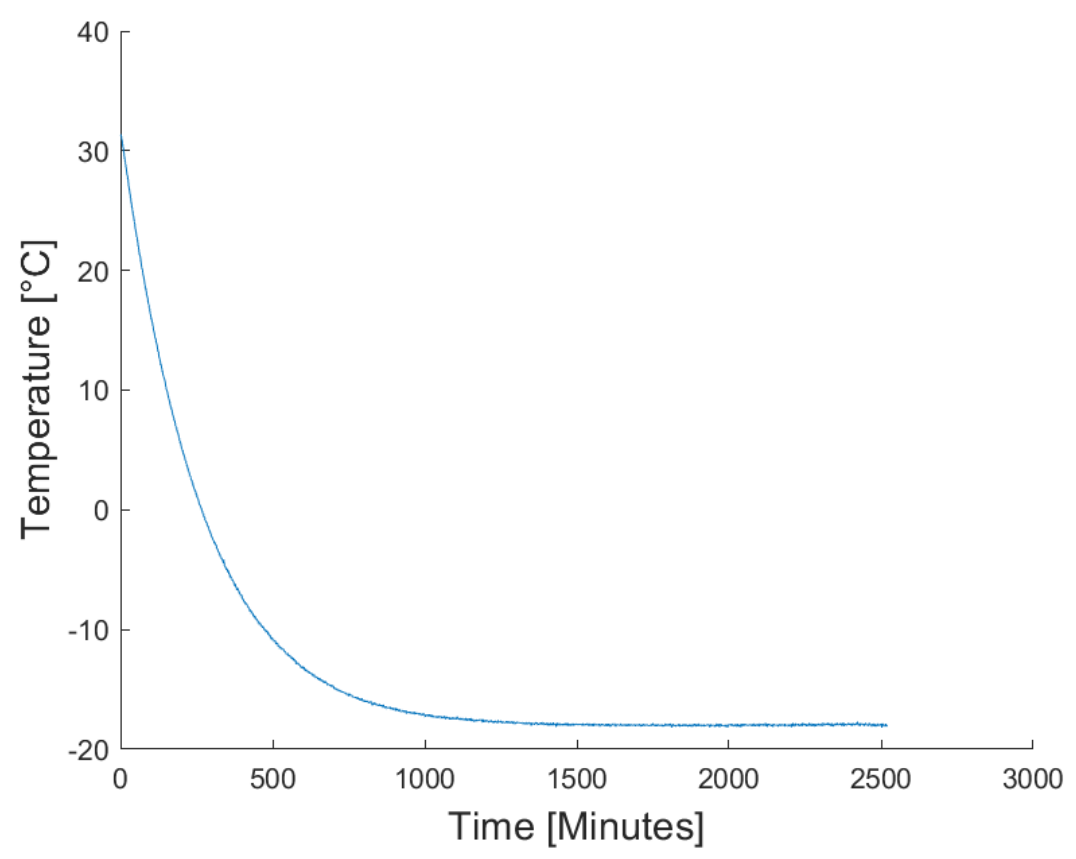

Figure 2-10 Freezer cabinet temperature pulling down to zero as measured by average of thermocouples embedded in brass weights

Average internal temperature data did not require smoothing since the thermal mass of the brass weights smoothed temperature fluctuations.

\subsubsection{HFS Repeatability Study}

The first test performed with the HFS inside the refrigerator was a repeatability test on the left wall of the unit, as shown in Figure 2-11. 


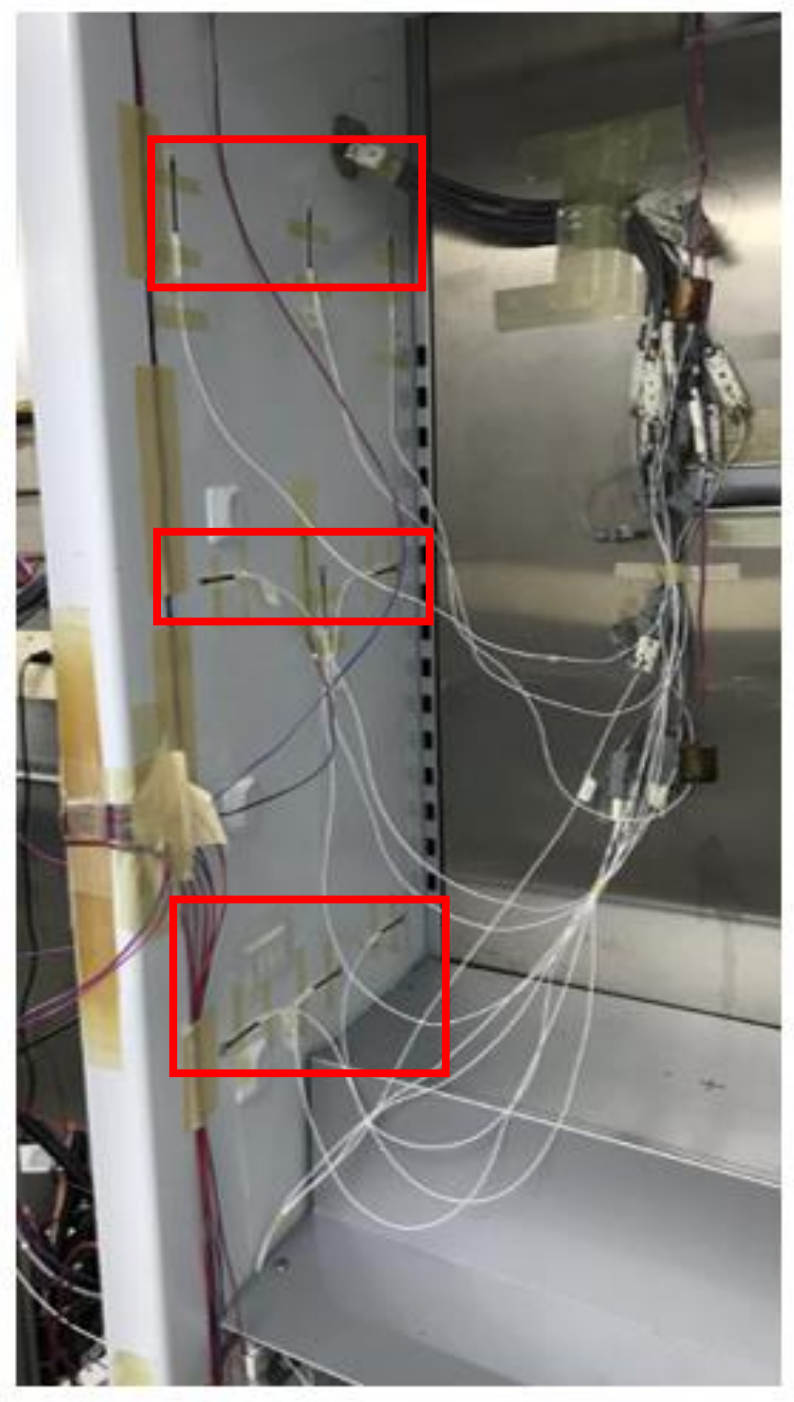

Figure 2-11 Sensors mounted to left wall for repeatability study. Sensors are boxed in red

This test was intended to prove the repeatability of measurements if the sensors were mounted in one location, removed and replaced in the same location. 12 HFS were mounted on the left side wall. Figure 2-12 shows the grid division of the left wall and the sensor numbers associated with each grid location. 


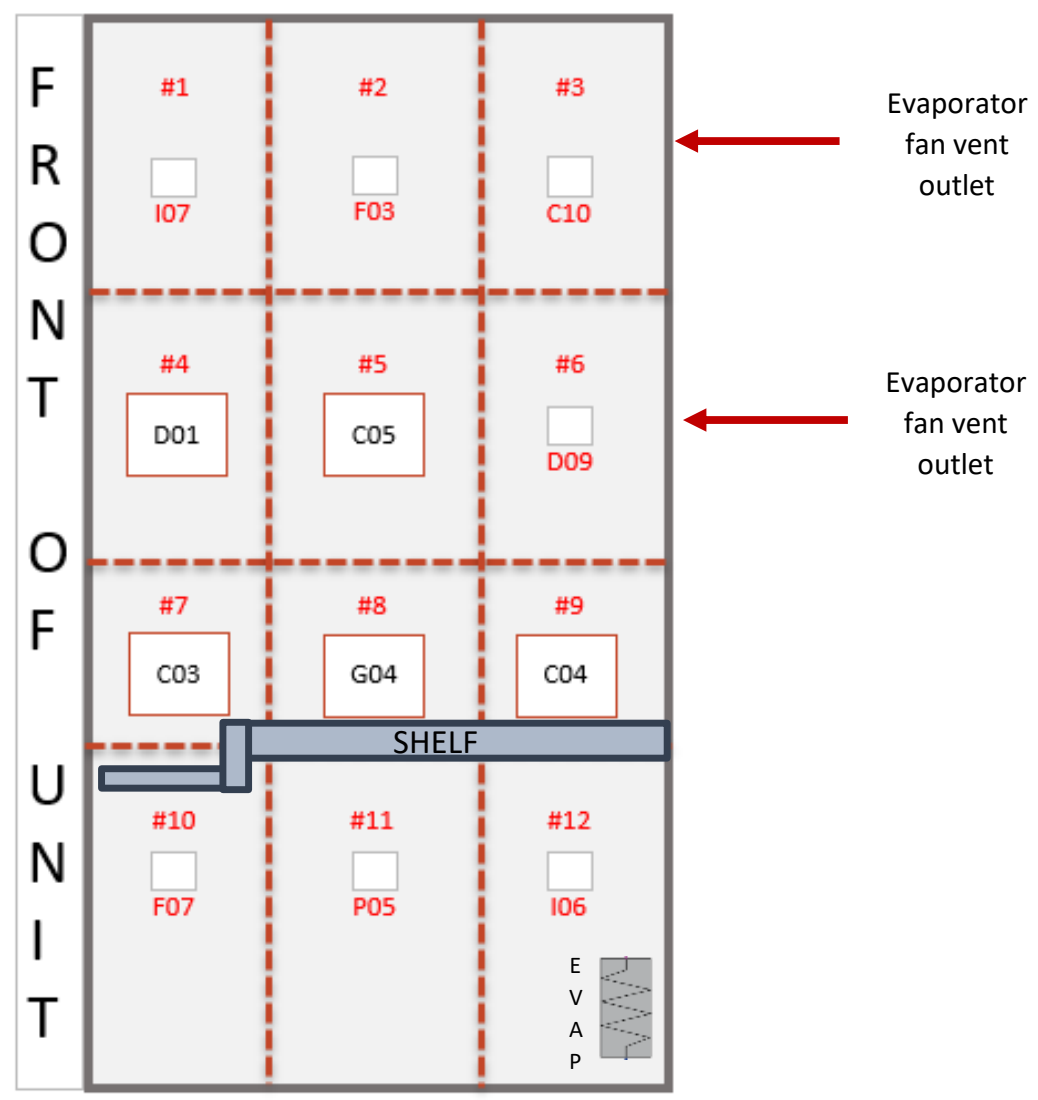

Figure 2-12 Left interior wall of unit. Numbers indicate grid location. Sensors not to scale

The repeatability study results are presented in section 3.1 "HFS Repeatability".

\subsubsection{Wall Heat Leak}

For the next set of tests, each wall was instrumented with the 12 HFS to determine the heat leak contribution from all walls. The grid area for each sensor varied slightly from wall to wall based on the geometric limitations of the refrigerator cabinet. Heat leak per wall was determined by summing the steady state sensor measurements multiplied by their corresponding grid surface areas, shown in 
Figure 2-13. Total heat leak into the cabinet is quantified by summing all heat leak grid areas (Equation 16). The wall heat leak results are presented in section 3.3, "Wall to Wall Comparison of Heat Leak".

$$
\dot{q}_{\text {total }}=\sum_{i=1}^{72} q^{\prime \prime}{ }_{i} A_{i}
$$

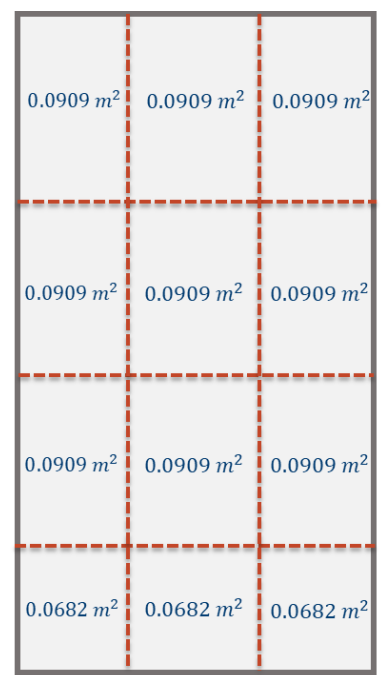

Back Wall

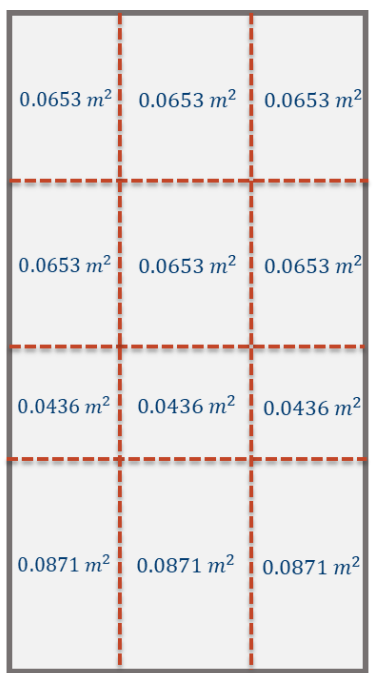

Right and Left Wall

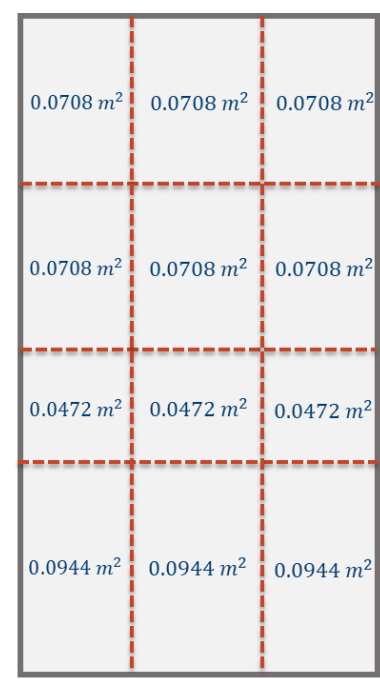

Door

\begin{tabular}{|c|c|c|}
\hline $0.028 \mathrm{~m}^{2}$ & $0.028 \mathrm{~m}^{2}$ & $0.028 \mathrm{~m}^{2}$ \\
\hline $0.028 \mathrm{~m}^{2}$ & $0.028 \mathrm{~m}^{2}$ & $0.028 \mathrm{~m}^{2}$ \\
\hline $0.028 \mathrm{~m}^{2}$ & $0.028 \mathrm{~m}^{2}$ & $0.028 \mathrm{~m}^{2}$ \\
\hline $0.028 \mathrm{~m}^{2}$ & $0.028 \mathrm{~m}^{2}$ & $0.028 \mathrm{~m}^{2}$ \\
\hline & Top \\
\hline $0.028 \mathrm{~m}^{2}$ & $0.028 \mathrm{~m}^{2}$ & $0.028 \mathrm{~m}^{2}$ \\
\hline $0.028 \mathrm{~m}^{2}$ & $0.028 \mathrm{~m}^{2}$ & $0.028 \mathrm{~m}^{2}$ \\
\hline $0.028 \mathrm{~m}^{2}$ & $0.028 \mathrm{~m}^{2}$ & $0.028 \mathrm{~m}^{2}$ \\
\hline $0.028 \mathrm{~m}^{2}$ & $0.028 \mathrm{~m}^{2}$ & $0.028 \mathrm{~m}^{2}$ \\
\hline
\end{tabular}

Bottom

Figure 2-13 Grid areas for HFS mounting for each wall of the cabinet

\subsubsection{Gasket Heat Leak}

A final round of tests was conducted to determine the impact of the gasket on overall cabinet heat leak. In these tests the door gasket was removed and sealed using polyurethane expanding foam. Comparison of the results from the sealed unit and the factory installed door gasket should provide insight into gasket leakage. 
All sensors were mounted to the left wall for the initial gasket removal test. For the second gasket removal test, two sensors were installed on the door, top, bottom, left and right walls. The back wall was not included due to the limited number of sensors available. It was assumed that the heat flux values on the back wall would not change significantly since it is the furthest from the gasket. This test was intended to determine the change in heat flux when the gasket heat leak is effectively removed compared to measurements with the gasket. Heat leak via the gasket is not accounted for with heat flux measurements taken only on the walls. Also, HFS cannot be used to quantify heat transfer through the gasket by mounting to the gasket surface due to the lack of a uniform mounting surface. Therefore, by eliminating the heat leak through the gasket the HFS will theoretically be able to quantify the majority of heat leak, which occurs through the plane wall surfaces of the unit. Table 8 lists all tests performed with the HFS. The results of the gasket heat leak study are presented in section 3.4.1, "Gasket Removal Testing to Quantify Heat Leak". 
Table 8 Summary of heat leak testing with HFS

\begin{tabular}{|c|c|c|c|c|}
\hline Test & Surface Tested & $\begin{array}{c}\text { Number of } \\
\text { HFS }\end{array}$ & Door Condition & Notes \\
\hline 1 & Left wall & 12 & Gasket & \\
\hline 2 & Door & 12 & Gasket & \\
\hline 3 & Right wall & 11 & Gasket & 1 sensor broken \\
\hline 4 & Top wall & 11 & Gasket & 1 sensor broken \\
\hline 5 & Bottom wall & 11 & Gasket & 1 sensor broken \\
\hline 6 & Back wall & 10 & Gasket & $\begin{array}{c}2 \text { sensors } \\
\text { broken }\end{array}$ \\
\hline 7 & $\begin{array}{l}\text { All walls with } \\
\text { missing } \\
\text { measurements } \\
\text { from tests 3-6 }\end{array}$ & 8 & Gasket & $\begin{array}{c}5 \text { sensors } \\
\text { measured } \\
\text { missing } \\
\text { locations (tests } \\
3-6 \text { ) and } 3 \\
\text { sensors } \\
\text { measured } \\
\text { locations with } \\
\text { previous } \\
\text { measurements }\end{array}$ \\
\hline 8 & Left wall & 8 & Gasket & $\begin{array}{c}\text { Repeatability } \\
\text { study for test } 1 \text {, } \\
4 \text { sensors } \\
\text { broken }\end{array}$ \\
\hline 9 & Left wall & 8 & $\begin{array}{l}\text { Foamed door } \\
\text { perimeter }\end{array}$ & $\begin{array}{c}4 \text { sensors } \\
\text { broken }\end{array}$ \\
\hline 10 & Right wall & 8 & $\begin{array}{l}\text { Foamed door } \\
\text { perimeter }\end{array}$ & $\begin{array}{l}4 \text { sensors } \\
\text { broken }\end{array}$ \\
\hline 11 & $\begin{array}{l}\text { All walls except } \\
\text { back wall }\end{array}$ & 8 & $\begin{array}{l}\text { Foamed door } \\
\text { perimeter }\end{array}$ & $\begin{array}{c}4 \text { sensors } \\
\text { broken }\end{array}$ \\
\hline
\end{tabular}




\section{RESULTS}

The following section presents the results of the experiments conducted to understand heat leak into a 490 -liter freezer compartment operating at $-17.8^{\circ} \mathrm{C}$ $\left(0^{\circ} \mathrm{F}\right)$. The results obtained in this study include HFS repeatability, spatial variability in heat flux over inner surfaces, wall by wall heat leak quantification, heat leak measurement comparison between calorimeter and HFS measurements for two cases and heat transfer coefficient determination via HFS measurements. Results of uncertainty analyses are also reported.

\subsection{HFS Repeatability}

To determine the repeatability of the sensor measurements inside the cabinet, the sensors were placed on the internal surface of the left wall as described in section 2.5 "Heat Flux Sensor Measurement Validation" in locations shown in Figure $3-1$. The unit was pulled down to $-17.8^{\circ} \mathrm{C}\left(0^{\circ} \mathrm{F}\right)$ until steady state was achieved and heat flux values were recorded. The sensors were then removed and replaced in the same location as the original test to determine if the measurements were repeatable.

Averages were taken once steady state was achieved over a period of at least one time constant. The range of percent difference was $24 \%-16 \%$ and the average was $11 \%$ between the two tests. The results of these tests are 
summarized in Table 9. The largest discrepancy in heat flux measurement was in location 3 of the left wall, which had a difference of $3.1 \mathrm{~W} / \mathrm{m}^{2}(24 \%)$. This difference is equal to the $3.1 \mathrm{~W} / \mathrm{m}^{2}$ average difference between expected and measured heat flux for the HFS validation experiment. Therefore, the HFS measurements were deemed repeatable.

Table 9 Repeatability study results

\begin{tabular}{|c|c|c|c|}
\hline $\begin{array}{l}\text { Location } \\
\text { [Left Wall] }\end{array}$ & $\begin{array}{l}\text { Test } 1 \\
{\left[\mathrm{~W} / \mathrm{m}^{2}\right]}\end{array}$ & $\begin{array}{r}\text { Test } 2 \\
{\left[\mathrm{~W} / \mathrm{m}^{2}\right]}\end{array}$ & $\begin{array}{c}\% \text { Difference } \\
\frac{q^{\prime \prime} \text { Test } 2-q^{\prime \prime} \text { Test } 1}{q^{\prime} \text { Test } 2}\end{array}$ \\
\hline 1 & 23.9 & 22.3 & $-6 \%$ \\
\hline 2 & 17.2 & 16.9 & $-2 \%$ \\
\hline 3 & 13.0 & 9.9 & $-24 \%$ \\
\hline 5 & 10.2 & 8.9 & $-13 \%$ \\
\hline 6 & 14.7 & 16.7 & $13 \%$ \\
\hline 8 & 13.2 & 12.7 & $-4 \%$ \\
\hline 10 & 14.8 & 17.2 & $16 \%$ \\
\hline 11 & 11.5 & 10.3 & $-10 \%$ \\
\hline \multicolumn{4}{|c|}{ Average Magnitude } \\
\hline
\end{tabular}

Figure 3-1 shows the locations of the sensors on the left wall for the repeatability study. Locations $4,7,9$, and 12 did not have a sensor since 4 of the sensors were broken. 


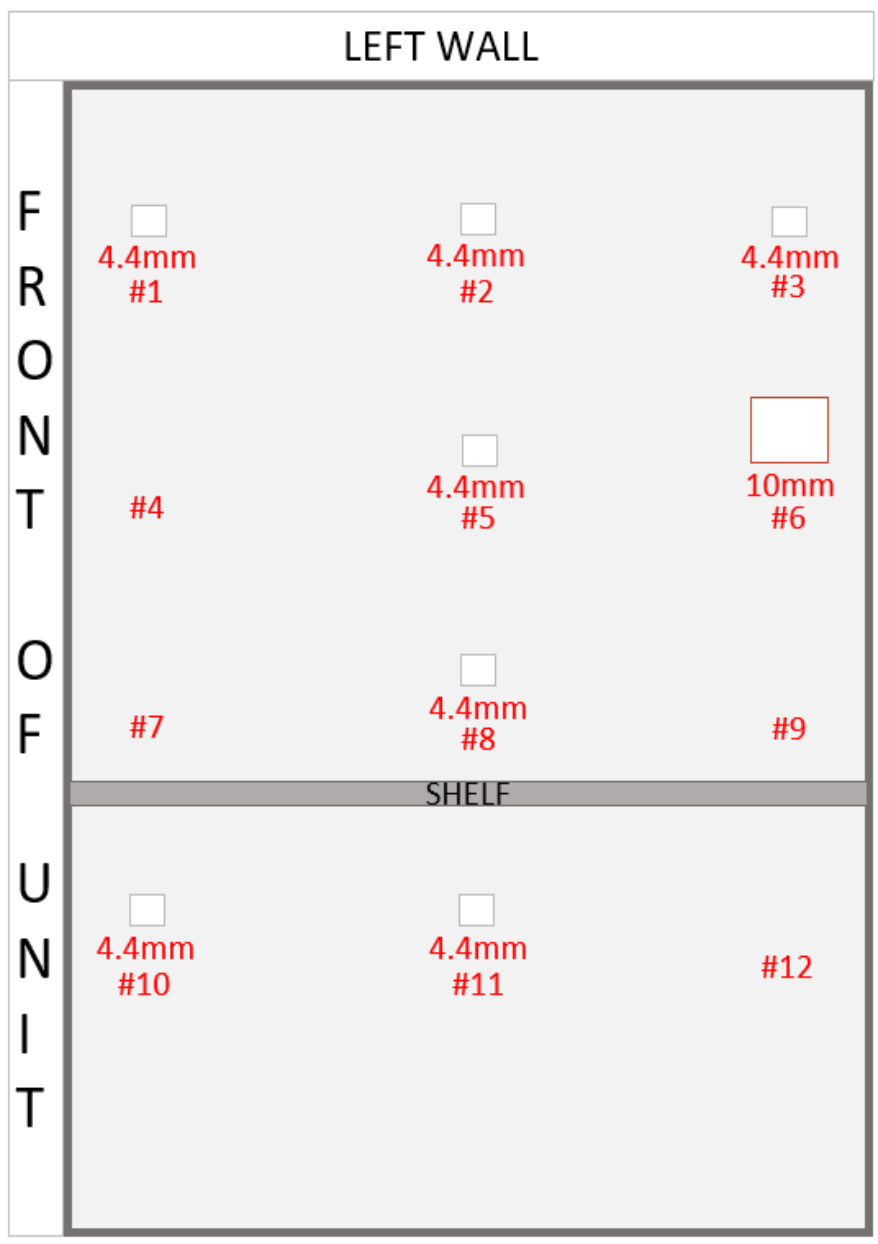

Figure 3-1 Location of sensors on left wall for repeatability study.

\subsection{Spatial Variation in Heat Flux}

Spatial variation of heat flux over inner surfaces, as viewed from inside the unit, can be seen in Figures 3-2, 3-3 and 3-4. Six tests were performed to determine the heat leak per wall of the unit. 


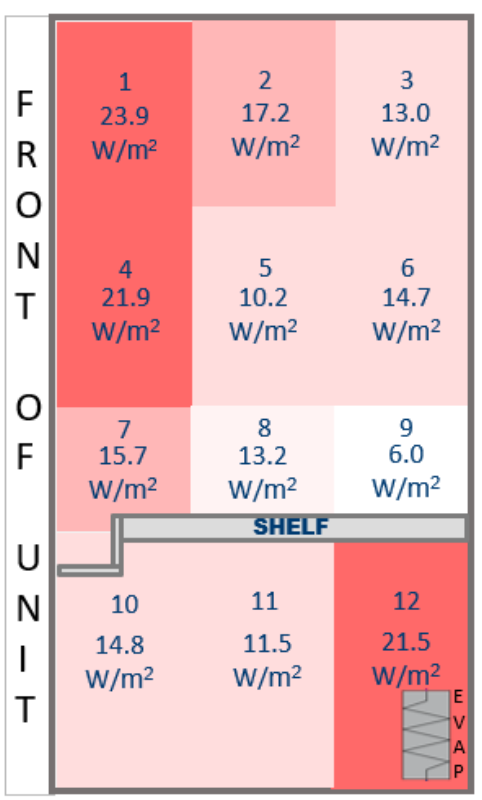

(a)

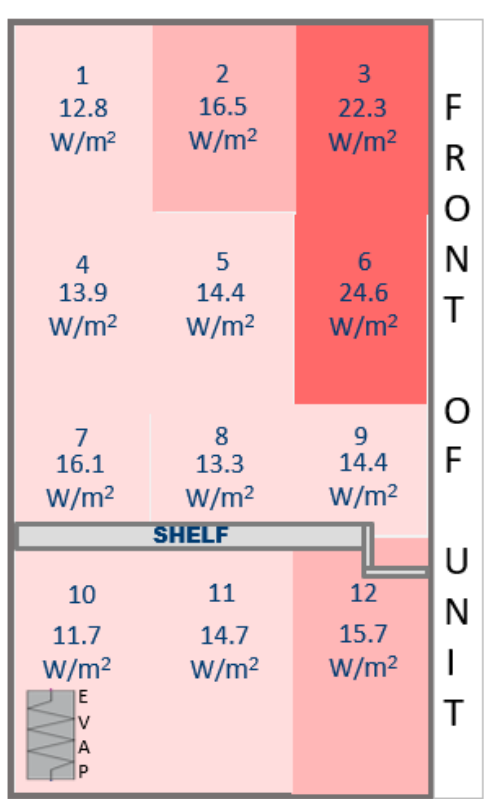

\begin{tabular}{|l|l|}
\multicolumn{1}{|l}{ Highest HF } & $25.0-40.9 \mathrm{~W} / \mathrm{m}^{2}$ \\
& $20.0-24.9 \mathrm{~W} / \mathrm{m}^{2}$ \\
\hline & $15.0-19.9 \mathrm{~W} / \mathrm{m}^{2}$ \\
\hline Lowest HF & $10.0-14.9 \mathrm{~W} / \mathrm{m}^{2}$ \\
\cline { 2 - 2 } & $4.0-9.9 \mathrm{~W} / \mathrm{m}^{2}$ \\
\hline
\end{tabular}

(b)

Figure 3-2 (a) Left wall heat leak (12.3 W total) (b) Right wall heat leak (12.4 W total)

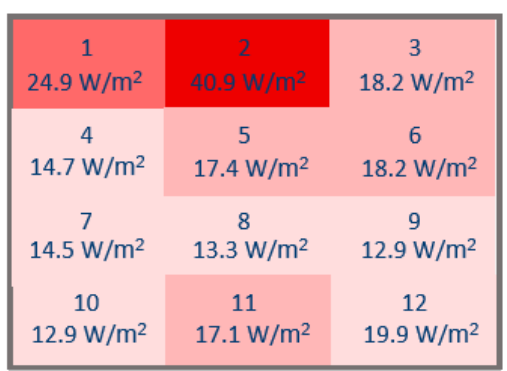

FRONT OF UNIT

\begin{tabular}{|ccc|}
\hline 1 & 2 & 3 \\
$8.3 \mathrm{~W} / \mathrm{m}^{2}$ & $7.4 \mathrm{~W} / \mathrm{m}^{2}$ & $8.1 \mathrm{~W} / \mathrm{m}^{2}$ \\
4 & 5 & 6 \\
$17.1 \mathrm{~W} / \mathrm{m}^{2}$ & $18.3 \mathrm{~W} / \mathrm{m}^{2}$ & $12.7 \mathrm{~W} / \mathrm{m}^{2}$ \\
7 & 8 & 9 \\
$21.7 \mathrm{~W} / \mathrm{m}^{2}$ & $19.8 \mathrm{~W} / \mathrm{m}^{2}$ & $17.1 \mathrm{~W} / \mathrm{m}^{2}$ \\
10 & 11 & 12 \\
$22.0 \mathrm{~W} / \mathrm{m}^{2}$ & $17.8 \mathrm{~W} / \mathrm{m}^{2}$ & $17.6 \mathrm{~W} / \mathrm{m}^{2}$ \\
\hline \multicolumn{2}{r}{ FRONT OF UNIT } \\
\hline
\end{tabular}

FRONT OF UNIT

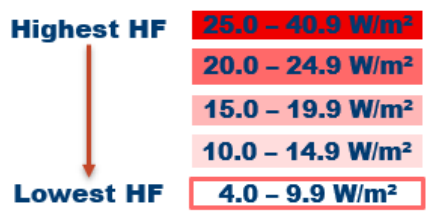

(b)

Figure 3-3 (a) Top wall heat flux (6.3 W total) (b) Bottom wall heat flux (5.1 W total) 


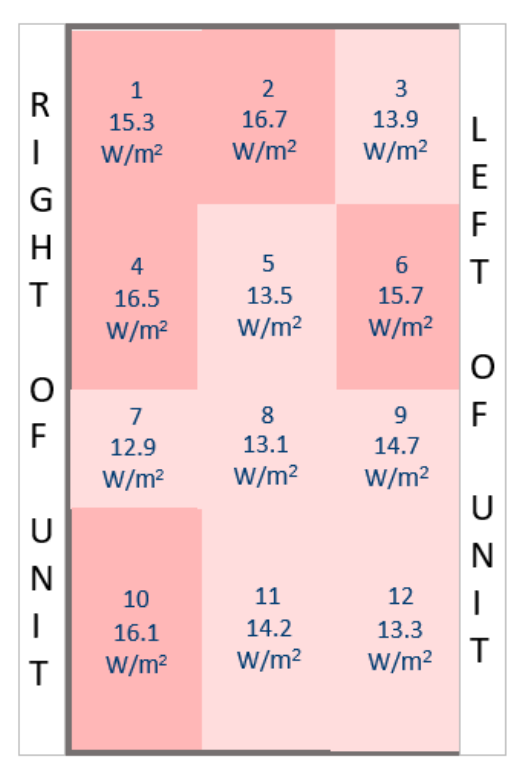

(a)

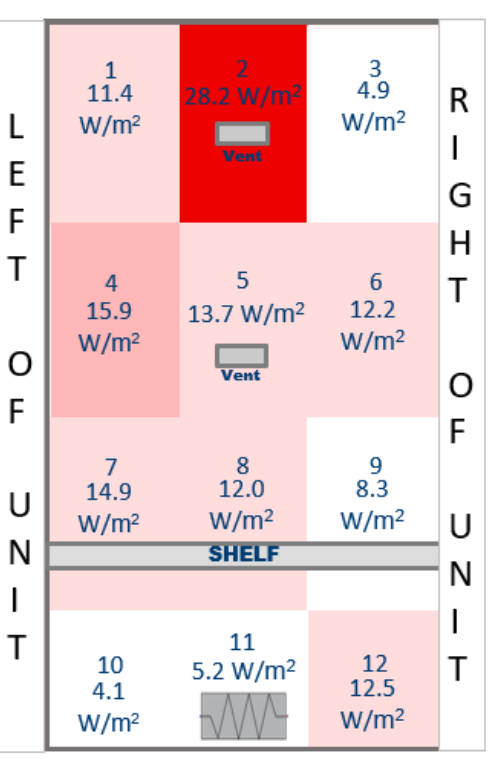

(b)

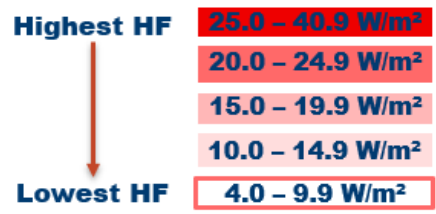

15.0 - $19.9 \mathrm{~W} / \mathrm{m}^{2}$

$4.0-9.9 \mathrm{~W} / \mathrm{m}^{2}$

Figure 3-4 (a) Door heat flux viewed from inside unit (12.5 W total) (b) Back wall heat flux (12.5 W total)

Figure 3-2 showing the left and right walls of the unit indicates that the areas closest to the gasket were typically the areas of highest heat flux. Another grid area high in heat flux seems to follow the forced convection airflow path generated by the evaporator fan and transported via ducting at the back wall of the unit. For example, the top middle grid location of the back wall where the evaporator fan vent opening was located had the highest heat leak value (Figure 3-4). This grid location is immediately in front of the fan duct outlet, which could explain the high heat leak due to cold temperatures and high airflow velocity on the exposed surface of the sensor. Location 2 on the top wall was also directly in front of the vent outlet. The boack wall sensors were not exposed to the free stream temperature measured by the brass weights since they were mounted behind the air tower cover. The sensor closest to the evaporator on the left wall was located 
next to the TXV, which could explain high flux in that location when compared to the right wall.

\subsection{Wall to Wall Comparison of Heat Leak}

The surfaces with the highest contribution to the overall heat leak into the cabinet were the door and the back wall, which both contributed $12.5 \mathrm{~W}$ to the overall heat leak (Table 10). The back wall and door have the two largest surface areas. Additionally, the door has the thinnest layer of insulating foam of all walls. The left and right wall contributed $12.3 \mathrm{~W}$ and $12.4 \mathrm{~W}$ to the overall heat leak, respectively. The average heat flux was largest on the top wall, which could be attributed to the high velocity, cold airflow exiting the air tower onto the top wall surface. A summary of the average heat flux of each wall and the wall contributions to the overall heat leak in this study compared to the findings of Melo et al. (2000) is shown in Table 10. The percentage contributions to overall heat leak for each wall in this study were very similar to those of the Melo et al. study.

Table 10 Total heat leak into cabinet comparison to Melo et al. (2000)

\begin{tabular}{|c|c|c|c|c|c|}
\hline & & & & This Study & Melo et al. \\
\hline Location & $\begin{array}{c}\text { Average } \\
\text { Heat Flux } \\
{\left[\mathrm{W} / \mathrm{m}^{2}\right]}\end{array}$ & $\begin{array}{c}\text { Surface } \\
\text { Area }\left[\mathrm{m}^{2}\right]\end{array}$ & $\begin{array}{l}\text { Heat Leak } \\
\text { [W] }\end{array}$ & $\begin{array}{l}\% \text { of Total } \\
\text { Heat Leak }\end{array}$ & $\begin{array}{l}\% \text { of Total } \\
\text { Heat Leak }\end{array}$ \\
\hline Left wall & 15.3 & 0.784 & 12.3 & $20.1 \%$ & $21.6 \%$ \\
\hline $\begin{array}{l}\text { Right } \\
\text { wall }\end{array}$ & 15.9 & 0.784 & 12.4 & $20.3 \%$ & $21.6 \%$ \\
\hline $\begin{array}{l}\text { Back } \\
\text { wall }\end{array}$ & 11.9 & 1.023 & 12.5 & $20.5 \%$ & $20.0 \%$ \\
\hline Door & 14.7 & 0.850 & 12.5 & $20.5 \%$ & $20.4 \%$ \\
\hline Top & 18.7 & 0.336 & 6.3 & $10.3 \%$ & $7.9 \%$ \\
\hline Bottom & 15.7 & 0.323 & 5.1 & $8.3 \%$ & $4.5 \%$ \\
\hline Total & - & 4.1 & 61.1 & - & - \\
\hline
\end{tabular}


The top and bottom walls had the largest discrepancy between the two studies which could be due to the airflow pattern generated by the evaporator fan in this study drawing colder air through those areas.

\subsection{Calorimeter Heat Flux Compared to HFS Measurements}

Two methods were used to quantify the heat leak into the cabinet. The primary method was to measure mass flow rate of refrigerant and change in enthalpy across the evaporator using the calorimeter. A secondary heat leak estimate was taken by multiplying heat flux values measured at 72 locations covering all inner wall surfaces by the area associated with each sensor and summing those values. The heat leak calculated via HFS measurement was compared to the heat leak calculated using the calorimeter measurements. A diagram of all heat leak components into the 490 -liter freezer compartment and total heat removed $\dot{q}_{\text {total }}$ is shown in Figure 3-5. 


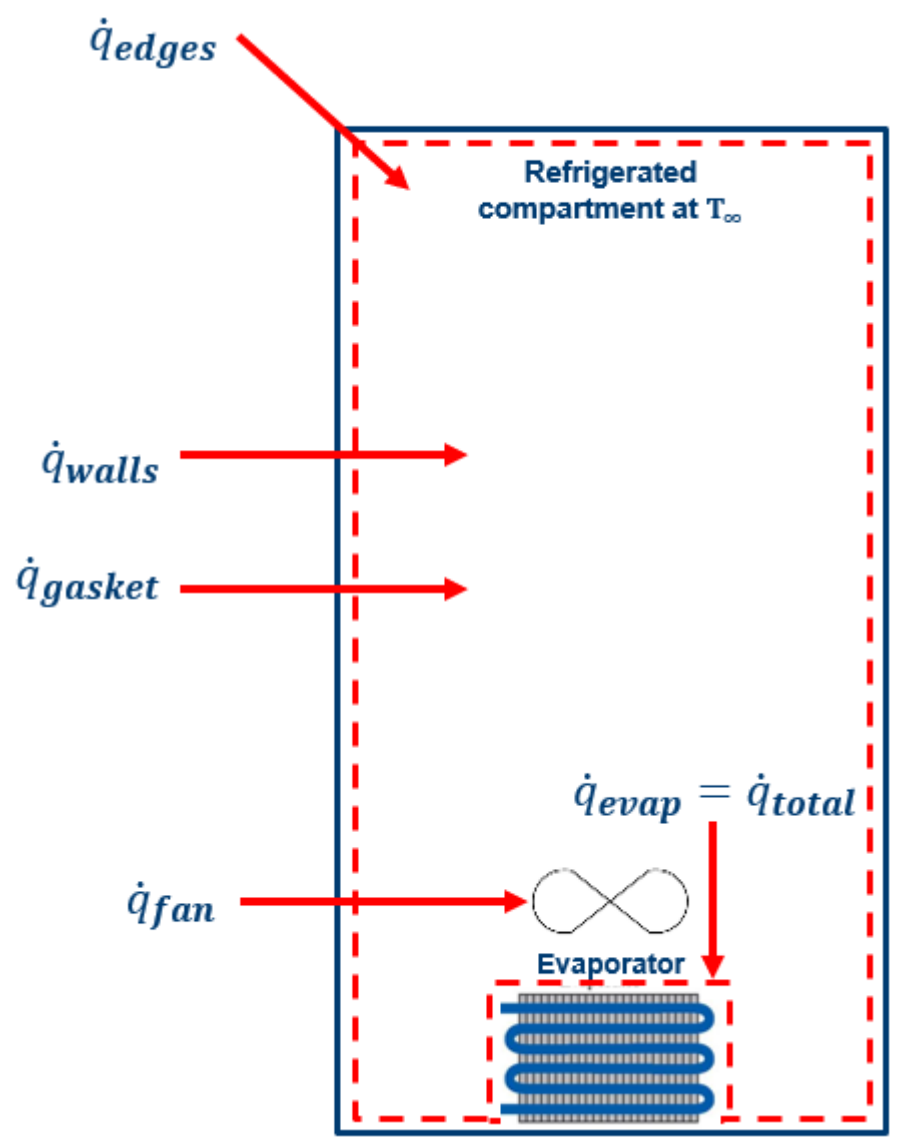

Figure 3-5 Heat leak components into refrigerated compartment of 490liter freezer

The total heat leak as measured by the heat flux sensor measurements on all walls was $61.1 \mathrm{~W}$. The average heat leak measured via the calorimeter for the six wall HFS heat leak tests was $101.8 \mathrm{~W}$ with a standard deviation of $3.2 \mathrm{~W}$. The result of the heat flux sensor testing shows a $40 \%$ underprediction of heat leak, as shown in Table 11. The large underprediction of heat leak by the HFS was attributed to heat leak through the door gasket, heat leak through the corners and edges of the unit, and underprediction of heat flux due to sensor error. The following sections describe the methods used to quantify these contributions to heat leak underprediction. 
Table 11 Comparison of HFS and calorimeter heat leak

\begin{tabular}{|c|c|}
\hline HFS Heat Leak [W] & 61.1 \\
\hline Calorimeter Heat Leak [W] & 101.8 \\
\hline \% difference & $-40.0 \%$ \\
\hline
\end{tabular}

\subsubsection{Gasket Removal Testing to Quantify Gasket Heat Leak}

In order to quantify the losses through the gasket, the gasket was removed and sealed with polyurethane expanding foam, as shown in Figure 3-6. Once the gasket was removed and the door was sealed, the unit was cooled to $-17.8^{\circ} \mathrm{C}\left(0^{\circ} \mathrm{F}\right)$ with the gasket area insulated. As expected, the heat leak into the unit was significantly reduced. The heat leak with the gasket foamed was $12 \%$ lower than with the gasket in place, as shown in Table 12.

Table 12 Heat leak values for different gasket conditions from calorimeter

\begin{tabular}{|c|c|}
\hline Gasket Condition & Calorimeter Heat Leak [W] \\
\hline With gasket in place & 101.8 \\
\hline With gasket area foamed & 90.5 \\
\hline \% Difference & $-12 \%$ \\
\hline
\end{tabular}




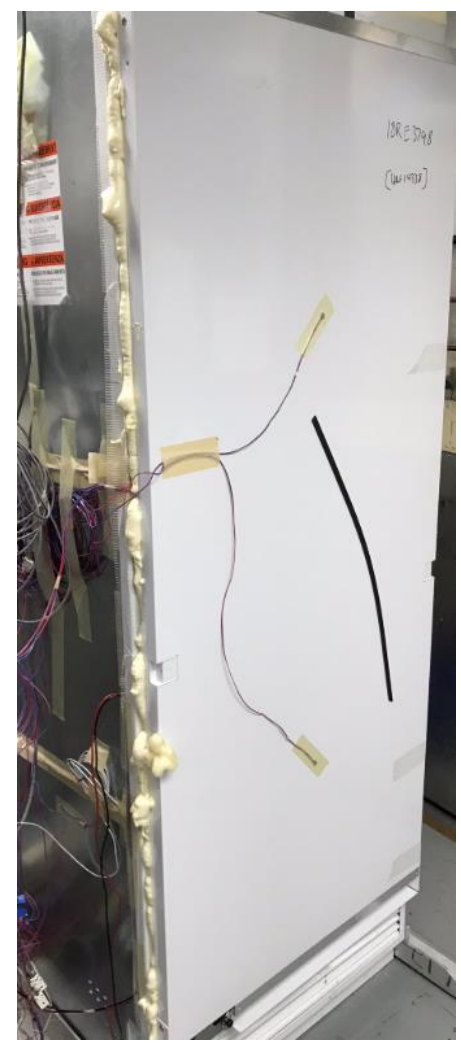

Figure 3-6 Freezer with gasket removed and insulating foam surrounding perimeter of door

In addition to the calorimeter heat leak measurement with the foamed gasket condition, heat flux sensors were mounted on walls to determine heat flux with the gasket area foamed. The results of this experiment showed an increase in heat flux on the door and the right and left side walls compared to the original case with the gasket in place. By contrast, the top and bottom surfaces of the unit did not experience a large change in heat flux. Heat flux through the back wall was not measured with the door perimeter insulated due to availability of sensors. However, the heat flux through the back wall is not expected to change significantly since that surface is the furthest away from the door perimeter. 
Table 13 shows the average heat flux of the left, right and door surfaces with the production gasket in place compared to the gasket area foamed. 12 sensors were used on the left and right walls. Since spatial heat flux variation was much less on the door, only two sensors were used to determine door heat flux with the gasket area foamed.

Table 13 Average heat flux comparison between production gasket and foamed gasket area for the left wall, right wall and door surfaces

\begin{tabular}{|c|c|c|c|}
\hline Location & $\begin{array}{c}\text { Average Heat Flux } \\
- \text { Gasket in Place } \\
{\left[\mathbf{W} / \mathbf{m}^{2}\right]}\end{array}$ & $\begin{array}{c}\text { Average Heat Flux } \\
- \text { Foamed Gasket } \\
{\left[\mathbf{W} / \mathbf{m}^{2}\right]}\end{array}$ & \% Difference \\
\hline Left Wall & 15.3 & 16.5 & $-7 \%$ \\
\hline Right Wall & 15.9 & 18.4 & $-14 \%$ \\
\hline Door & 14.7 & 15.9 & $-8 \%$ \\
\hline
\end{tabular}

Since the percent difference between the wall heat flux between the two tests was comparable to the differences seen in the validation experiment, it was assumed that the HFS heat leak values remained the same between tests. Table 14 shows the comparison of heat leak for all surfaces with the gasket in place versus the gasket area foamed. 
Table 14 Heat leak comparison between production gasket and foamed gasket area.

\begin{tabular}{|c|c|c|}
\hline Location & $\begin{array}{c}\text { Heat Leak } \\
\text { Gasket in } \\
\text { Place [W] }\end{array}$ & $\begin{array}{c}\text { Heat Leak } \\
\text { Gasket } \\
\text { Foamed [W] }\end{array}$ \\
\hline Total (HFS Heat Leak) [W] & \multicolumn{2}{|c|}{61.1} \\
\hline Calorimeter Heat Leak [W] & 101.8 & 90.5 \\
\hline $\begin{array}{c}\text { \% Difference Between } \\
\text { HFS and Calorimeter Heat } \\
\text { Leak }\end{array}$ & $-40.0 \%$ & $-32.5 \%$ \\
\hline
\end{tabular}

The elimination of the heat flow path through the gasket brought the heat leak found from HFS closer to the value from the calorimeter data to within approximately $33 \%$.

\subsubsection{Other Heat Leak Effects}

Corner and edge effects would contribute to the HFS heat leak underprediction as well. An estimate of the impact of corners and edges was determined by doing an energy balance of the freezer using surface areas and standard corner and edge shape factors. The full analysis can be found in Appendix III. It was determined that the edges were approximately $7 \%$ of the total heat leak and the corners contributed less than $1 \%$ of the overall heat leak. To adjust the heat leak value to include edge effects the overall HFS heat leak value was divided by 0.93 , as shown in Equation 17.

$$
\dot{q}=\frac{61.1 \mathrm{~W}}{0.93}=65.7 \mathrm{~W}
$$

In addition to the edge effects, the evaporator fan wattage must be considered since the fan power is energy flow into the freezer cavity. The evaporator fan inside the freezer is a $5 \mathrm{~W}$ fan. Therefore, $5 \mathrm{~W}$ should be added to 
the HFS calculated heat leak value to determine total heat removed by the evaporator.

The final foamed gasket heat leak value calculated with HFS and corrected for edge effects and fan heat was $70.7 \mathrm{~W}$. When comparing this value to the average heat leak value determined by the calorimeter for the foamed gasket test, the HFS method still underpredicts heat leak by $22 \%$. This large underprediction could be attributed to losses via the foamed gasket area due to gaps in foam. The thermal resistance of the insulating foam sprayed around the door perimeter may not be as high as the insulation of the unit walls. Sensor measurement error may have caused this underprediction as well. Assuming a 7\% underprediction of heat flux based on the results of the HFS validation experiment the HFS heat leak value would be $75.6 \mathrm{~W}$, as shown in Equation 18 .

$$
\dot{q}=70.7 * 1.07=75.6 \mathrm{~W}
$$

This would make the percent difference between the HFS and calorimeter heat leak approximately $16 \%$. Table 15 shows a comparison between HFS heat leak and the calorimeter determined heat leak. 
Table 15 Heat leak comparison between calorimeter measurement and all variations of HFS heat leak quantification

\begin{tabular}{|c|c|c|c|}
\hline $\begin{array}{l}\text { HFS Heat Leak Components } \\
\text { Accounted For }\end{array}$ & $\begin{array}{l}\text { Heat Leak } \\
{[\text { [W] }}\end{array}$ & $\begin{array}{c}\text { Calorimeter } \\
\text { Heat Leak - } \\
\text { Gasket } \\
\text { Foamed [W] }\end{array}$ & $\begin{array}{c}\% \\
\text { Difference }\end{array}$ \\
\hline HFS Heat Leak & 61.1 & \multirow{5}{*}{90.5} & $-33 \%$ \\
\hline Gasket Foamed & 61.1 & & $-33 \%$ \\
\hline Gasket Foamed, Edge Effects & 65.7 & & $-27 \%$ \\
\hline $\begin{array}{c}\text { Gasket Foamed, Edge Effects, } \\
\text { Fan Watts }\end{array}$ & 70.7 & & $-22 \%$ \\
\hline $\begin{array}{c}\text { Gasket Foamed, Edge Effects, } \\
\text { Fan Watts, Sensor } \\
\text { Underprediction }\end{array}$ & 75.6 & & $-16 \%$ \\
\hline
\end{tabular}

\subsection{Convective Heat Transfer Coefficients}

Convective heat transfer coefficients were calculated for each wall except the top and back wall of the unit using the steady state free stream and wall temperatures and the wall average of the heat flux measurements. Local convection coefficients were also calculated for HFS with thermocouples mounted directly next to the sensor. Two thermocouples were mounted to the door, left wall, right wall and back wall while a single thermocouple was mounted to the top and bottom surfaces of the freezer. The thermocouple closest to the HFS of interest was used to calculate the convection coefficient using the thermal resistance (Equation 19).

$$
h=\frac{q^{\prime \prime} \text { measured }}{T_{w}-T_{\infty}}
$$


An example of wall and air temperatures measured, and local convection coefficients calculated is shown in Table 16.

Table 16 Air and wall temperatures and local convection coefficients inside freezer compartment

\begin{tabular}{|c|c|c|c|c|}
\hline Location & $\begin{array}{c}\text { Air } \\
\text { Temperature } \\
\text { (Brass } \\
\text { Weights) } \\
{\left[{ }^{\circ} \mathrm{C}\right]}\end{array}$ & $\begin{array}{c}\text { Steady State } \\
\text { Temperature } \\
{\left[{ }^{\circ} \mathrm{C}\right]}\end{array}$ & $\begin{array}{c}\text { Difference } \\
{\left[{ }^{\circ} \mathrm{C}\right]}\end{array}$ & $\begin{array}{c}\text { Heat } \\
\text { Transfer } \\
\text { Coefficient } \\
{\left[\mathrm{W} / \mathrm{m}^{2} \mathbf{k}\right]}\end{array}$ \\
\hline Left Wall Top & \multirow{10}{*}{-18.5} & -16.7 & 1.8 & 6.0 \\
\hline Left Wall Bottom & & -15.6 & 2.9 & 6.7 \\
\hline Right Wall Top & & -17.0 & 1.5 & 10.1 \\
\hline Right Wall Bottom & & -16.0 & 2.5 & 10.4 \\
\hline Bottom & & -16.2 & 2.3 & 17.5 \\
\hline Top & & -21.3 & -2.8 & - \\
\hline Door Top & & -17.3 & 1.2 & 14.5 \\
\hline Door Bottom & & -16.9 & 1.6 & 13.9 \\
\hline Back Top & & -19.6 & -1.1 & - \\
\hline Back Bottom & & -20.8 & -2.3 & - \\
\hline
\end{tabular}

Three locations had wall temperatures that were colder than the free stream air temperature. The top and bottom of the back wall had thermocouples mounted inside the air tower and were exposed to the airflow from the evaporator fan, as shown in Figure 3-7. In this case, the free stream temperature measured by the brass weights was not representative of the free stream temperature inside the air duct. Since the duct temperature was not measured, the convection coefficients were not calculated for the back top and bottom sensors. The top wall thermocouple also measured a temperature lower than the free stream brass weight air temperature. The thermocouple on the top wall was mounted directly in front of the air tower duct outlet. The cold temperatures follow the airflow pattern 
through the unit as shown in Figure 3-7. Due to the negative temperature difference the convection coefficient was not calculated on the top wall.

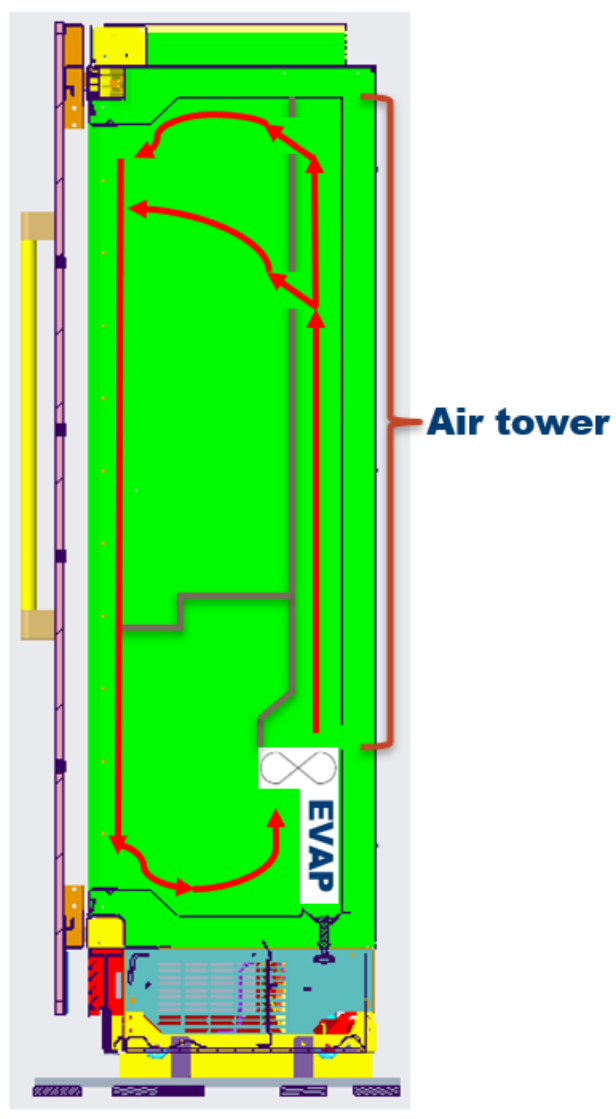

Figure 3-7 Cross section of 490-liter freezer with arrows indicating airflow pattern

The average and local convective heat transfer coefficient for each wall can be seen in Table 17. The local convection coefficients are the convection coefficients for the vertical walls in locations with a temperature measurement directly next to the HFS. The average convection coefficients were obtained by calculating the convection coefficient of each individual sensor and averaging all 12 values for a single wall. 
Table 17 Average and local convective heat transfer coefficients for each internal wall of freezer

\begin{tabular}{|c|c|c|c|c|c|c|}
\hline Location & $\begin{array}{c}\text { Air } \\
\text { Temperature } \\
\text { (Brass } \\
\text { Weights) } \\
{\left[{ }^{\circ} \mathrm{C}\right]} \\
\end{array}$ & $\begin{array}{c}\text { Steady State } \\
\text { Temperature } \\
{\left[{ }^{\circ} \mathrm{C}\right]}\end{array}$ & $\begin{array}{c}\text { Difference } \\
{\left[{ }^{\circ} \mathrm{C}\right]}\end{array}$ & $\begin{array}{c}\text { Local Heat } \\
\text { Transfer } \\
\text { Coefficient } \\
{\left[\mathrm{W} / \mathrm{m}^{2} \mathrm{k}\right]}\end{array}$ & $\begin{array}{c}\text { Average } \\
\text { Heat } \\
\text { Transfer } \\
\text { Coefficient } \\
{\left[\mathrm{W} / \mathrm{m}^{2} \mathrm{k}\right]} \\
\end{array}$ & $\begin{array}{c}\% \\
\text { Difference }\end{array}$ \\
\hline $\begin{array}{l}\text { Left Wall } \\
\text { Top }\end{array}$ & \multirow{10}{*}{-18.5} & -16.7 & 1.8 & 6.0 & \multirow{2}{*}{8.9} & $-33 \%$ \\
\hline $\begin{array}{c}\text { Left Wall } \\
\text { Bottom }\end{array}$ & & -15.6 & 2.9 & 6.7 & & $-25 \%$ \\
\hline $\begin{array}{c}\text { Right } \\
\text { Wall Top }\end{array}$ & & -17.0 & 1.5 & 10.1 & \multirow[b]{2}{*}{11.2} & $-10 \%$ \\
\hline $\begin{array}{l}\text { Right } \\
\text { Wall } \\
\text { Bottom }\end{array}$ & & -16.0 & 2.5 & 10.4 & & $-7 \%$ \\
\hline Bottom & & -16.2 & 2.3 & 17.5 & 14.6 & $-20 \%$ \\
\hline Top & & -21.3 & -2.8 & - & - & - \\
\hline $\begin{array}{l}\text { Door } \\
\text { Top }\end{array}$ & & -17.3 & 1.2 & 14.5 & \multirow{2}{*}{14.5} & $0 \%$ \\
\hline $\begin{array}{c}\text { Door } \\
\text { Bottom }\end{array}$ & & -16.9 & 1.6 & 13.9 & & $-4 \%$ \\
\hline $\begin{array}{c}\text { Back } \\
\text { Top }\end{array}$ & & -19.6 & -1.1 & - & \multirow[b]{2}{*}{ - } & - \\
\hline $\begin{array}{c}\text { Back } \\
\text { Bottom }\end{array}$ & & -20.8 & -2.3 & - & & - \\
\hline
\end{tabular}

The table entries without a value indicate locations with wall temperatures colder than the free stream air temperature. Although the percent difference between the local and average heat transfer coefficients was as high as $33 \%$ in some cases, the maximum absolute difference between the two values was 3.1 $\mathrm{W} / \mathrm{m}^{2} \mathrm{~K}$.

Based on these results there should be more emphasis placed on accurate temperature measurement at the location of the HFS and air to ensure an accurate temperature difference is being used for the convective heat transfer coefficient 
calculations. Both the local and average convective heat transfer coefficient calculation methods are a viable method for determining a realistic range of convection coefficients for a wall; however, the temperature variability on a wall and between tests is too high for this to be a viable method of determining convection coefficients. Future work should focus on characterizing spatial temperature variability and the repeatability of temperature measurements between tests.

The average HTC values of each wall measured with the HFS are between 8.9 and $14.6 \mathrm{~W} / \mathrm{m}^{2} \mathrm{~K}$. The local convection coefficients shown in the tables above are between 6.0 and $17.5 \mathrm{~W} / \mathrm{m}^{2} \mathrm{~K}$. Although these values are within an order of magnitude when comparing to values in the literature, the variability of temperature makes this method too uncertain for accurate convection coefficient calculations.

\subsection{Uncertainty and Sensitivity Analysis}

A sequential perturbation uncertainty analysis was performed to determine uncertainty of heat leak calculated via the calorimeter and the sensitivity of the convective heat transfer coefficient to varying wall temperatures.

Table 18 shows the results of the uncertainty analysis for the calorimeter heat leak quantification method. 
Table 18 Results of uncertainty analysis of calorimeter and HFS methods for typical calorimeter operating conditions

\begin{tabular}{|c|c|}
\hline $\begin{array}{c}\text { Heat Leak Measurement } \\
\text { Tool }\end{array}$ & $\begin{array}{c}\text { Overall Uncertainty } \\
\text { in } \dot{\boldsymbol{q}}[\mathrm{W}]\end{array}$ \\
\hline Calorimeter & 1.0 \\
\hline
\end{tabular}

Table 19 shows the sensitivity of the convective heat transfer coefficient to the wall temperature at a heat flux value of $10 \mathrm{~W} / \mathrm{m}^{2}$ and air temperature of $-18.5^{\circ} \mathrm{C}$.

Table 19 Convective heat transfer coefficient based on HFS and varying wall temperature with heat flux of $10 \mathrm{~W} / \mathrm{m}^{2}$ and air temperature of $-18.5^{\circ} \mathrm{C}\left(-1.3^{\circ} \mathrm{F}\right)$

\begin{tabular}{|c|c|}
\hline $\mathbf{T}_{\mathbf{W}}\left[{ }^{\circ} \mathbf{C}\right]$ & $\mathbf{h}\left[\mathbf{W} / \mathbf{m}^{2} \mathbf{K}\right]$ \\
\hline-17.8 & 13.7 \\
\hline-17.2 & 7.7 \\
\hline-16.8 & 5.9 \\
\hline
\end{tabular}

Table 20 shows the sensitivity of the convective heat transfer coefficient to the wall temperature at a heat flux value of $20 \mathrm{~W} / \mathrm{m}^{2}$ and air temperature of $-18.5^{\circ} \mathrm{C}$.

Table 20 Convective heat transfer coefficient based on HFS and varying wall temperature with heat flux of $20 \mathrm{~W} / \mathrm{m}^{2}$ and air temperature of $-18.5^{\circ} \mathrm{C}\left(-1.3^{\circ} \mathrm{F}\right)$

\begin{tabular}{|c|c|}
\hline $\mathbf{T}_{\mathbf{W}}\left[{ }^{\circ} \mathbf{C}\right]$ & $\mathbf{h}\left[\mathbf{W} / \mathbf{m}^{2} \mathbf{K}\right]$ \\
\hline-17.8 & 27.4 \\
\hline-17.2 & 15.5 \\
\hline-16.8 & 11.7 \\
\hline
\end{tabular}

The results indicate that the heat transfer coefficient calculation is highly sensitivity to the wall and free stream temperatures. A change in $T_{w}$ of approximately $1{ }^{\circ} \mathrm{C}$ can impact the convection coefficient value by $15.7 \mathrm{~W} / \mathrm{m}^{2} \mathrm{~K}$ when the air and wall temperature are very close. The air temperature was taken 
as the average temperature of the brass weights inside the unit, and the wall temperature was obtained from the thermocouple closest to the HFS. Since there are likely to be spatial variations in the air temperature inside the freezer, a more accurate local free stream temperature should be measured in close proximity to the HFS and the wall temperature should be measured at the exact sensor location; however, instrumenting the freezer with additional thermocouples could have impacted airflow patterns and heat leak into the unit due to routing of additional wires. The full uncertainty and sensitivity study can be found in Appendix IV. 


\section{CONCLUSIONS}

\subsection{Important Results}

The goal of this study was to examine a method of quantifying heat leak into a 490-liter upright freezer using both surface HFS measurements and in-line refrigerant property measurements taken with a heat leak calorimeter. Heat leak quantified with the HFS was compared to calorimeter heat leak measurements to determine the accuracy of the HFS. Additionally, the feasibility of using HFS to determine convective local and average heat transfer coefficients of the internal walls of the freezer was examined. The key conclusions of this study are listed below.

- A HFS repeatability study on the internal wall of the freezer compartment found that the range of percent difference of heat flux measurements between tests was $-24 \%$ to $+16 \%$ and the average of the absolute values of percent difference was $11 \%$.

- Based on HFS heat leak calculations, the surfaces with the highest contribution to the overall heat leak into the cabinet were the door and the back wall, which both contributed $12.5 \mathrm{~W}$ to the overall heat leak. The left wall and right wall contributed $12.3 \mathrm{~W}$ and $12.4 \mathrm{~W}$ to the overall heat leak, 
respectively. This indicates that all vertical walls had comparable contribution to overall heat leak.

- The door gasket contributed approximately $12 \%$ to overall heat leak into the freezer cabinet. This is similar to the results reported by Gao et al. (2017) who concluded the gasket contributed $14 \%$ to the overall heat leak in a freezer compartment.

- HFS heat leak estimate underpredicted heat leak by $22 \%$ when considering gasket heat leak, edge effects and evaporator fan power. When sensor underprediction is included in this HFS heat leak calculation, HFS underpredict heat leak by approximately $16 \%$

- The back and top wall surface temperature measurements were below the free stream air temperature; therefore, no heat transfer coefficients were calculated for those surfaces. The back wall experienced high velocity, low temperature airflow through the air tower from the evaporator fan and the top wall was directly adjacent to the air tower outlet.

- The average heat transfer coefficient values of the remaining walls measured with the HFS were between 8.9 and $14.6 \mathrm{~W} / \mathrm{m}^{2} \mathrm{~K}$. The local convection coefficients were between 6.0 and $17.5 \mathrm{~W} / \mathrm{m}^{2} \mathrm{~K}$.

- The calculated convection coefficient values were reasonable with respect to expected values in a cold compartment with forced airflow; however, a sensitivity study of the HFS ability to measure heat transfer coefficients indicated that the coefficient calculation is sensitive to wall surface 
temperature. Due to the variability in wall temperature, the HFS are not a reliable method of determining heat transfer coefficients.

\subsection{Future Work}

A primary takeaway from this study was that HFS measurements on the wall surface of a freezer compartment cannot provide an accurate estimation of heat leak into the cabinet. Additionally, HFS and surface temperature measurements are not a reliable method of determining convective heat transfer coefficients due to the spatial and test to test temperature variability. Instead of investing significant resources to purchase additional HFS, a temperature repeatability study should be performed on each wall to determine the spatial variation in wall temperature and the variation between tests. If the variability proves to be large, then HFS should not be used for convection coefficient measurements.

Although cost was a limiting factor when acquiring sensors for experimentation, additional sensors would have allowed for multiple wall measurements at once instead of only single wall testing. Additionally, having more sensors would have reduced the need to remove the sensors from the wall so frequently, which caused irreparable damage to several sensors.

Future tests should try different means of insulating the door gasket to eliminate heat leak in that area. Although polyurethane foam is a good insulator, consumer

grade spray polyurethane foam has a foaming agent that has higher thermal conductivity values than the cabinet foam. Therefore, there is a possibility that heat 
leak was higher around the door perimeter since its insulating properties were not as robust as the walls of the unit.

The unit could also be operated at various temperatures and fan conditions to understand the impact of boundary conditions on heat flux measurements. Running the unit at various operating temperatures could indicate the change in overall heat leak into the unit when internal temperatures change. 


\section{REFERENCES}

Boughton, Clausing, Newell. An Investigation of Household Refrigerator Cabinet Loads. Urbana: Air Conditioning and Refrigeration Center, 1992.

Engineers Edge. Heat Transfer Knowledge and Engineering. < https://www.engineersedge.com/heat_transfer/heat_transfer_table_conten t.htm/>. 2019.

Fluxteq. Fluxteq. 2018. <https://www.fluxteq.com/>. 27 July 2019.

Gao, Naini, Wagner, Miller. "An Experimental and Numerical Study of Refrigerator Heat Leakage at the Gasket Region." International Journal of Refrigeration 73: 99-110. 2017.

Gardon. "An instrument for the direct measurement of intense thermal radiation." Rev. Sci. Instrum: 366-370. 1953.

Hasanuzzaman, Saidur, Masjuki. "Effects of Operating Variables on Heat Transfer and Energy Consumption of a Household Refrigerator-Freezer During Closed Door Operation." Energy 34.2: 196-198. 2009.

Hevey, Langley. Schmidt-Boelter Gage. Patent 6186661B1. 11 September 1998.

Inan, Newell, Egrican. Heat and Mass Transfer Through a Domestic Refrigerator and Evaluation of Evaporator Performance Under Frosted Conditions. Urbana: Air Conditioning and Refrigeration Center, 2000.

Knackstedt, Newell, Clausing. A Study of Convective and Mass Heat Transfer in a Residential Refrigerator During Open Door Conditions. Urbana: Air Conditioning and Refrigeration Center, 1995.

Laguerre. "Heat Transfer and Air Flow in a Domestic Refrigerator." Mathematical Modelling of Food Processing. Boca Raton: CRC Press. 445-474. 2010.

Laguerre, Hoang, Flick. "Heat Transfer Modelling in a Refrigerated Display Cabinet: The Influence of Operating Conditions." Journal of Food Engineering 108: 353-364. 2012.

Melo, da Silva, Pereira. "Experimental Evaluation of the Heat Transfer Through the Walls of Household Refrigerators." International Refrigeration and Air Conditioning Conference. West Lafayette, 2000. 
Kline, McClintock. "Describing Uncertainties in Single Sample Experiments." Mechanical Engineering: 3-8. 1953.

Wikipedia. Thermopile. 9 September 2014.

Williams, Clausing, Newell. An Experimental Investigation of Natural Convection Heat Transfer in a Refrigerator During Closed Door Conditions. Urbana: Air Conditioning and Refrigeration Center, 1994. 


\section{APPENDICES}

\section{Appendix l: Calorimeter Overview}

A forward heat leak calorimeter with a refrigeration sealed system was designed to operate a 490-liter upright freezer (Figure A1).

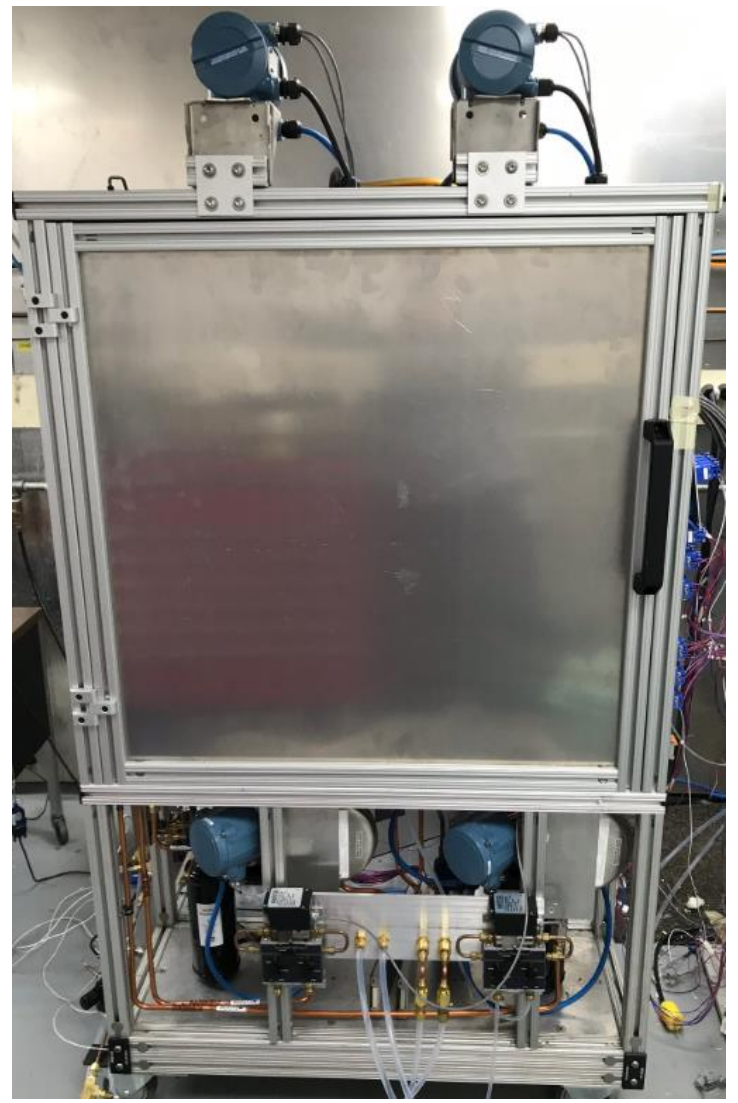

(a)

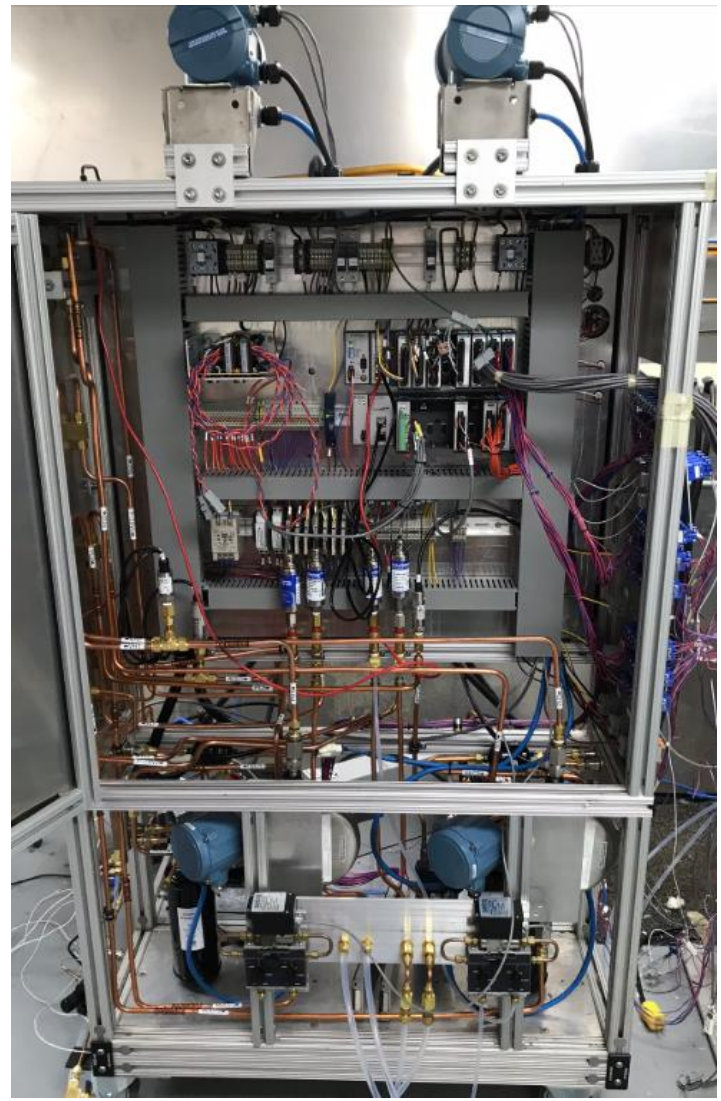

(b)

Figure A1 Forward heat leak calorimeter fixture with (a) door closed and (b) open 
The calorimeter has the capability of operating two sealed systems. Only one sealed system was used for this study since a single evaporator, single freezer compartment was used for the experiment. Both heat leak calorimeters for each sealed system were built with the same components. Figure A2 shows a schematic of the forward heat leak calorimeter with all instruments shown. The arrows pointing to the components show the input and output voltages of the instruments. The top left of the diagram shows a P-h diagram of the refrigeration cycle with the locations of each stage indicated on the calorimeter diagram. Circles with a "P" indicate pressure transducers. Circles with a " $T$ " indicate temperature sensors. Red and blue arrows indicate the direction of refrigerant flow.

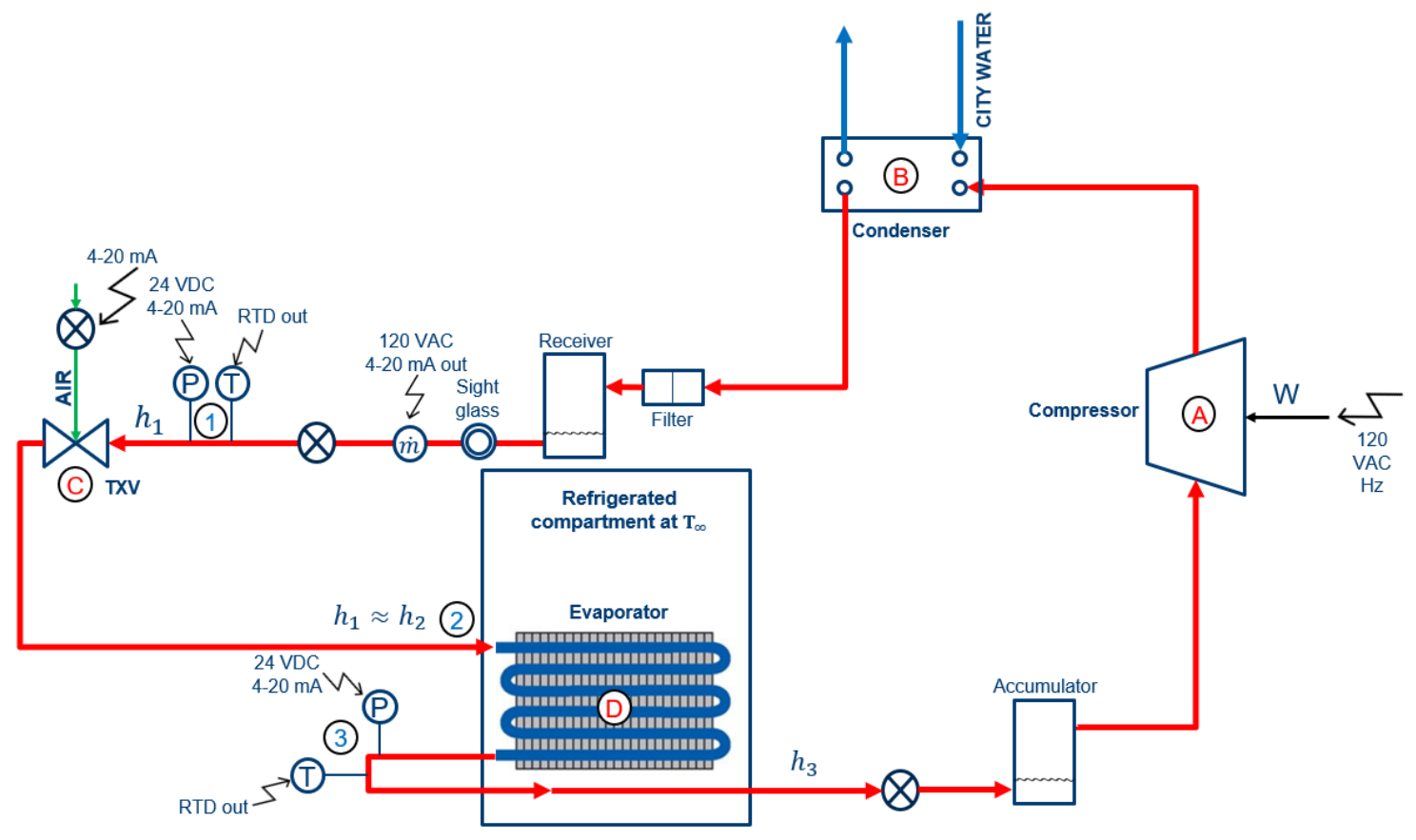

Figure A2 Schematic of instrumented forward heat leak calorimeter 
One sealed system will be described for the sake of simplicity. An Embraco VEGD $7 \mathrm{H}$ variable speed compressor was used with $\mathrm{R} 134 \mathrm{a}$ refrigerant and is shown in Figure A3.

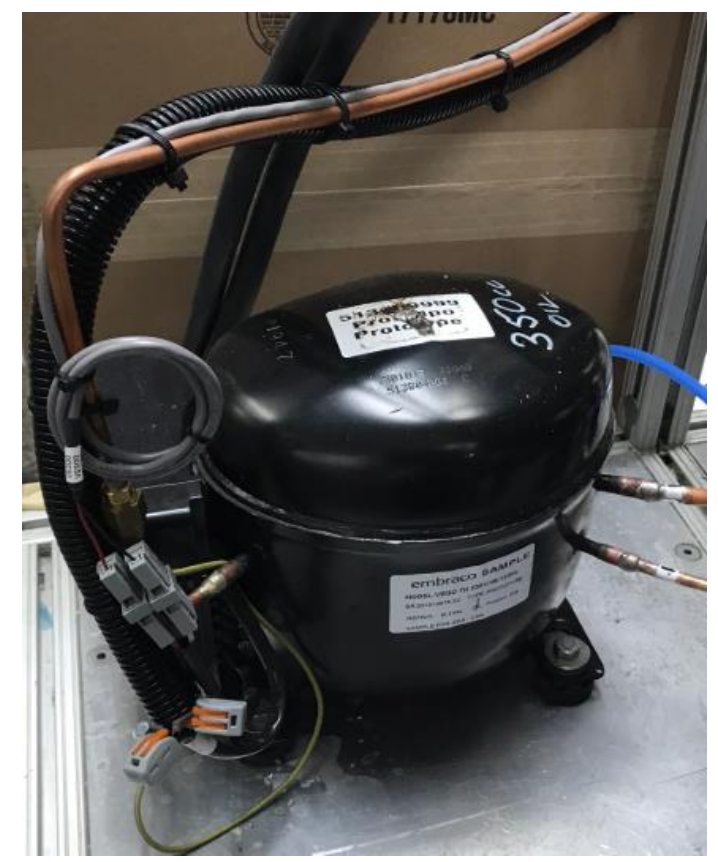

Figure A3 Embraco VEGD 7H mounted to forward heat leak calorimeter fixture

The charge port of the compressor was connected to a valve on the side panel of the calorimeter fixture to allow for easy charging during use. Valves to isolate high and low sides of the sealed system as well as the charging port valve and sight glasses mounted to the side panel are shown in Figure A4. 


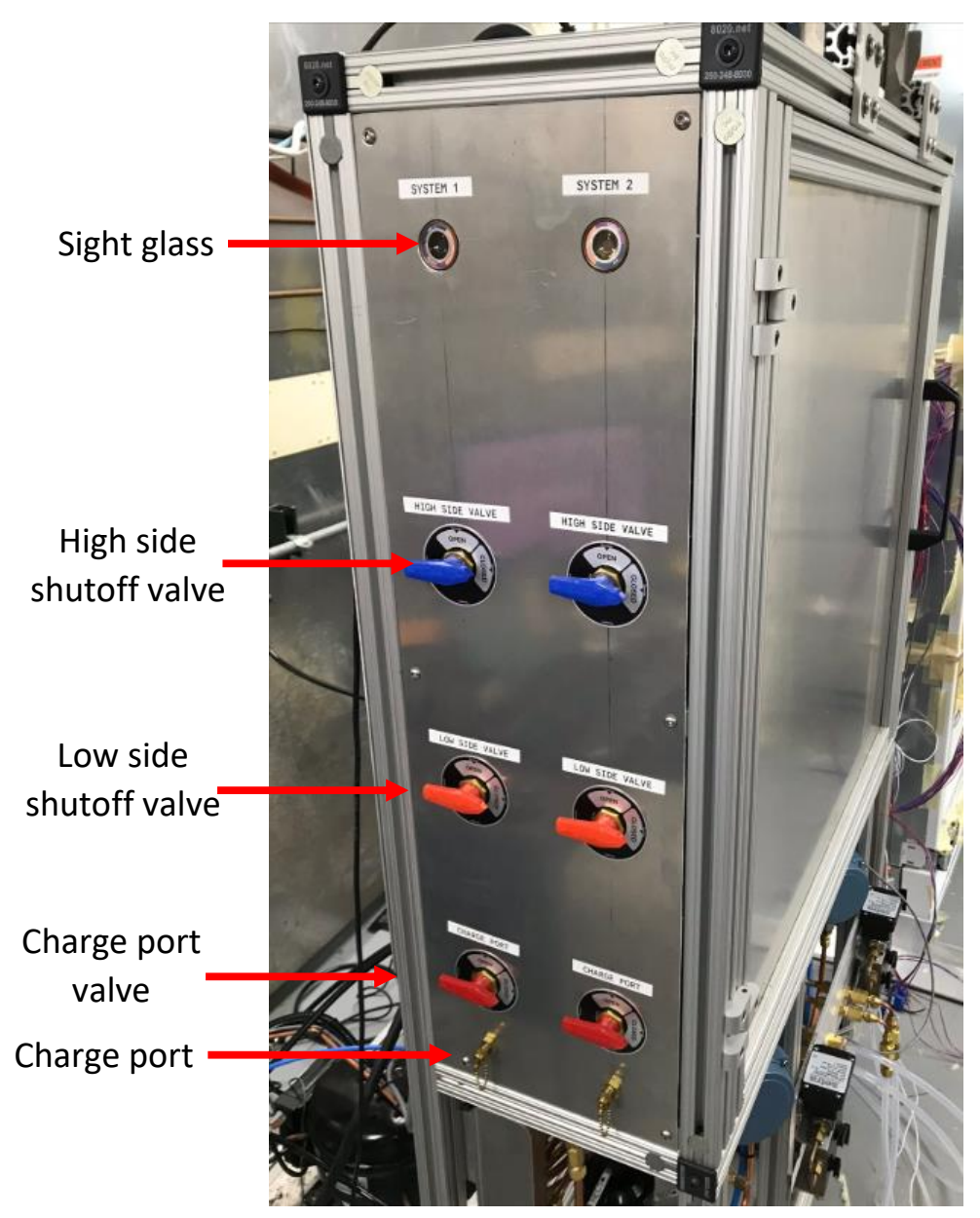

Figure A4 Side panel of calorimeter with refrigerant charge ports, isolation valves and sight glasses

The outlet of the compressor was connected with copper tubing to the inlet of the condenser. The condenser was an Alfa Laval AC16 brazed plate heat exchanger. City water was connected to the heat exchanger as the cooling liquid. The outlet of the condenser connected to a Parker Hannifin 450145-001 filter dryer shown in Figure A5. This device removes moisture and non-condensable gases from the refrigerant flow. 


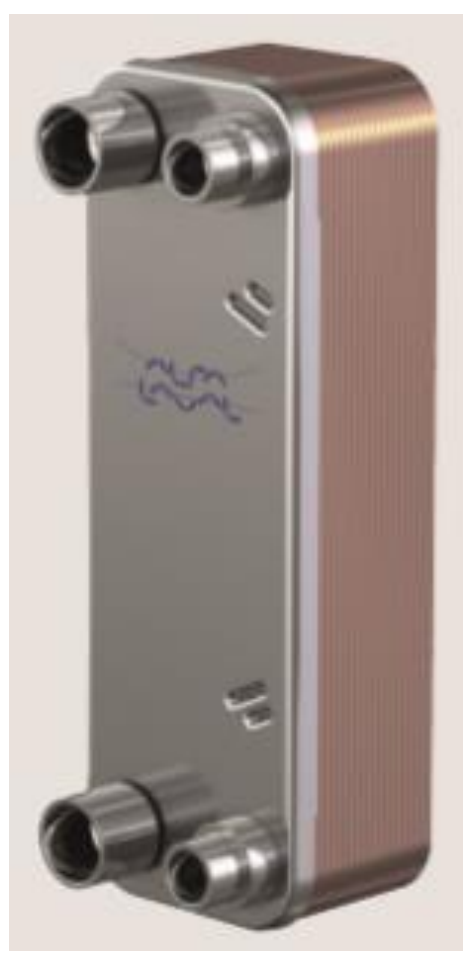

(a)

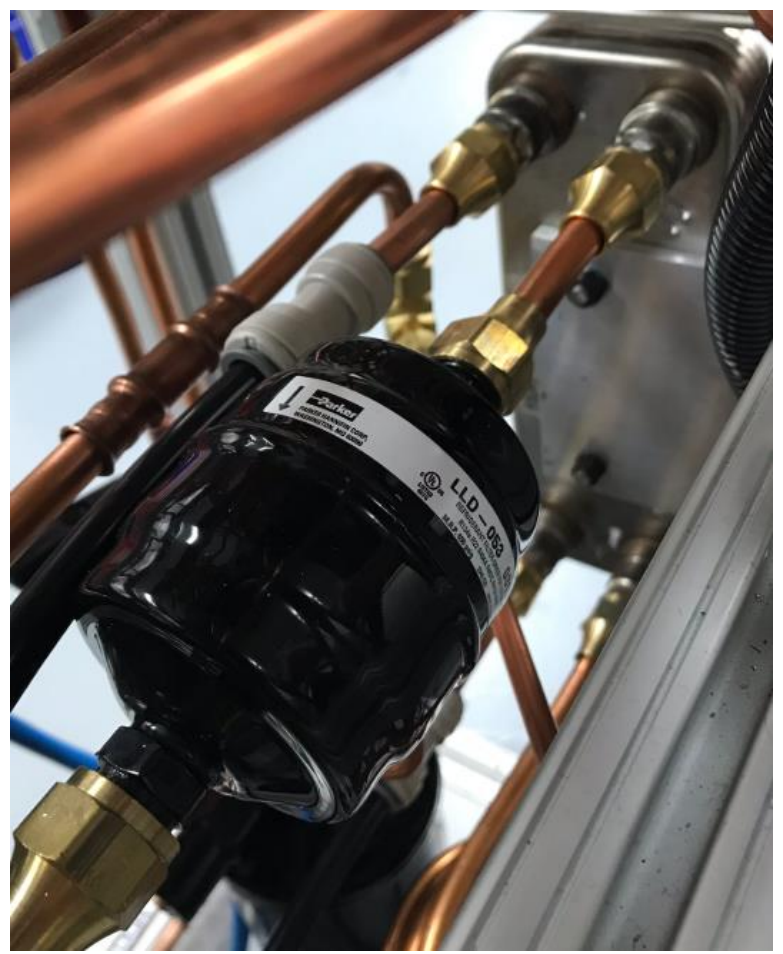

(b)

Figure A5 (a) Alfa Laval AC16 connected to (b) filter dryer and mounted to forward heat leak calorimeter fixture

Refrigerant from the filter dryer is routed to a Parker Hannifin 450145-001 liquid line receiver (Figure A6). The receiver is a device that holds excess refrigerant and ensures single-phase subcooled liquid enters the mass flow meter. A Refrigeration Research suction line accumulator (Figure A6) installed at the inlet of the compressor ensures only superheated vapor enters the compressor to avoid damage. 


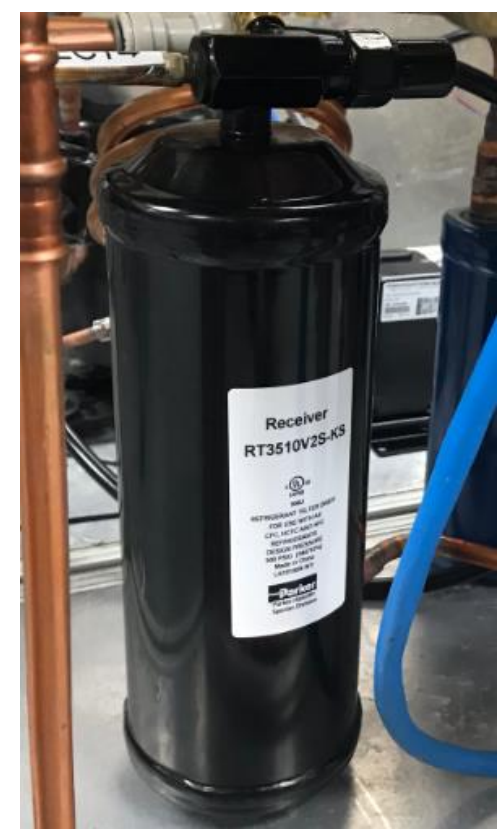

(a)

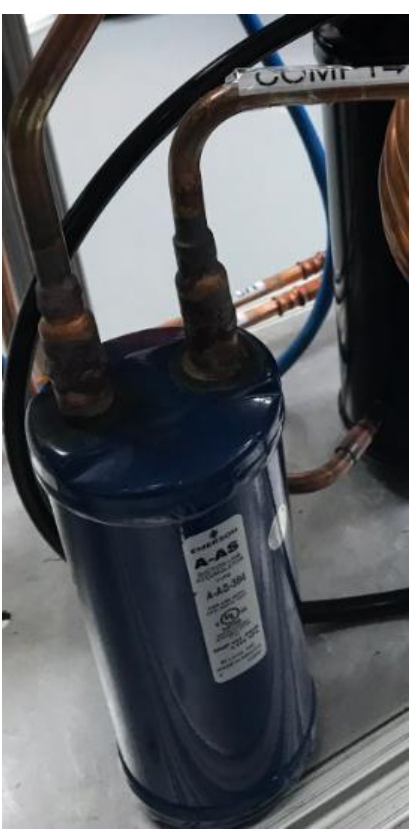

(b)

Figure A6 (a) Liquid line receiver (b) suction line accumulator

The outlet of the receiver was connected to an Emmerson Flow sight glass to visualize refrigerant phase and then to a Micro Motion CMF-10 Coriolis mass flow meter. After exiting the mass flow meter, the refrigerant flows to a Danfoss TXV where it undergoes a rapid expansion to two-phase refrigerant. The TXV was pneumatically controlled via shop airflow, which was regulated with a ProportionAir pressure transducer. The TXV closure was user controlled via the LabVIEW program. In order to access the evaporator, a hole was drilled in the back of the unit to the left of the evaporator cover. Copper tube from the mass flow meter and a plastic line from the air pressure regulator were passed through the hole. The evaporator was cut, and fittings were attached to connect the evaporator in line with refrigerant flow. Figure $A 7$ shows the freezer with the fittings and TXV installed with refrigerant lines connecting to the evaporator. 


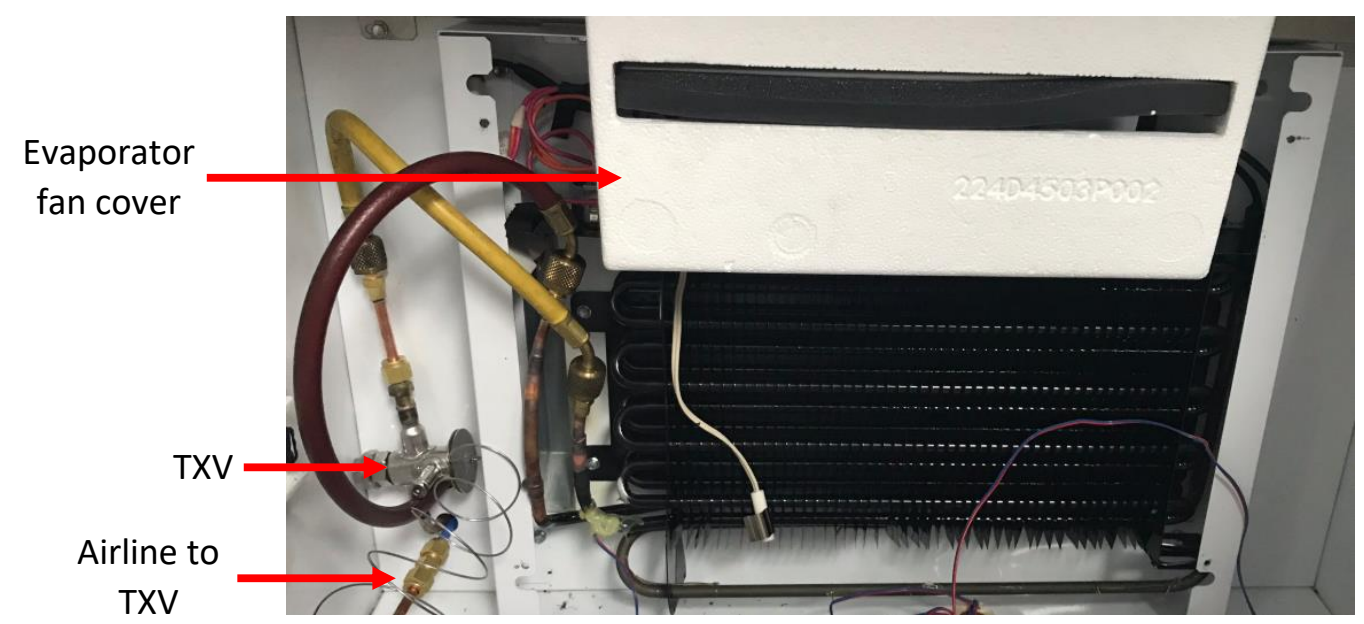

Figure A7 Evaporator with refrigerant fittings installed

The refrigerant flows through the evaporator as a two-phase mixture and enters the accumulator as a superheated vapor. Superheated vapor enters the compressor where it is compressed into a high-pressure gas. Figure A8 shows the unit with the evaporator cover installed prior to sealing the drilled hole with foam. 


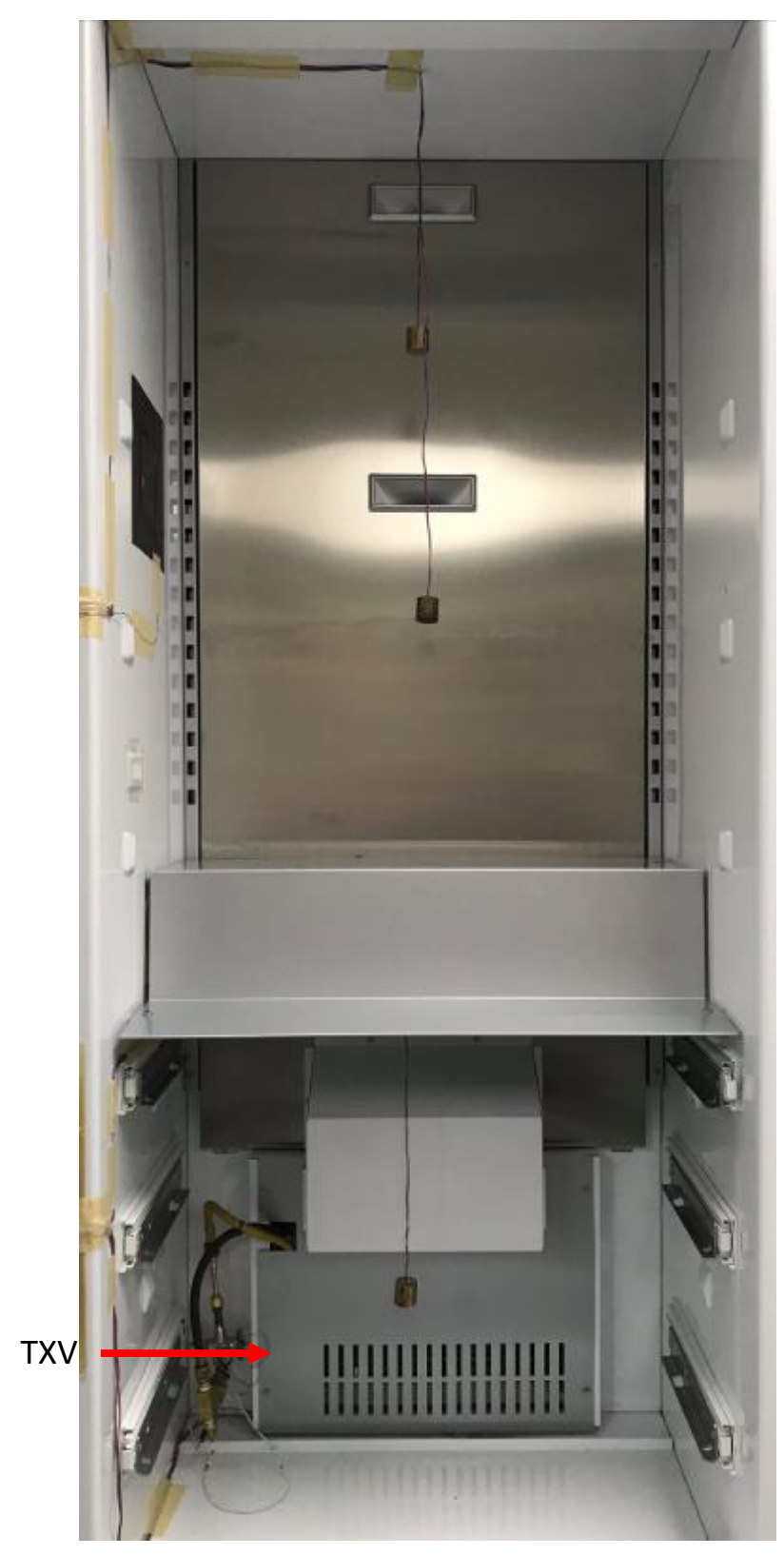

Figure A8 Front view of unit with TXV and evaporator cover installed

The opening used to pass refrigerant lines to the evaporator was insulated with expanding polyurethane foam. Foam was wrapped around the tubing inside the unit to reduce heat transfer between the refrigerated compartment and the refrigerant lines (Figure A9). Pressure transducers and RTDs were placed in-line 
with the refrigerant flow in various locations. Setra AccuSense ASM pressure transducers (Figure A9) and RTDs were used at the inlet of the TXV and outlet of the evaporator. These measurements were used to calculate enthalpy change across the evaporator and subsequently the overall heat leak into the cabinet.

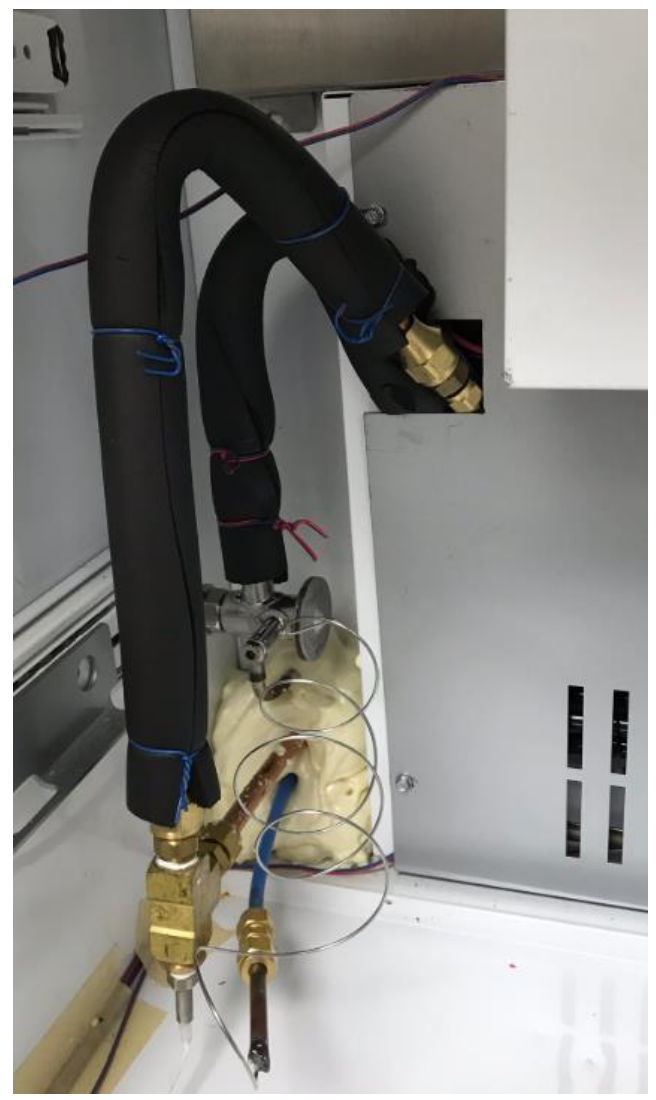

(a)

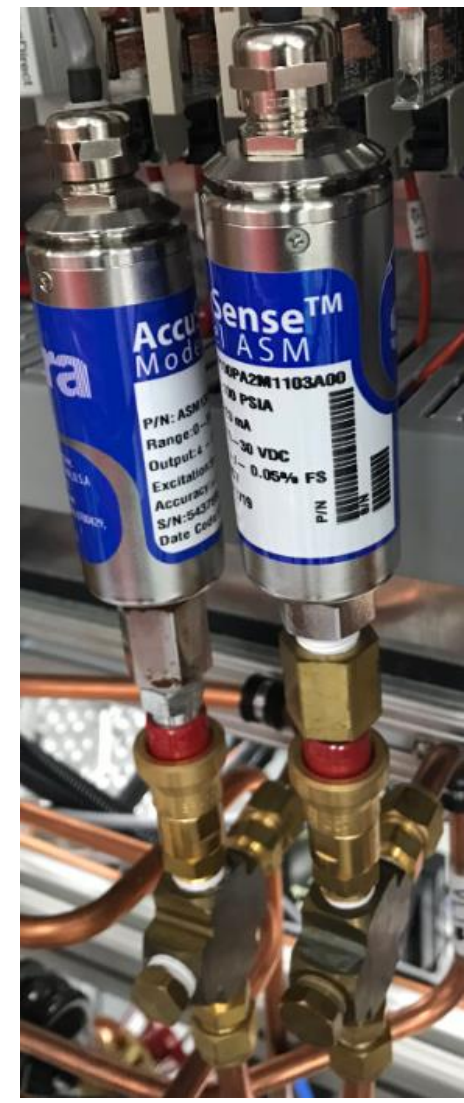

(b)

Figure A9 (a) Insulated copper tubes (b) Setra AccuSense pressure transducers installed on high and low side of sealed system

The side panel at the other side of the fixture shown in Figure A10 has electrical quick connections for thermocouples and fans. 


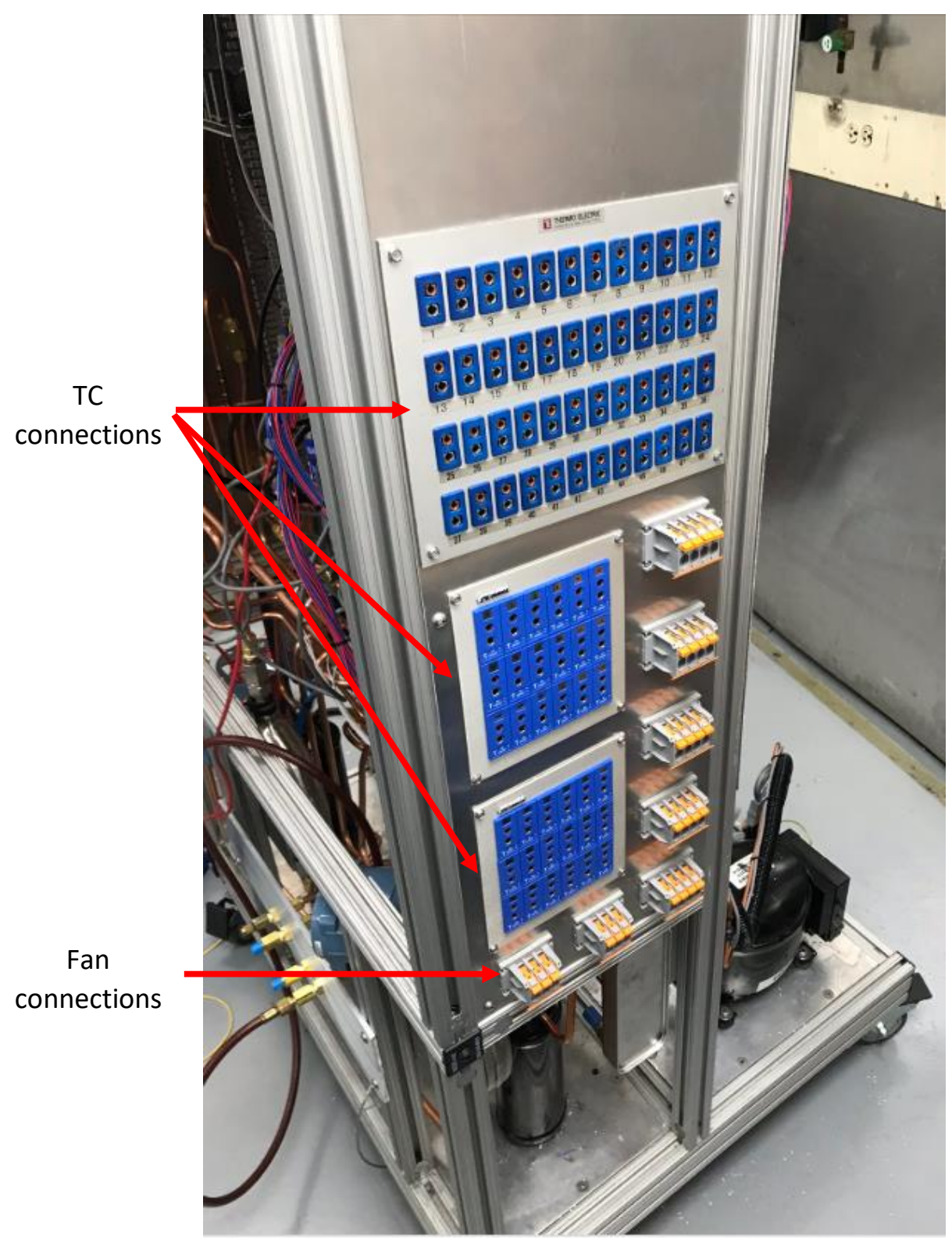

Figure A10 Panel for thermocouple and fan quick connections

The thermocouples and fan connection ports were routed to $\mathrm{NI}$ modules used for data acquisition mounted to the calorimeter fixture. Only the evaporator fan was connected for this study and was operated at $100 \%$ duty cycle. The rest of the instruments connected to the $\mathrm{NI}$ modules were routed inside the calorimeter fixture (Figure A11). 


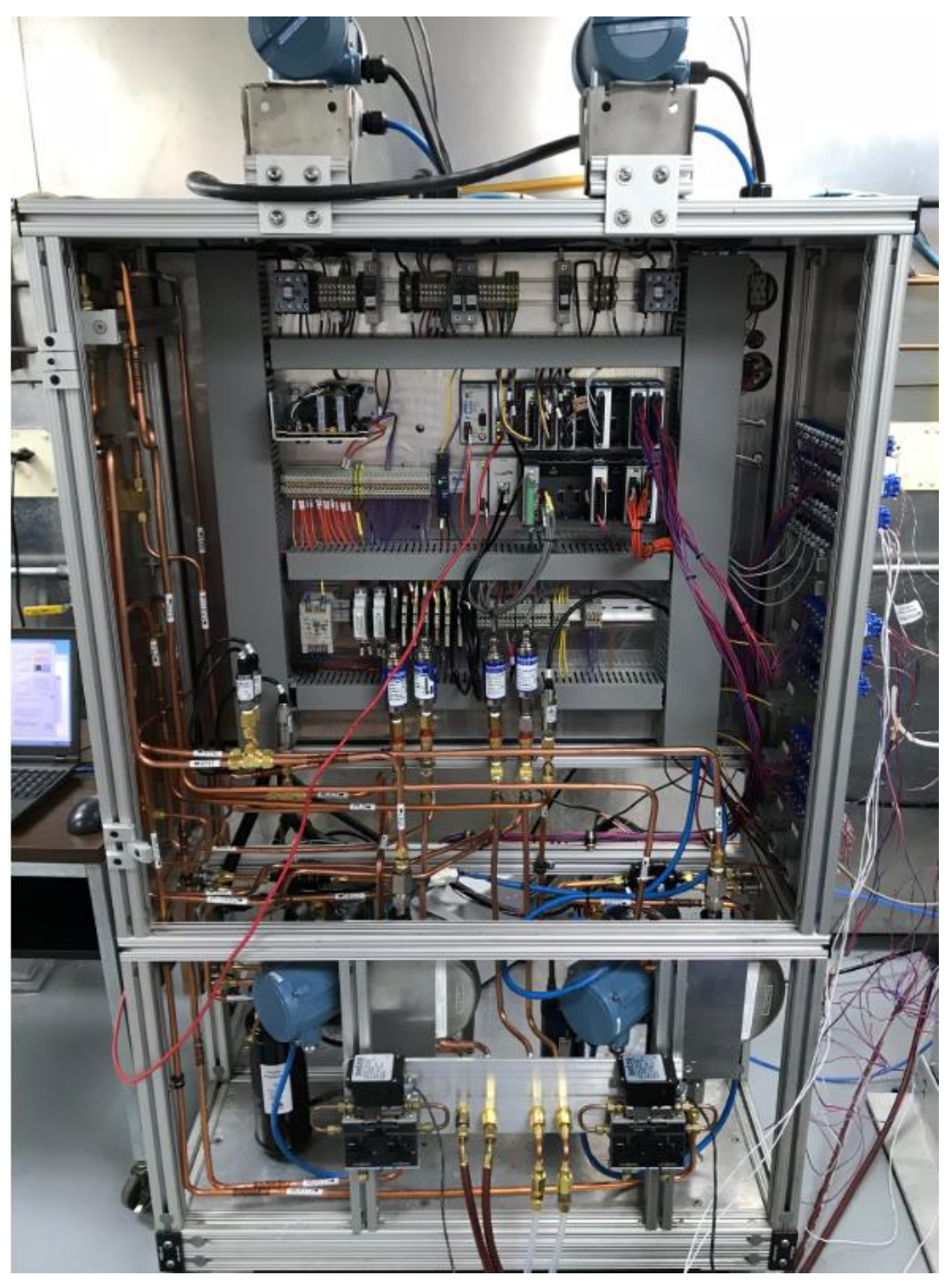

Figure A11 Calorimeter with all instruments and power connected

A full list of $\mathrm{NI}$ modules used, and their functionality is shown in Table A1. 
Table A1 NI modules and their functionality

\begin{tabular}{|c|c|}
\hline $\begin{array}{c}\text { National } \\
\text { Instruments } \\
\text { Module }\end{array}$ & Function \\
\hline NI 9474 & $\begin{array}{r}\text { Sending frequency signal to the compressor and pulse width } \\
\text { modulated signals to DC fans }\end{array}$ \\
\hline NI 9219 & $\begin{array}{c}\text { Measure mA signals for mass flow and temperature from CMF- } \\
10 \text { Coriolis mass flow meter transmitter }\end{array}$ \\
\hline NI 9213 & Thermocouple and heat flux measurements \\
\hline NI 9207 & Measure mA signals from in line pressure transducers \\
\hline NI 9481 & Solid state relay control of fans and power supplies \\
\hline NI 9485 & Solid state relay control of fans and power supplies \\
\hline NI 9217 & In line refrigerant RTD temperature measurements \\
\hline NI 9265 & Current output for TXV pressure regulator \\
\hline
\end{tabular}


Appendix II: Heat Flux Sensor Technology

A primary focus for this study was the use of thermopile HFS to quantify heat leak into a refrigerated cabinet. There are various types of HFS available in a range of sensitivity, size, and cost. The goal for this study was to obtain enough sensors to map the heat flux across the surface of a single wall of a freezer. 12 sensors were purchased from greenTEG who specialize in heat flux and laser power sensors for research and manufacturing applications; however, different heat flux sensing technologies and manufacturers were investigated to determine the sensor that best fit this application and was cost effective.

One requirement for selecting a HFS was that it had to be able to resolve the level of heat flux seen through the walls of a $-17.8^{\circ} \mathrm{C}\left(0^{\circ} \mathrm{F}\right)$ freezer in a $32.2^{\circ} \mathrm{C}$ $\left(90^{\circ} \mathrm{F}\right)$ room. Previous testing indicated the heat leak into a the same 490 -liter freezer unit was approximately $100 \mathrm{~W}$. Dividing this number by the internal surface area of the unit gave a rough estimate of the expected heat flux through the walls of the unit, which was $25 \mathrm{~W} / \mathrm{m}^{2}$. The sensor also had to be easily mounted to the freezer walls, have a low thermal resistance, and be readily available due to timeline constraints.

Several types of HFS exist that are readily available for research purposes. One sensor considered for this study was the Gardon gauge that produces a voltage difference proportional to temperature difference across the sensor and is also known as a circular foil gauge. Radiation strikes the top surface of the foil of constantan (Figure A12 A) that is black and soldered around the circumference of 
a copper block (Figure A12 B). The copper block acts as a heat sink for the thermal energy traveling from the outer radius of the foil towards the center of the sensor. The temperature difference between the inner and outer layers of the cylindrical sensor is proportional to the radiant flux intensity and is measured by adhering a copper wire to the center of the foil (Gardon, 1953).

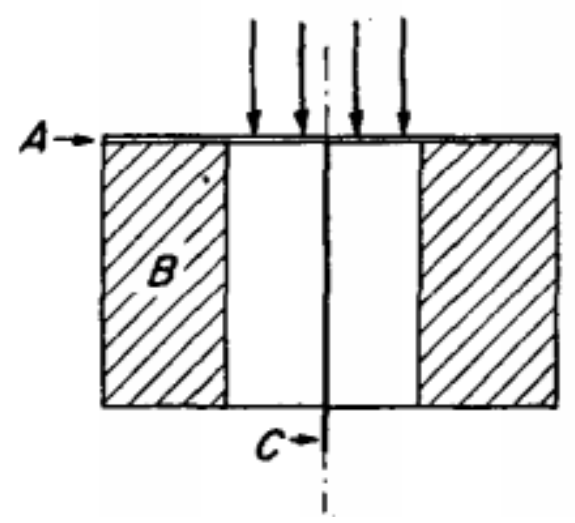

Figure A12 Cross sectional schematic of Gardon gauge (1953)

Although this sensor can be used to determine convective heat transfer, the dominant mode of heat transfer measured with Gardon gauges is radiation. Since this experiment does not involve a significant amount of radiation this sensor was not selected. Schmidt-Boelter gauges consist of a flat wafer formed of a thermally conductive dielectric material with a spiral winding of metal and operate similarly to Gardon gauges (Hevey, 1998). Although Schmidt-Boelter gauges typically have higher sensitivities and faster response times, they are still most effective at quantifying radiative heat flux.

The primary sensor considered and ultimately selected for this study was the thermopile HFS. Thermopile HFS utilize Seebeck effect, which is a 
phenomenon where a voltage is generated due to the temperature difference between the junction of at least two dissimilar metals. The voltage generated is proportional to the temperature gradient.

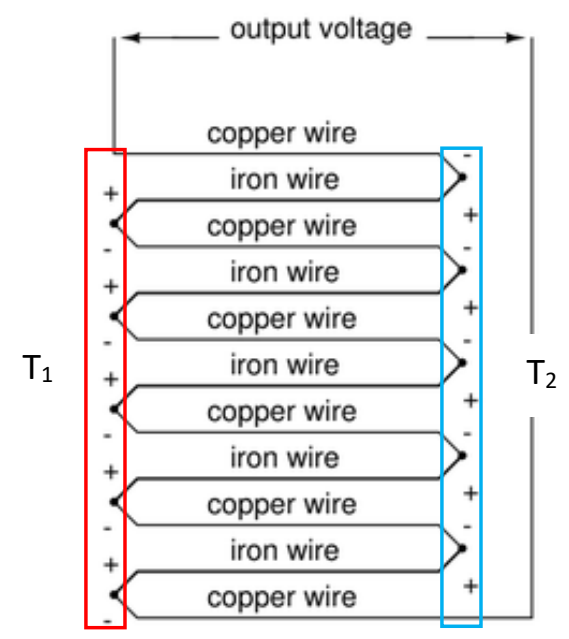

Figure A13 Schematic of thermopile heat flux sensor (Wikipedia, 2014)

Figure $\mathrm{A} 13$ shows a schematic of a thermopile heat flux transducer, which consists of a series of dissimilar metal junctions. If $T_{1}$ is equal to $T_{2}$ then the output voltage will be zero. If there is a difference in temperature between the outer surfaces of the sensors, an electrical signal proportional to the temperature difference will be generated. The sensitivity of the signal is proportional to the number of junctions in the thermopile. The more junctions, the larger the amplification of the signal and the higher the sensitivity. Thermopile sensors were chosen for this study due to their availability, low cost, and ability to measure within the expected range of heat flux for this experiment. Several thermopile HFS suppliers were considered. Table A2 shows the final four sensors considered for the experiment. 
Table A2 Thermopile heat flux sensors considered for study

\begin{tabular}{|c|c|c|c|c|c|}
\hline Manufacturer & $\begin{array}{c}\text { Measurement } \\
\text { Range } \\
{\left[\mathrm{kW} / \mathrm{m}^{2}\right]}\end{array}$ & $\begin{array}{c}\text { Sensitivity } \\
{\left[\mu \mathrm{V} /\left(\mathrm{W} / \mathrm{m}^{2}\right)\right]}\end{array}$ & $\begin{array}{c}\text { Sensing } \\
\text { area } \\
{\left[\mathrm{m}^{2}\right]}\end{array}$ & Cost \\
\hline Hukseflux & HFP03 & -2 to 2 & 500 & 0.0064 & $\$ 2,315$ \\
\hline greenTEG & gSKIN®-XM 26 9C & -150 to 150 & 4 & 0.00002 & $\$ 279$ \\
\hline greenTEG & gSKIN®-XP 26 9C & -150 to 150 & 20 & 0.0001 & $\$ 429$ \\
\hline FluxTeq & PHFS-09e & -150 to 150 & 8 & 0.0084 & $\$ 250$ \\
\hline
\end{tabular}

The sensor initially selected was the FluxTeq PHFS-09e due to its low cost and relatively high sensitivity. The PHFS-09e sensors did not have good correlation when tested in the validation experiment and were easily damaged during removal from mounting surfaces. Five gSKIN®-XM $269 \mathrm{C}$ and $10 \mathrm{gSKIN} \circledast-\mathrm{XP} 269 \mathrm{C}$ were purchased once the FluxTeq sensors proved unreliable. Although the XP sensors were preferred, only 5 could be purchased due to budget restrictions. 


\section{Appendix III: Shape Factor Calculations}

The HFS mounted to the internal walls of the freezer unit measured onedimensional heat flux q" at the inner surface of each wall. These measurements were multiplied by the internal surface areas of each wall to calculate the overall heat leak through the freezer walls. These measurements did not account for the heat leak via the corners and edges of the unit. Conduction shape factors were used to approximate the heat leak through the corners and edges, as shown in Figures A14 and A15.

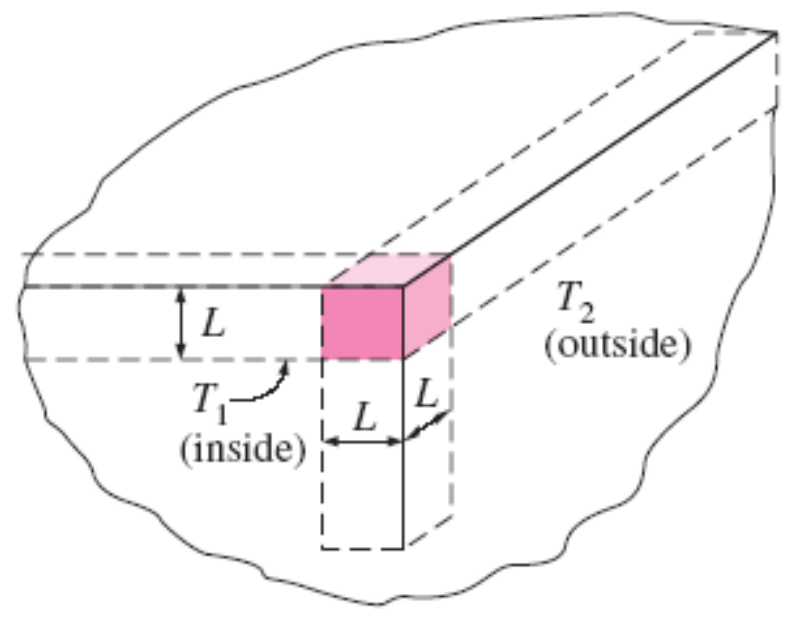

Figure A14 Conduction through corner of three perpendicular walls with a temperature difference of $\Delta T_{2-1}$ (Engineers Edge, 2019) 


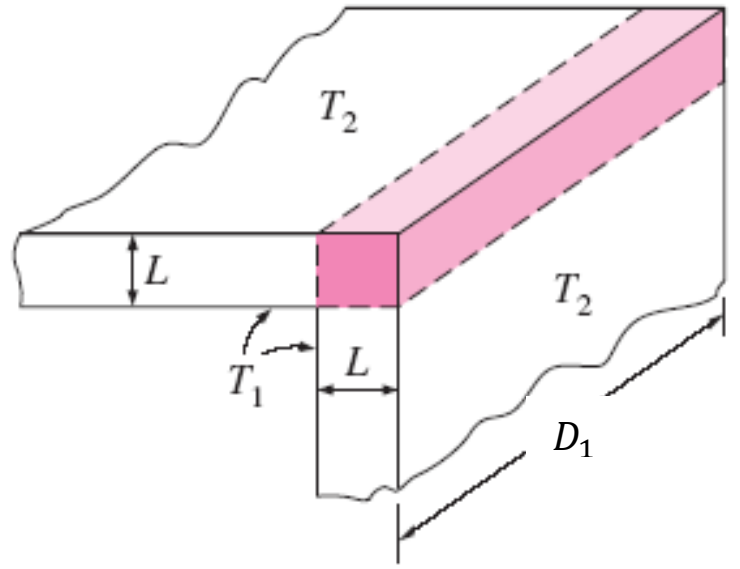

Figure A15 Conduction through the edge of adjoining walls (Engineers Edge, 2019)

The shape factors for these geometries and $\dot{q}$ based on shape factor and plane wall conduction are shown in equations 20, 21, 22 and 23 (Incropera and DeWitt, 2011).

$$
\begin{gathered}
S_{\text {corner }}=0.15 L \\
S_{\text {edge }}=0.54 D \\
\dot{q}=S k \Delta T \\
\dot{q}_{w}=\frac{k A \Delta T}{L}
\end{gathered}
$$

The total heat leak $\dot{q}_{\text {total }}$ is a combination of all wall, corner, and edge heat leak values (Equation(24), 25, 26).

$$
\begin{gathered}
\dot{q}_{\text {total }}=\dot{q}_{w}+\dot{q}_{\text {corners }}+\dot{q}_{\text {edges }} \\
\dot{q}_{\text {total }}=\dot{q}_{w}+(8) \dot{q}_{\text {corner }}+(4) \dot{q}_{\text {edge_depth }}+(4) \dot{q}_{\text {edge_width }} \\
+(4) \dot{q}_{\text {edge_height }}
\end{gathered}
$$




$$
\dot{q}_{w}=\dot{q}_{t o p}+\dot{q}_{\text {bottom }}+\dot{q}_{\text {left }}+\dot{q}_{\text {right }}+\dot{q}_{\text {back }}+\dot{q}_{\text {door }}
$$

All $\Delta T$ and thermal conductivity $(\mathrm{k})$ values are assumed to be the same for each surface for simplicity sake. $\mathrm{k}$ and $\Delta T$ were factored out in all terms of the $\dot{q}_{\text {total }}$ equation and therefore the numerical values of each were not needed to determine the percentage contribution of each $\dot{q}$ term. $\mathrm{L}$ is the thickness of the cabinet. $D_{1}$, $D_{2}$ and $D_{3}$ are the depth, width and height dimensions of the freezer. These dimensions are shown in Table A3. Wall surface areas are shown in Table A4.

Substituting in Equations $20-23$ into 25 and 26 yields:

$$
\begin{gathered}
\dot{q}_{\text {total }}=\frac{k \Delta T}{L} A_{\text {total }}+(8) 0.15 L k \Delta T+(4) 0.54 D_{1} k \Delta T \\
+(4) 0.54 D_{2} k \Delta T+(4) 0.54 D_{3} k \Delta T
\end{gathered}
$$

Table A3 Dimensions of freezer unit

\begin{tabular}{|c|c|}
\hline Dimension & Length [m] \\
\hline Depth $D_{1}$ & 0.49 \\
\hline Width $D_{2}$ & 0.63 \\
\hline Height $D_{3}$ & 1.65 \\
\hline Wall thickness L & 0.051 \\
\hline
\end{tabular}

Table A4 Wall surface areas

\begin{tabular}{|c|c|}
\hline Location & Surface Area $\left[\mathbf{m}^{2}\right]$ \\
\hline$A_{\text {top }}$ & 0.336 \\
\hline$A_{\text {bottom }}$ & 0.323 \\
\hline$A_{\text {left }}$ & 0.784 \\
\hline$A_{\text {right }}$ & 0.784 \\
\hline$A_{\text {back }}$ & 1.023 \\
\hline$A_{\text {door }}$ & 0.850 \\
\hline$A_{\text {total }}$ & 4.100 \\
\hline
\end{tabular}


Based on these calculations the total heat leak from the walls, corners and edges was calculated. The percentage contribution of each $\dot{q}$ term was determined and is shown in Equation 28 and Table A5.

$$
\dot{q}_{\text {total }}=93 \% \dot{q}_{\text {total }}+0.1 \% \dot{q}_{\text {total }}+6.9 \% \dot{q}_{\text {total }}
$$

Table A5 Percentage of total heat leak attributed to walls, edges and corners of freezer

\begin{tabular}{|c|c|}
\hline Component of Total Heat Leak & Percentage of $\dot{\boldsymbol{q}}_{\text {total }}$ \\
\hline$\dot{q}_{\text {walls }}$ & $93 \%$ \\
\hline$\dot{q}_{\text {edges }}+\dot{q}_{\text {corners }}$ & $7 \%$ \\
\hline
\end{tabular}

The heat leak calculated with measurements from HFS contributed $93 \%$ of the total heat leak. Since the HFS data could not account for the heat leak through corners and edges, the wall heat leak value was divided by $93 \%$ to estimate $\dot{q}_{\text {total }}$ (Equation 29).

$$
\dot{q}_{\text {total }}=\frac{\dot{q}_{w a l l s}}{0.93}
$$




\section{Appendix IV: Uncertainty Analysis}

The forward heat leak calorimeter consists of a variety of sensors and sealed system components used to calculate overall heat leak into the cabinet. The ability of the forward heat leak calorimeter to accurately quantify heat transfer rate is paramount in order to draw conclusions from the data collected. A sequential perturbation uncertainty analysis was performed to determine overall uncertainty of heat leak calculated via the calorimeter and the sensitivity of the convective heat transfer coefficient when changing wall temperatures.

Sequential perturbation is a numerical approach to estimate the propagation of uncertainty through to a result and is generally the preferred method when direct partial differentiation is too cumbersome or the number of variables is too large (Kline and McClintock, 1953). Sequential perturbation uses a finitedifference method to approximate the derivatives.

The first step in determining the uncertainty using sequential perturbation is to determine the mean operating value $R_{\circ}$ (Equation 30). The next step is to determine the operating value after increasing the independent variables by their respective uncertainties $\delta X_{i}$. A normal distribution is assumed and therefore this process is not analyzed with the independent variables decreased by their respective uncertainties. The overall uncertainty $u$ is the root sum of squares of the difference between the mean output and mean operating result $\left(\mathrm{Ri}_{\mathrm{i}}\right)$ calculated with the independent variables $\left(X_{1}, X_{2}, \ldots, X_{N}\right) . \sum_{i=1}^{N}\left(\delta R_{i}\right)^{2}$ is the squared delta term referred to in the following equations. 


$$
\begin{gathered}
R_{o \text { (measured })}=f\left(X_{1}, X_{2}, \ldots, X_{N}\right) \\
R_{1}=f\left(X_{1}+u_{X 1}, X_{2}, \ldots, X_{N}\right) \\
R_{2}=f\left(X_{1}, X_{2}+u_{X 2}, \ldots, X_{N}\right) \\
\ldots \\
\delta R_{i}=R_{i}-R_{o} ; i=1 \rightarrow N \\
u=\left\{\sum_{i=1}^{N}\left(\delta R_{i}\right)^{2}\right\}^{1 / 2}
\end{gathered}
$$

where $\mathrm{N}$ is the number of independent variables. Microsoft Excel was used to perform these calculations for all independent variables. Table A6 shows the uncertainties of each individual sensor used to determine heat leak.

Table A6 Instrument uncertainties

\begin{tabular}{|c|c|c|}
\hline Instrument & Units & Uncertainty \\
\hline RTD inlets and outlets & ${ }^{\circ} \mathrm{C}$ & $0.25 \%$ of reading \\
\hline Pressure transducers & $\mathrm{MPa}$ & $0.05 \%$ of reading \\
\hline Mass flow meter & $\mathrm{kg} / \mathrm{s}$ & $0.1 \%$ of reading \\
\hline Thermocouples & ${ }^{\circ} \mathrm{C}$ & 0.5 absolute \\
\hline Heat flux sensors & $\mu \mathrm{V}$ & $3 \%$ of reading \\
\hline
\end{tabular}

\section{Forward Heat Leak Calorimeter Uncertainty}

Heat leak was calculated using the temperature and pressure measurements at the inlet of the TXV and outlet of the evaporator. Uncertainties were first calculated for inlet and outlet enthalpies using pressure and temperature uncertainty values. The overall uncertainty for the inlet and outlet enthalpy values was $1.15 \mathrm{~kJ} / \mathrm{kg}$ and $0.66 \mathrm{~kJ} / \mathrm{kg}$ respectively when assuming a mass flow of $7.6 \mathrm{E}-7$ $\mathrm{kg} / \mathrm{s}(6 \mathrm{lb} / \mathrm{hr})$, inlet temperature of $26.9^{\circ} \mathrm{C}\left(80.4^{\circ} \mathrm{F}\right)$ and outlet temperature of $36.9^{\circ} \mathrm{C}$ $\left(98.4^{\circ} \mathrm{F}\right)$. The absolute uncertainty term is the sum of the squared delta terms. 
Once the absolute uncertainty values of the inlet and outlet enthalpy were determined, they were input to the total heat leak uncertainty sequential perturbation analysis.

Tables A7, A8 and A9 show the results of the sequential perturbation of the mass flow, inlet and outlet temperatures. The overall uncertainty of $\dot{q}$ increases with increasing mass flow and outlet temperature. The input variables were changed sequentially to determine the impact of each instrument on the overall uncertainty. The variable columns have the absolute values of each variable used in the calculation for overall heat leak and its uncertainty. Independent variable values were chosen to resemble temperatures and mass flow rates seen during calorimeter operation. Three values were chosen to understand the impact of changing temperatures and mass flow on overall uncertainty.

Table A7 Sequential perturbation results for overall heat leak, varying mass flow rate

\begin{tabular}{|c|c|c|c|}
\hline \multicolumn{3}{|c|}{ Variables } & $\begin{array}{c}\text { Overall } \\
\text { Uncert }\end{array}$ \\
\hline $\begin{array}{c}\text { T_in } \\
{\left[{ }^{\circ} \mathrm{C}\right]}\end{array}$ & $\begin{array}{c}\text { T_out } \\
{\left[{ }^{\circ} \mathrm{C}\right]}\end{array}$ & m_dot $[\mathrm{kg} / \mathrm{s}]$ & $\mathrm{d} \dot{q}[\mathrm{~W}]$ \\
\hline 26.9 & 36.9 & 0.0005 & 0.7 \\
\hline 26.9 & 36.9 & 0.0008 & 1.0 \\
\hline 26.9 & 36.9 & 0.001 & 1.4 \\
\hline
\end{tabular}


Table A8 Sequential perturbation results for overall heat leak, varying inlet temperature

\begin{tabular}{|c|c|c|c|}
\hline \multicolumn{3}{|c|}{ Variables } & $\begin{array}{c}\text { Overall } \\
\text { Uncert }\end{array}$ \\
\hline $\begin{array}{r}\text { T_in } \\
{\left[{ }^{\circ} \mathrm{C}\right]}\end{array}$ & $\begin{array}{c}\text { T_out } \\
{\left[{ }^{\circ} \mathrm{C}\right]}\end{array}$ & m_dot $[\mathrm{kg} / \mathrm{s}]$ & $\mathrm{d} \dot{q}[\mathrm{~W}]$ \\
\hline 21.9 & 36.9 & 0.0008 & 1.0 \\
\hline 16.9 & 36.9 & 0.0008 & 1.0 \\
\hline 11.9 & 36.9 & 0.0008 & 1.0 \\
\hline
\end{tabular}

Table A9 Sequential perturbation results for overall heat leak, varying outlet temperature

\begin{tabular}{|c|c|c|c|}
\hline \multicolumn{3}{|c|}{ Variables } & $\begin{array}{c}\text { Overall } \\
\text { Uncert }\end{array}$ \\
\hline $\begin{array}{c}\text { T_in } \\
{\left[{ }^{\circ} \mathrm{C}\right]}\end{array}$ & $\begin{array}{c}\text { T_out } \\
{\left[{ }^{\circ} \mathrm{C}\right]}\end{array}$ & m_dot $[\mathrm{kg} / \mathrm{s}]$ & $\mathrm{d} \dot{q}[\mathrm{~W}]$ \\
\hline 21.9 & 41.9 & 0.0008 & 1.01 \\
\hline 21.9 & 46.9 & 0.0008 & 1.01 \\
\hline 21.9 & 66.9 & 0.0008 & 1.03 \\
\hline
\end{tabular}

The average overall uncertainty $d \dot{q}$ for Tables A7, A8 and A9 is $1.01 \mathrm{~W}$. Since the overall heat leak into the unit at $-17.8^{\circ} \mathrm{C}\left(0^{\circ} \mathrm{F}\right)$ is approximately $100 \mathrm{~W}$, the uncertainty of the heat leak calorimeter only accounts for about $1 \%$ of the total heat leak. Uncertainty of the HFS ability to quantify heat leak into the freezer was not analyzed since the validation experiment accounts for sensor underprediction.

\section{Convective Heat Transfer Coefficient Sensitivity Analysis}

In addition to the uncertainty analysis of the calorimeter, a sensitivity study was performed for the convective heat transfer coefficient to understand the impact of variations in wall temperature and heat flux on the convective heat transfer coefficient. The convective heat transfer coefficient was approximated by dividing 
the heat flux calculated with the HFS by the difference between the free stream and wall temperature. Table A10 shows the uncertainty in the convective heat transfer coefficient when varying the wall temperature at a heat flux value of 10 $\mathrm{W} / \mathrm{m}^{2}$ and air temperature of $-18.5^{\circ} \mathrm{C}$.

Table A10 Convective heat transfer coefficient based on HFS and varying wall temperature with heat flux of $10 \mathrm{~W} / \mathrm{m}^{2}$ and air temperature of $-18.5^{\circ} \mathrm{C}$

\begin{tabular}{|c|c|}
\hline $\mathbf{T}_{\mathbf{W}}\left[{ }^{\circ} \mathbf{C}\right]$ & $\mathbf{h}\left[\mathbf{W} / \mathbf{m}^{2} \mathbf{K}\right]$ \\
\hline-17.8 & 13.7 \\
\hline-17.2 & 7.7 \\
\hline-16.7 & 5.4 \\
\hline
\end{tabular}

Table A11 shows the uncertainty in the convective heat transfer coefficient when varying the wall temperature at a heat flux value of $20 \mathrm{~W} / \mathrm{m}^{2}$ and air temperature of $-18.5^{\circ} \mathrm{C}$.

Table A11 Convective heat transfer coefficient based on HFS and varying wall temperature with heat flux of $20 \mathrm{~W} / \mathrm{m}^{2}$ and air temperature of $-18.5^{\circ} \mathrm{C}$

\begin{tabular}{|c|c|}
\hline $\mathbf{T}_{\mathbf{W}}\left[{ }^{\circ} \mathbf{C}\right]$ & $\mathbf{h}\left[\mathbf{W} / \mathbf{m}^{2} \mathbf{K}\right]$ \\
\hline-17.8 & 27.4 \\
\hline-17.2 & 15.5 \\
\hline-16.7 & 10.8 \\
\hline
\end{tabular}

The results indicate that the method of determining convective heat transfer coefficients for this study is very sensitive to the wall temperature variation. A change in $\mathrm{T}_{w}$ of approximately $1.1^{\circ} \mathrm{C}$ can impact the convection coefficient value by $16.6 \mathrm{~W} / \mathrm{m}^{2} \mathrm{~K}$ when the air and wall temperature are very close. The air temperature was taken as the average temperature of the brass weights inside the unit, and the wall temperature obtained from the thermocouple closest to the HFS. 
Since there are likely to be spatial variations in the air temperature in the freezer, a more accurate local free stream temperature should be measured in close proximity to the HFS and the wall temperature should be measured at the exact sensor location; however, instrumenting the freezer with additional thermocouples would have potentially impacted airflow patterns and heat leak into the unit due to routing of wires. An example of air and wall temperatures inside the freezer are shown in Table A12.

Table A12: Air and wall temperatures inside freezer compartment for single test

\begin{tabular}{|c|c|}
\hline Location & Steady State Temperature $\left[{ }^{\circ} \mathbf{C}\right]$ \\
\hline Average of Brass Weights (Air) & -18.5 \\
\hline Left Wall Top & -16.7 \\
\hline Left Wall Bottom & -15.6 \\
\hline Right Wall Top & -17.0 \\
\hline Right Wall Bottom & -16.0 \\
\hline Bottom & -16.2 \\
\hline Top & -21.3 \\
\hline Door Top & -17.3 \\
\hline Door Bottom & -16.9 \\
\hline Back Top & -19.6 \\
\hline Back Bottom & -20.8 \\
\hline
\end{tabular}

A plot of temperatures at various locations inside the unit is shown in Figures A16, A17, A18, A19 and A20. 


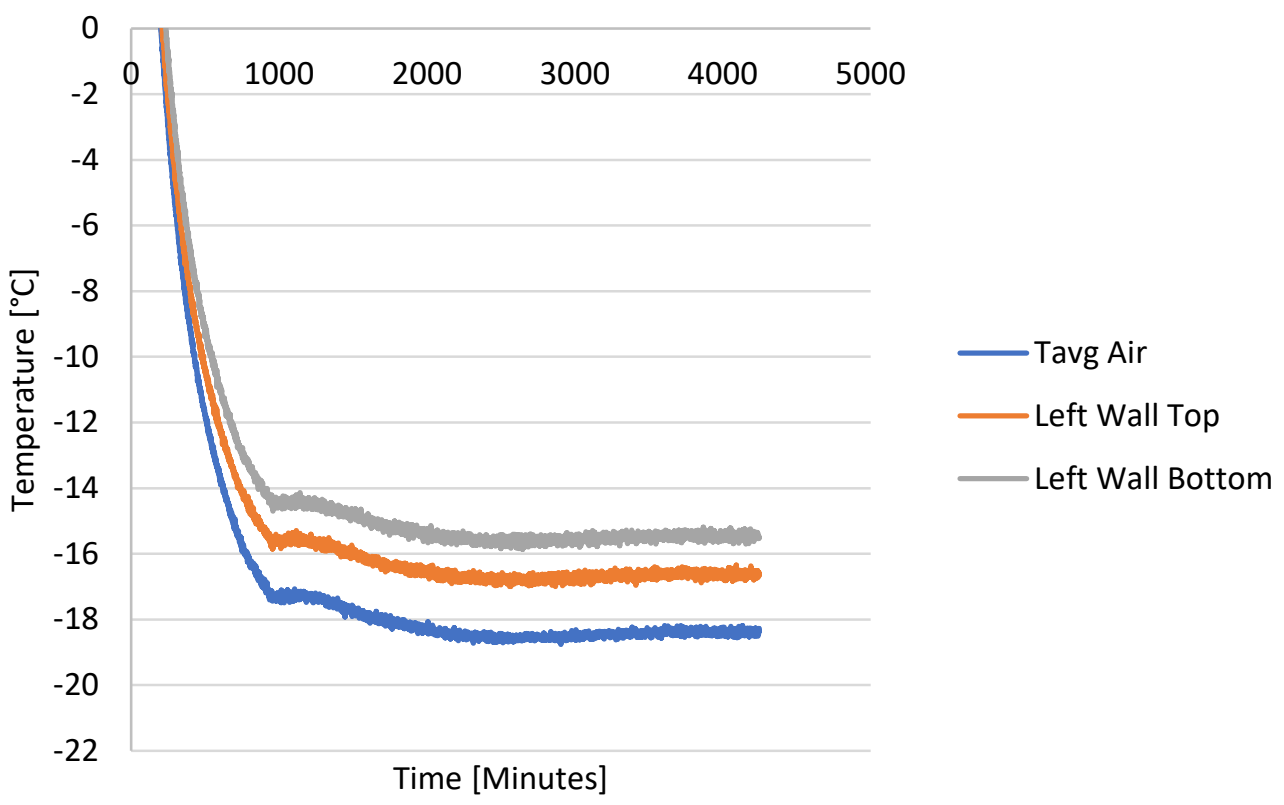

Figure A16 Temperature of left wall and air inside freezer

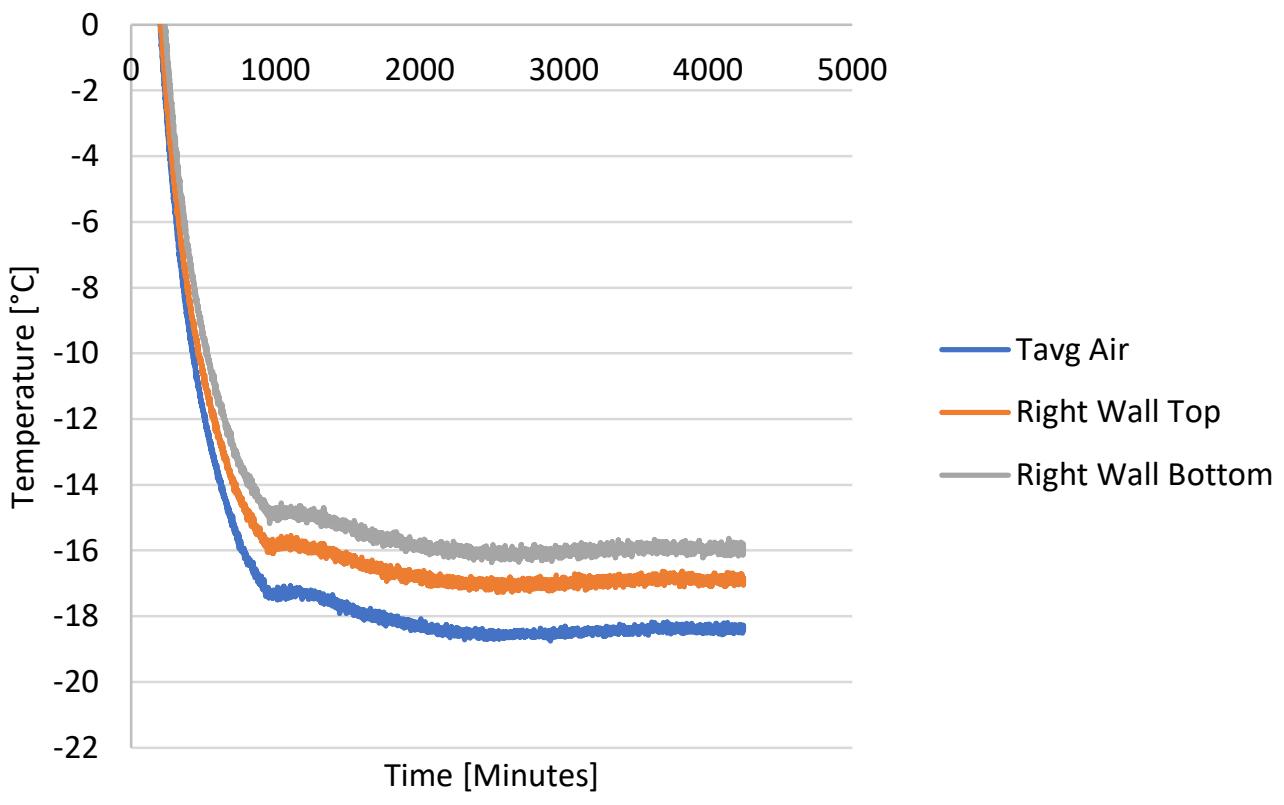

Figure A17 Temperature of right wall and air inside freezer 


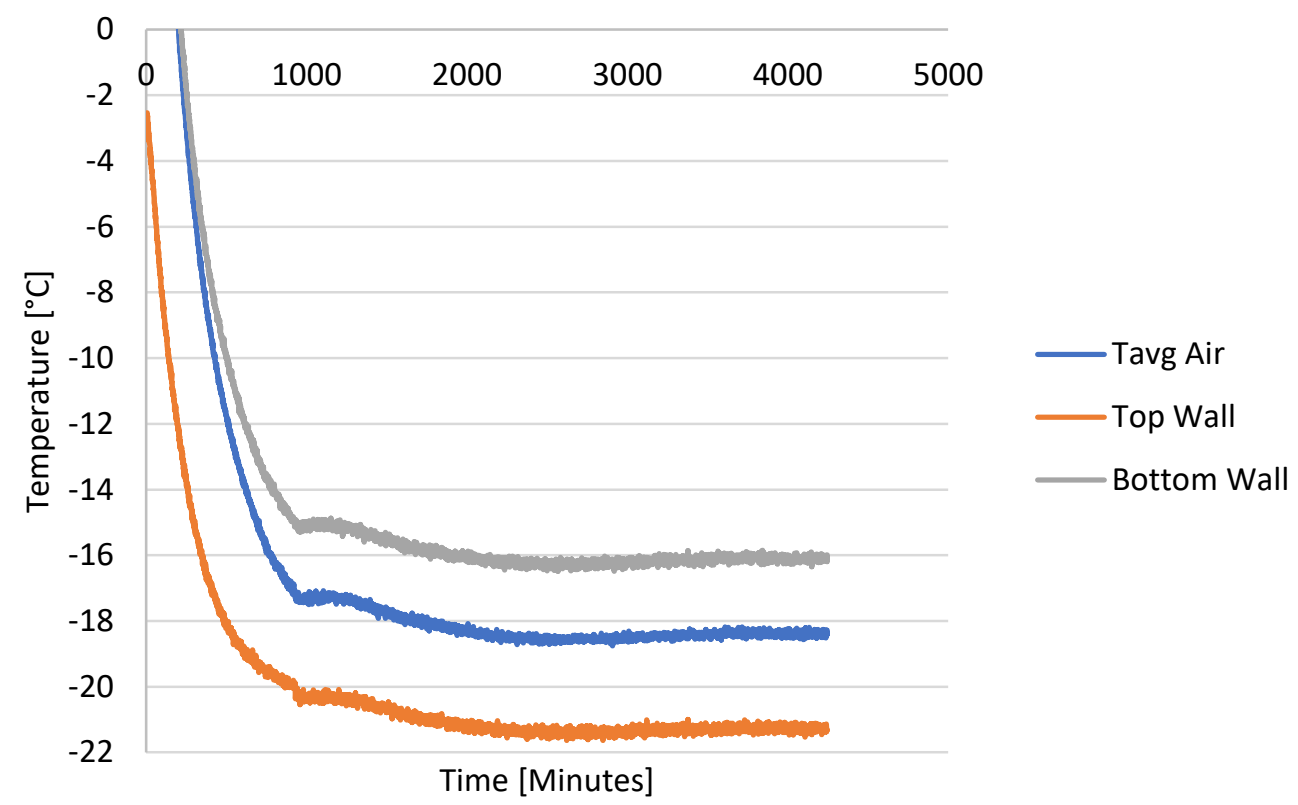

Figure A18 Temperature of top and bottom wall and air inside freezer

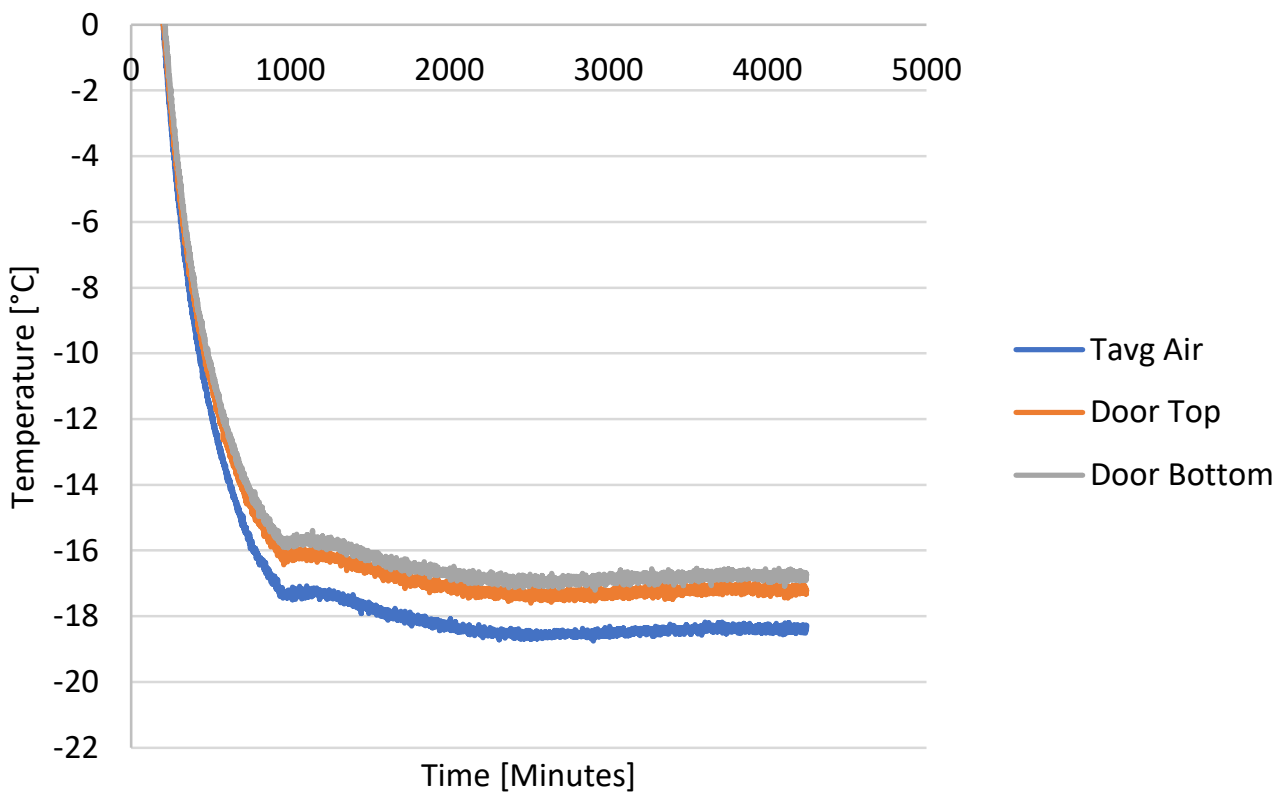

Figure A19 Temperature of door and air inside freezer 


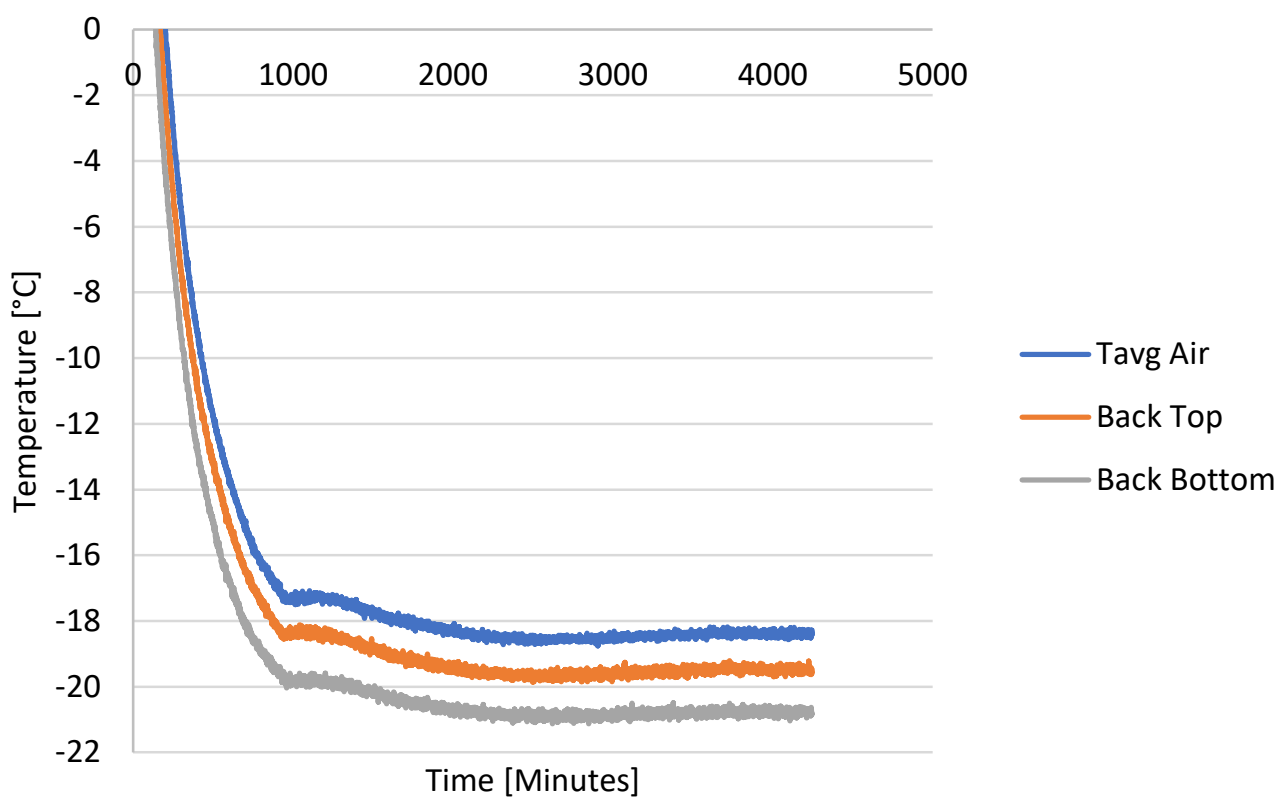

Figure A20 Temperature of back wall and air inside freezer 


\section{Appendix V: Additional Results}

The summary of key results from this study are found in Chapter 3 of this study. This section contains the heat flux plots for all wall tests, foamed gasket tests and repeatability study tests. The traces show a moving average of the raw data over an interval of 180 minutes. Plotting a moving average allowed the heat flux trendlines to be smoothed. Each wall test was split into two plots in order to visualize all trendlines without significant overlap. Due to breakage of sensors some tests did not have all 12 sensors mounted to the wall. To ensure all 12 locations had data collected, a test was performed with three sensors mounted in a previously measured location and the rest of the sensors mounted in locations with missing data.
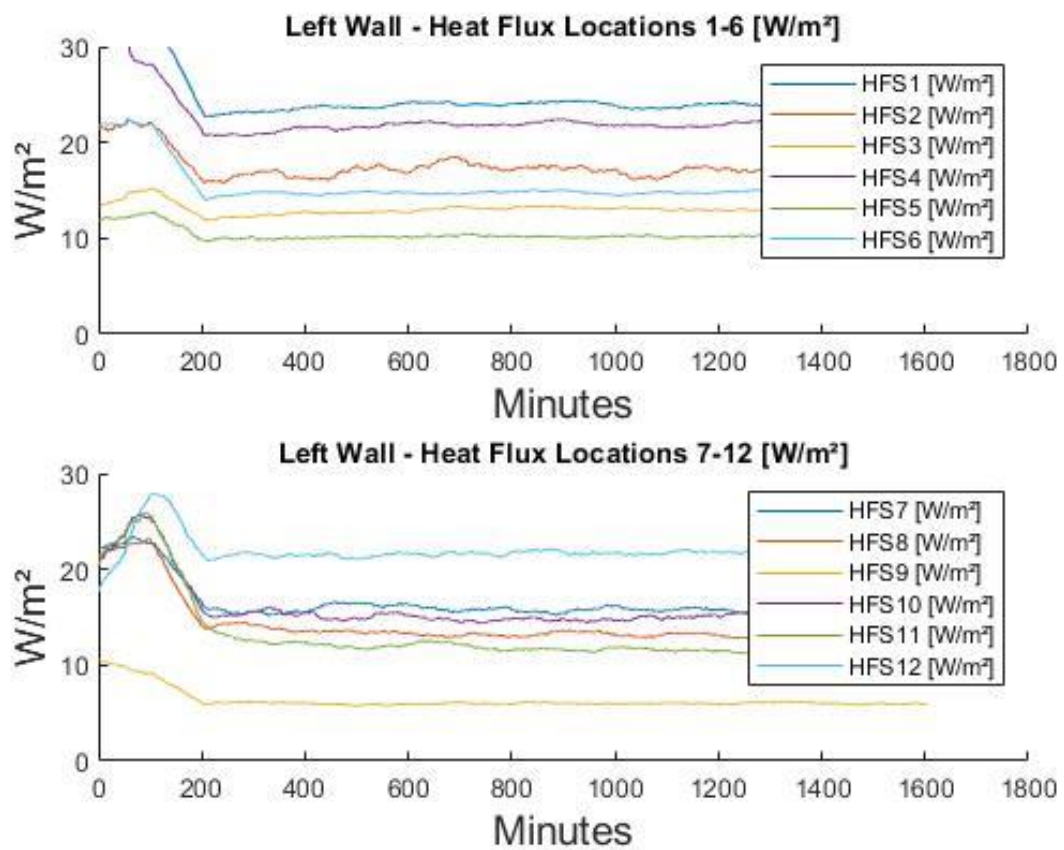

Figure A21 Left wall heat flux measurements 

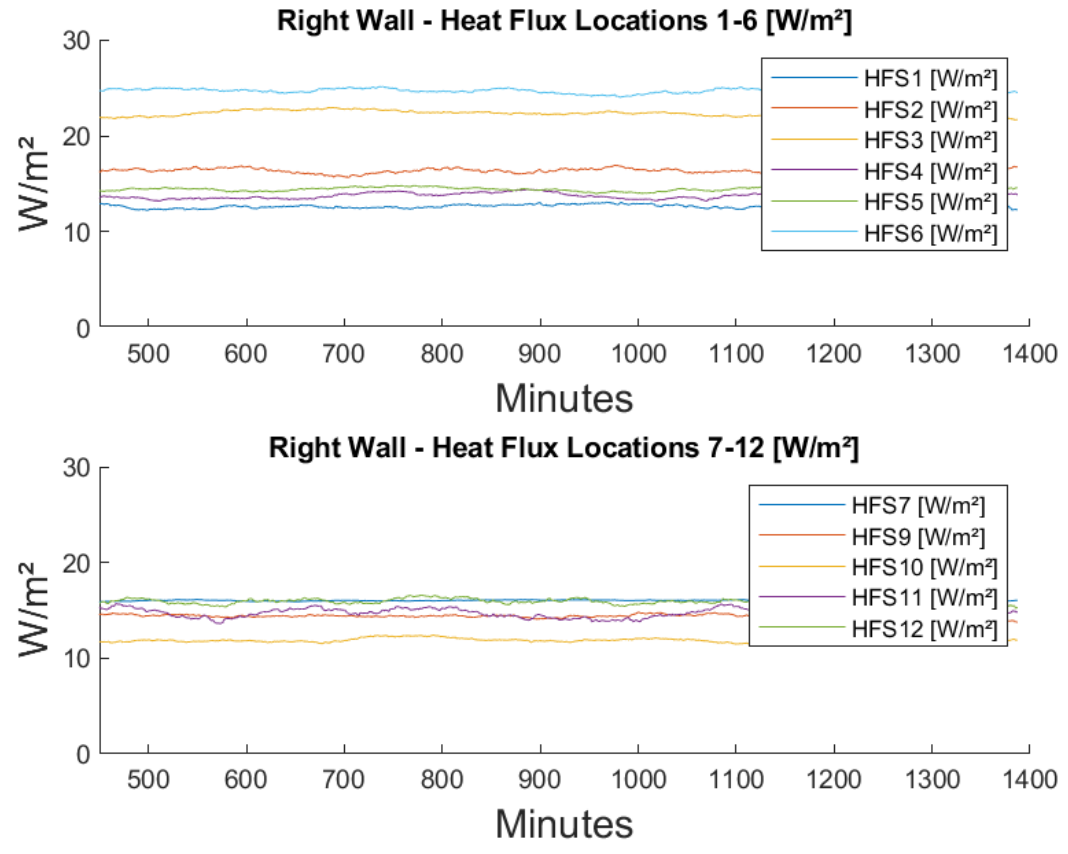

Figure A22 Right wall heat flux measurements
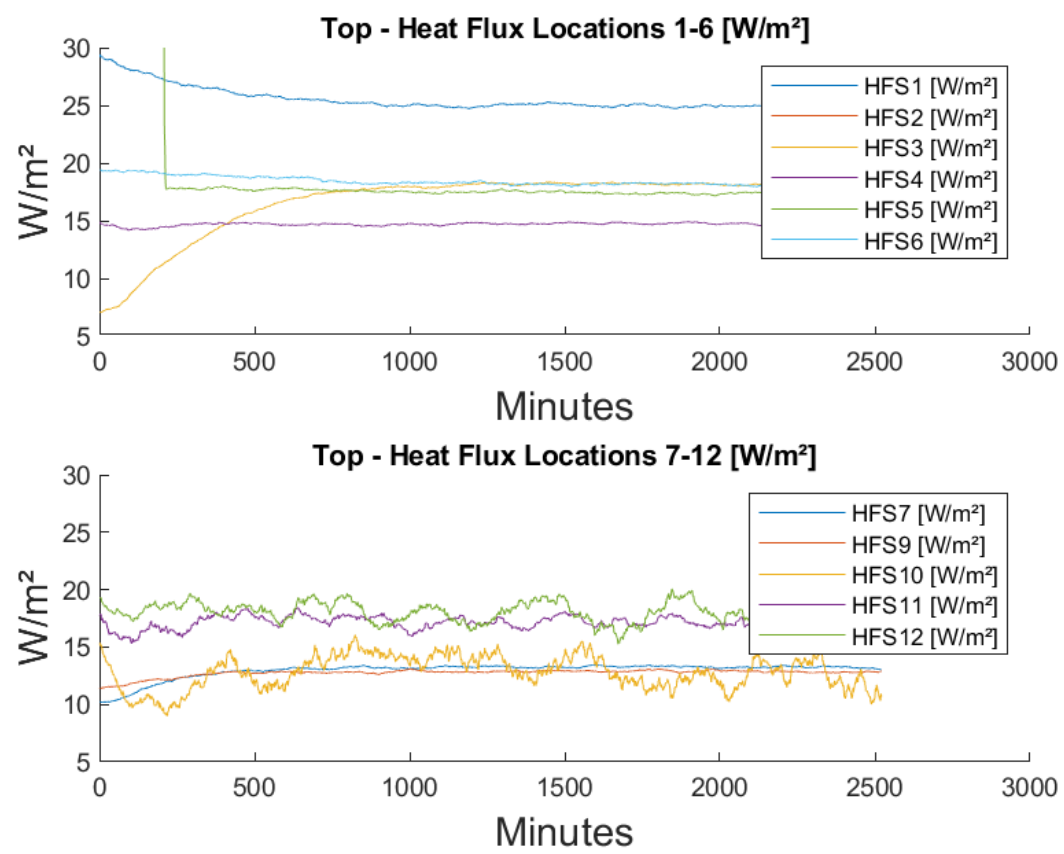

Figure A23 Top wall heat flux measurements 

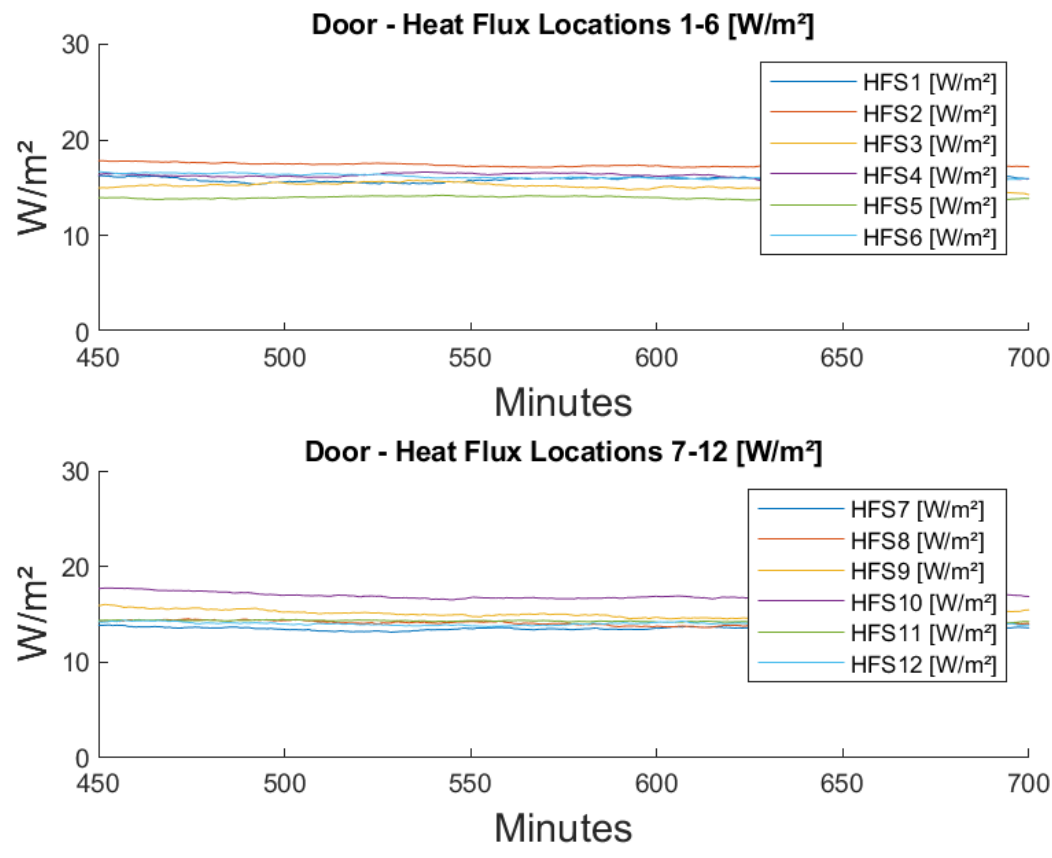

Figure A24 Door heat flux measurements
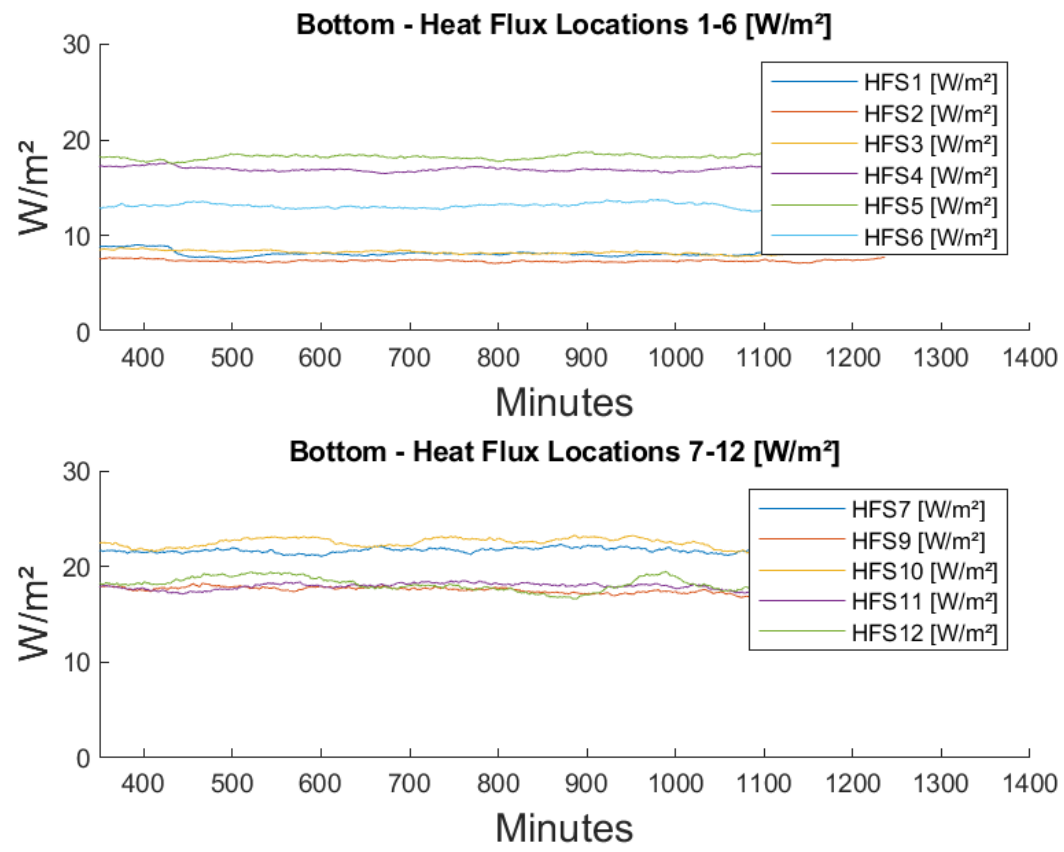

Figure A25 Bottom wall heat flux measurements 

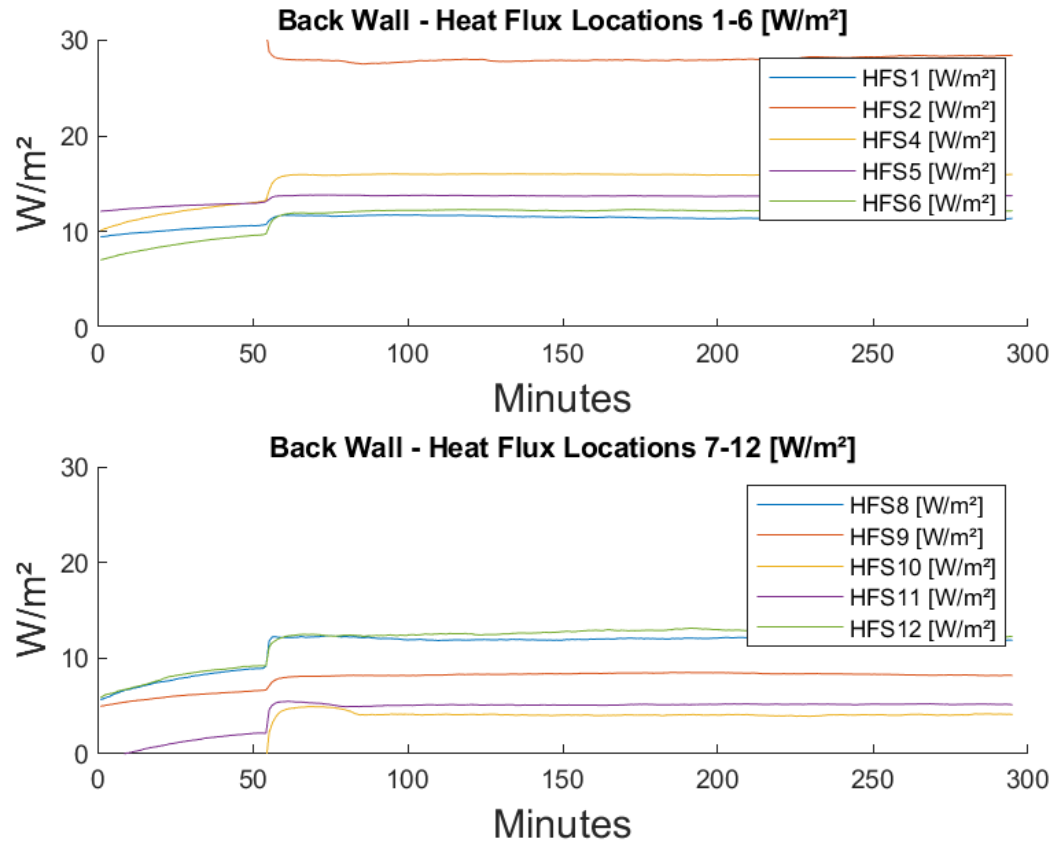

Figure A26 Back wall heat flux measurements

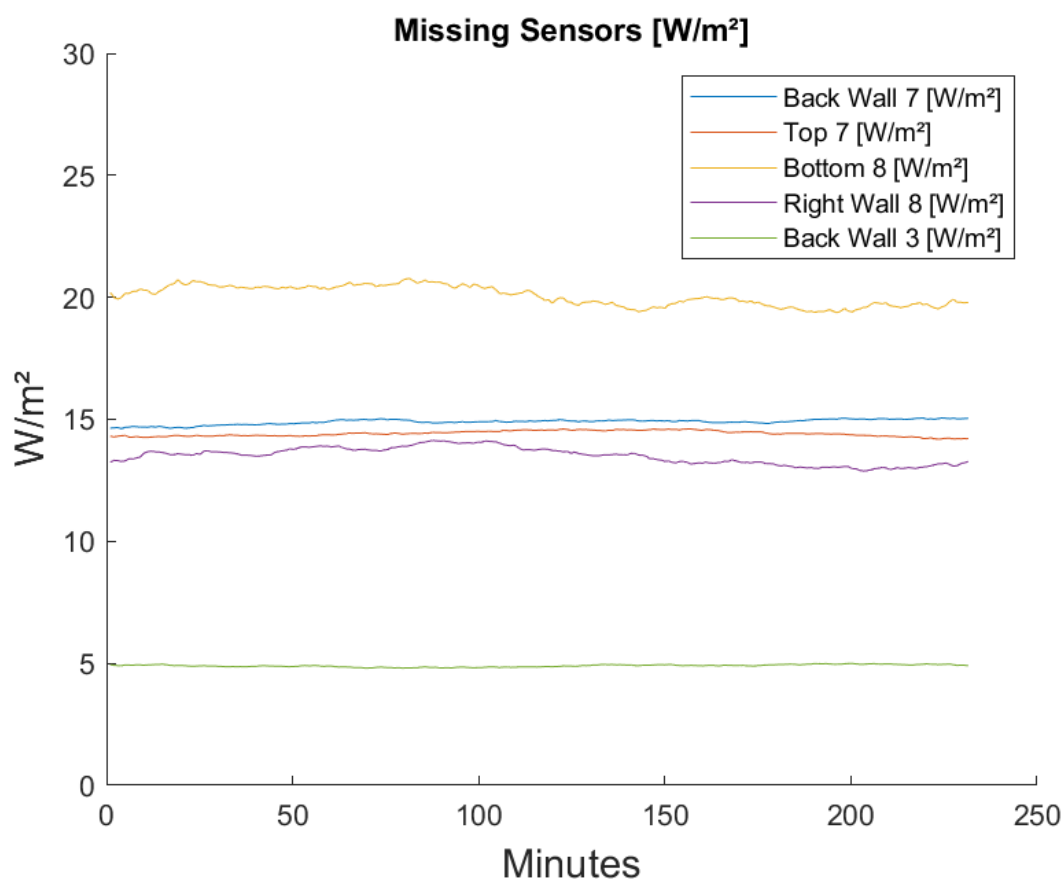

Figure A27 Heat flux measurements of locations that were previously missing sensors 

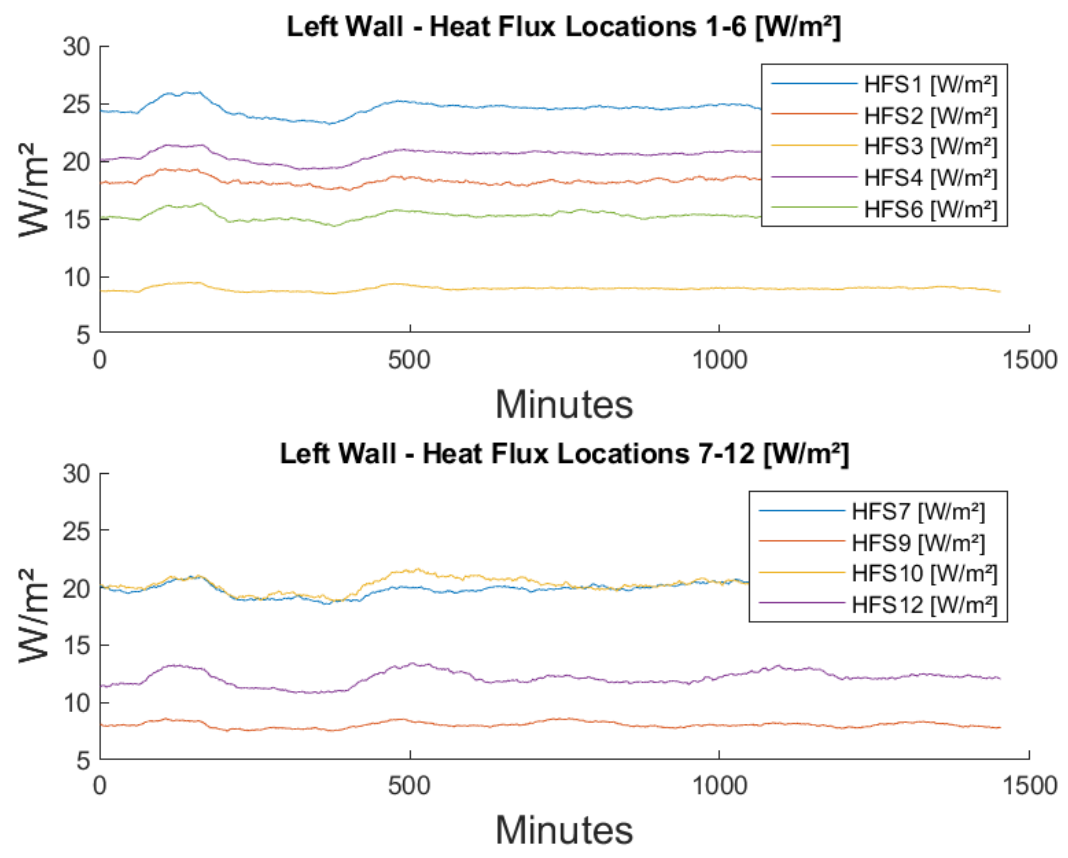

Figure A28 Left wall heat flux measurements with gasket foamed
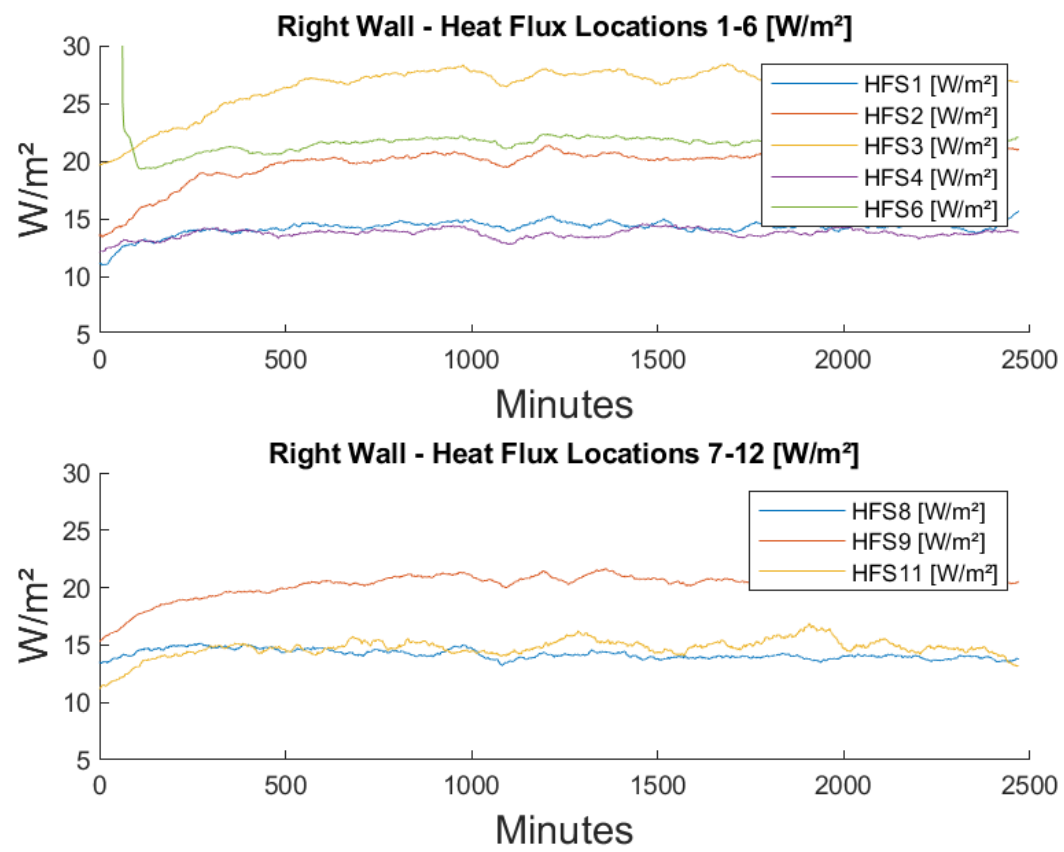

Figure A29 Right wall heat flux measurements with gasket foamed 

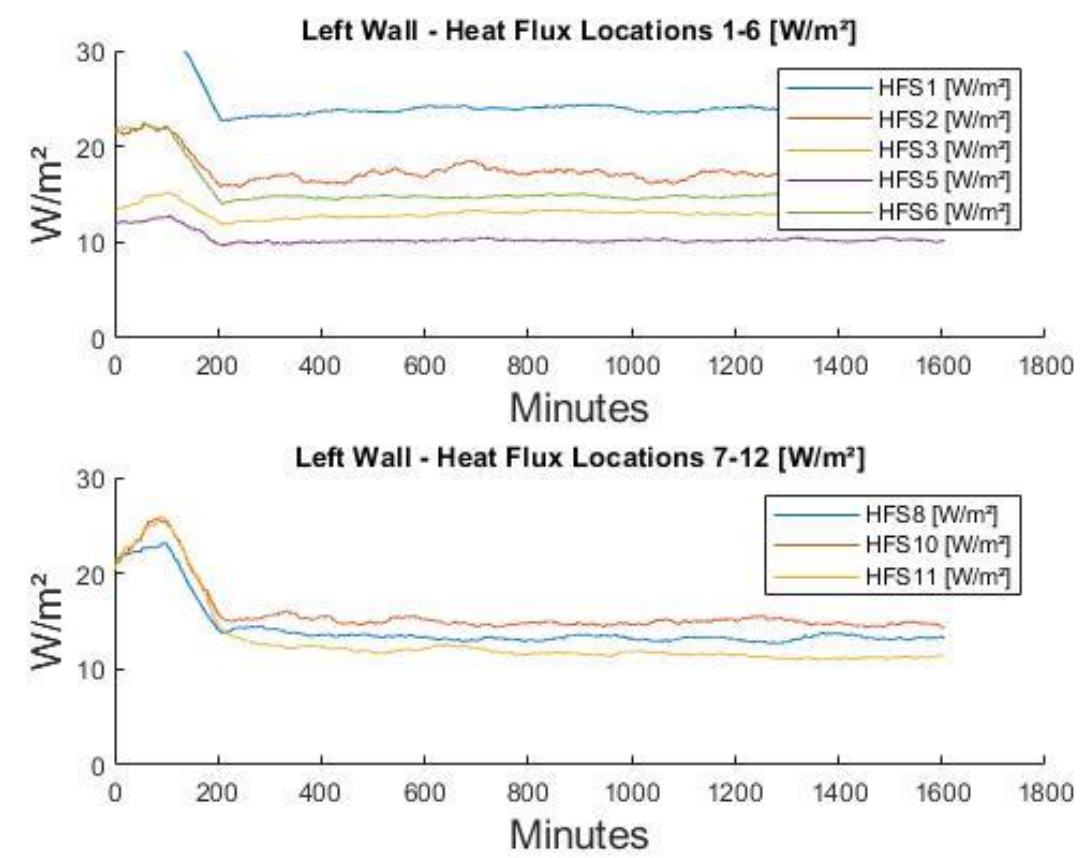

Figure A30 Left wall heat flux measurements repeatability study first test
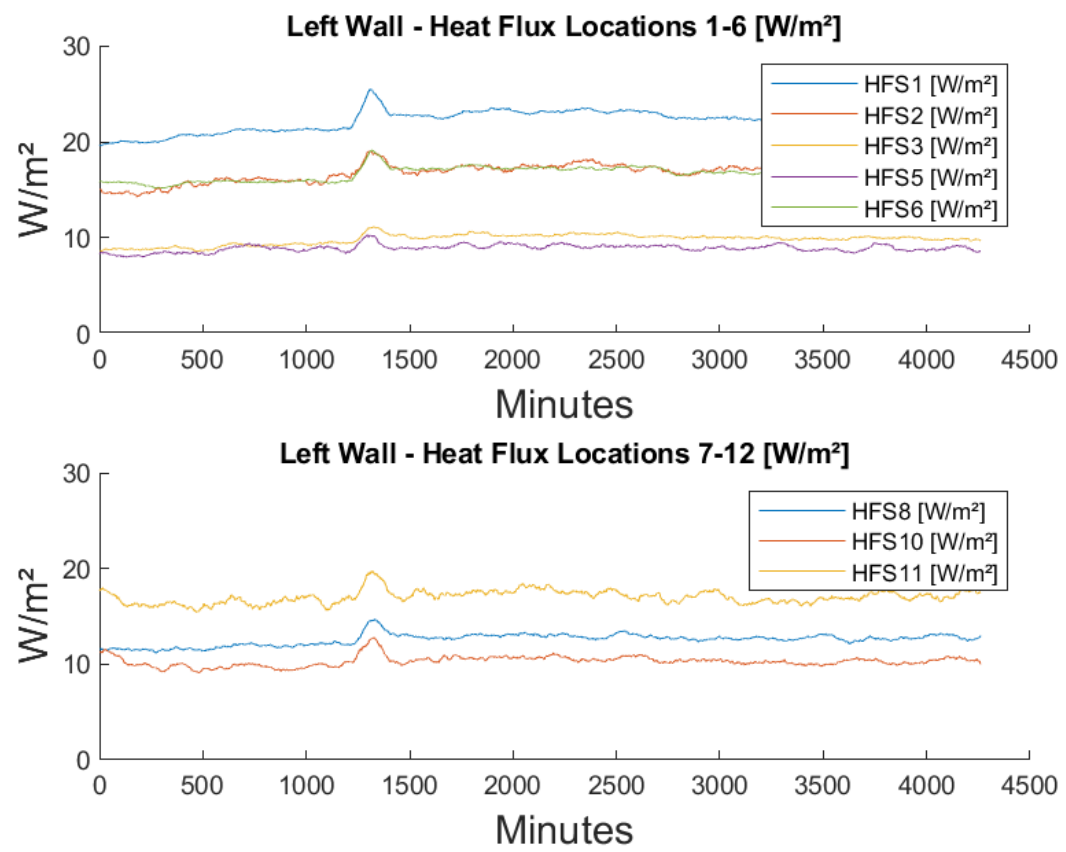

Figure A31 Left wall heat flux measurements repeatability study second test 


\section{$\underline{\text { Heat Leak Fluctuation }}$}

A significant fluctuation in heat leak obtained from calorimeter results was seen in some tests. Examples of high and low fluctuation cases are shown in Figure A32 and A33. The heat leak calculated using the calorimeter method depended on mass flow measurements and property data for the refrigerant at the evaporator inlet and outlet. The mass flow meter measurement stability relies on single phase refrigerant flow through the Coriolis sensor. Two-phase flow causes additional vibration that leads to fluctuating mass flow measurements. A liquid line receiver was installed upstream of the mass flow meter in an effort to ensure only subcooled liquid would enter the mass flow meter; however, adding too much charge to the system increased the high side pressure beyond the limits of the pressure transducer and resulted in insufficient charge and cause two-phase induced large fluctuations in mass flow, resulting in large fluctuations in the heat leak measurement.

Figure A32 shows heat leak from a case with stable mass flow, whereas the flow was unstable in the case shown in Figure A33. Both cases had the same conditions inside the unit and although the mass flow standard deviation is much higher in Figure A33, the average heat leak for both cases agreed to within $1.5 \mathrm{~W}$, as shown in Table A13. Therefore, it was concluded that the cases with more variability in mass flow readings resulted in valid average values. 
Table A13 Average temperatures inside freezer and heat leak for stable and unstable mass flow conditions

\begin{tabular}{|c|c|c|}
\hline Test & $\begin{array}{c}\text { Average } \\
\text { Cabinet } \\
\text { Temperature [F] }\end{array}$ & $\begin{array}{c}\text { Average Heat } \\
\text { Leak [W] }\end{array}$ \\
\hline Stable mass flow & $-18.0\left(-0.4^{\circ} \mathrm{C}\right)$ & 98.3 \\
\hline Fluctuating mass flow & $-18.2^{\circ} \mathrm{F}\left(-0.7^{\circ} \mathrm{C}\right)$ & 99.8 \\
\hline
\end{tabular}

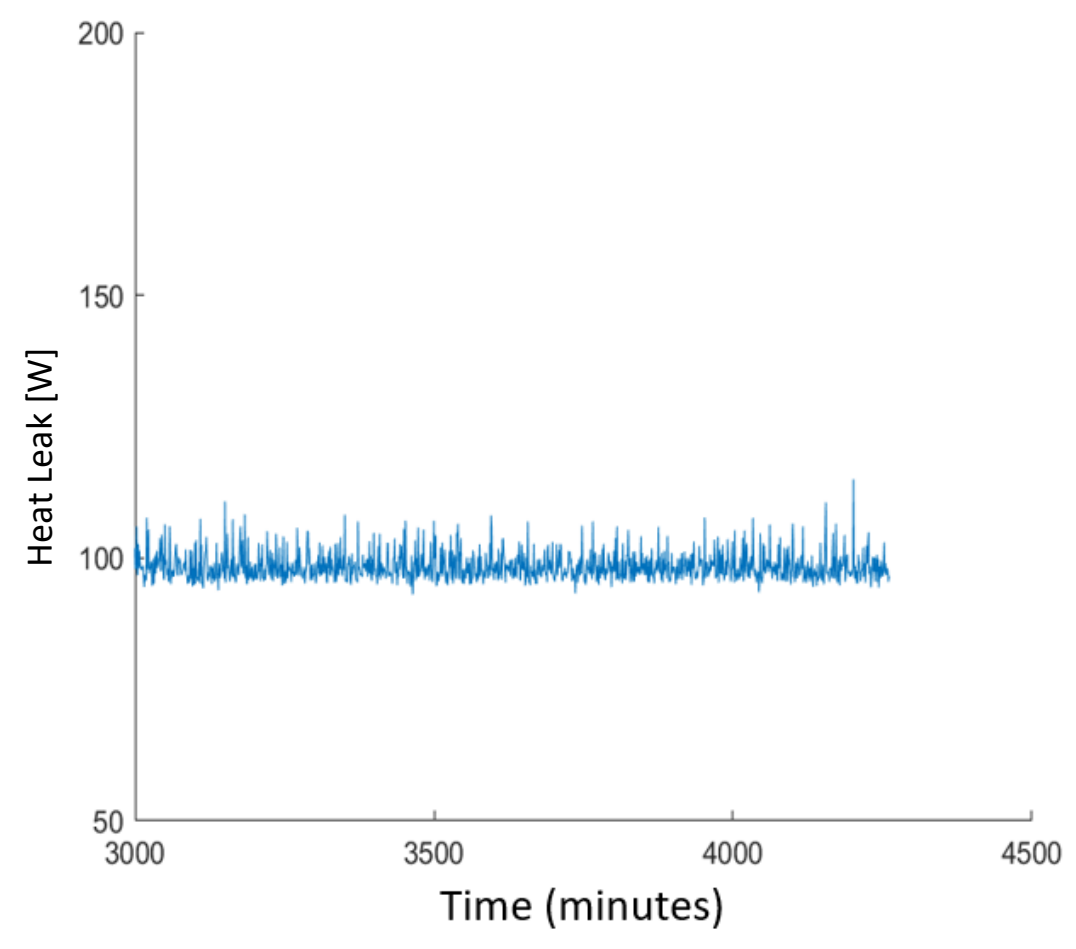

Figure A32 Heat leak into freezer with stable mass flow 


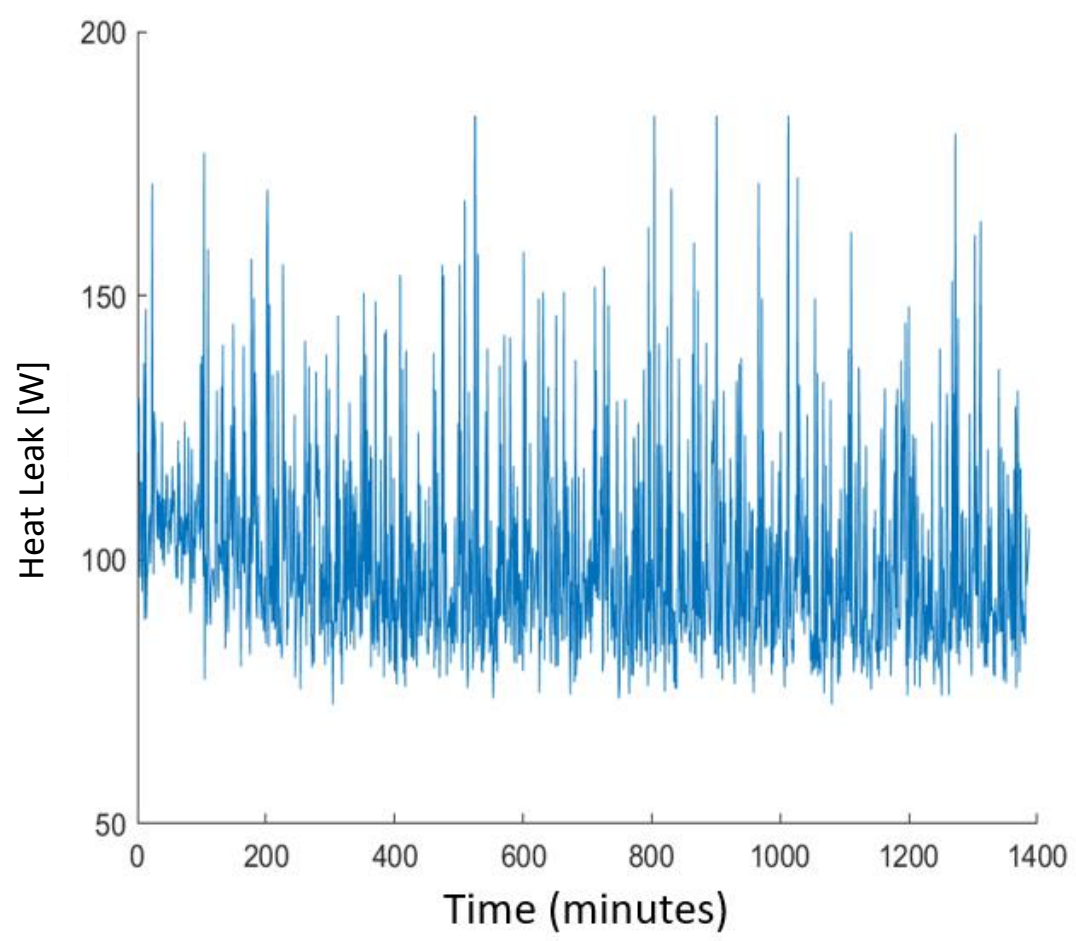

Figure A33 Heat leak into freezer with unstable mass flow 
Appendix VI: Additional Resources

Table A14 Additional reading on heat leak calorimetry and heat flux sensors

\begin{tabular}{|c|c|}
\hline Reference & Summary \\
\hline $\begin{array}{l}\text { Beasley, Donald E., and } \\
\text { Richard S. Figliola. } \\
\text { "Ahalysis Of A Local Heat } \\
\text { Flux Probe." Proceeding of } \\
\text { International Heat Transfer } \\
\text { Conference 8, } 1986 .\end{array}$ & $\begin{array}{l}\text { Study of a metallic film sensor. Authors wanted to } \\
\text { understand effects of heat probe design on its } \\
\text { reported response and thermal characteristics. } \\
\text { Performed transient analysis and two-dimensional } \\
\text { numerical analysis of a constant temperature heat } \\
\text { flux probe mounted on an isothermal heated } \\
\text { convective surface. }\end{array}$ \\
\hline $\begin{array}{l}\text { Bergman, Theodore, } \\
\text { Adrienne S. Lavine, Frank } \\
\text { P. Incropera, and David P. } \\
\text { Dewitt. Fundamentals of } \\
\text { Heat and Mass Transfer. } \\
\text { 7th. Hoboken: John Wiley } \\
\quad \text { \& Sons, 2011. }\end{array}$ & $\begin{array}{l}\text { Heat transfer textbook provides details on mixed, } \\
\text { forced, and natural convective heat transfer, as } \\
\text { well as numerous other heat transfer topics. }\end{array}$ \\
\hline $\begin{array}{l}\text { Chaomuang, Nattawut, et } \\
\text { al. "Experimental Analysis } \\
\text { of Heat Transfer and } \\
\text { Airflow in a Closed } \\
\text { Refrigerated Display } \\
\text { Cabinet." Journal of Food } \\
\text { Engineering, vol. } 244 \text {, } \\
\text { 2019, pp. 101-114. }\end{array}$ & $\begin{array}{l}\text { Airflow and temperature measurements were taken } \\
\text { on the shelves of a refrigerator display cabinet to } \\
\text { understand the temperature profile of the cabinet. } \\
\text { Compared open vs. closed display cabinet. } \\
\text { Analyzed a cabinet with and without a load inside } \\
\text { of the unit. Results suggested there are periodic } \\
\text { temperature fluctuations due to the on/off } \\
\text { compressor cycle and the defrosting cycle. }\end{array}$ \\
\hline $\begin{array}{l}\text { Danielsson, U. "Convective } \\
\text { Heat Transfer Measured } \\
\text { Directly with a Heat Flux } \\
\text { Sensor." Journal of Applied } \\
\text { Physiology, vol. 68, no. 3, } \\
\text { Jan. 1990, pp. 1275-1281. }\end{array}$ & $\begin{array}{l}\text { Study focused on a HFS calibration experiment. } \\
\text { Determined local heat transfer coefficients around } \\
\text { cylinder mimicking a human leg. Compared natural } \\
\text { to forced convection in laminar air streams. Placed } \\
\text { sensors on human with HFS to various angles to } \\
\text { mimic abdomen, legs, neck, thigh, hand, forearm } \\
\text { etc. and pushed down hall at constant speed. }\end{array}$ \\
\hline
\end{tabular}




\begin{tabular}{|c|c|}
\hline $\begin{array}{l}\text { Demuynck, J., et al. "Local } \\
\text { Heat Flux Measurements in } \\
\text { a Hydrogen and Methane } \\
\text { Spark Ignition Engine with } \\
\text { a Thermopile } \\
\text { Sensor." International } \\
\text { Journal of Hydrogen } \\
\text { Energy, vol. 34, no. 24, } \\
\text { 2009, pp. 9857-9868. }\end{array}$ & $\begin{array}{l}\text { Experimental investigation of heat transfer inside a } \\
\text { CFR spark ignition engine. Describes various } \\
\text { methods of measuring heat flux (Fourier methods, } \\
\text { impulse response processing method). Four } \\
\text { groups of sensors were explored (coaxial type, pair } \\
\text { wire type, film type, thermistor type) }\end{array}$ \\
\hline $\begin{array}{l}\text { Jayamaha, S.e.g., et al. } \\
\text { "Measurement of the Heat } \\
\text { Transfer Coefficient for } \\
\text { Walls." Building and } \\
\text { Environment, vol. 31, no. 5, } \\
\text { 1996, pp. 399-407. }\end{array}$ & $\begin{array}{c}\text { Convective heat transfer coefficients analyzed in a } \\
\text { lab and outdoor environment. The experiment } \\
\text { revealed that commonly used correlation for } \\
\text { predicting the convective heat transfer coefficient } \\
\text { overestimates, especially at high wind speeds. It } \\
\text { was also found that the wind direction did not have } \\
\text { a significant effect on the heat transfer coefficient } \\
\text { for large walls. }\end{array}$ \\
\hline $\begin{array}{l}\text { Langley, L.w., et al. "High- } \\
\text { Sensitivity, Surface- } \\
\text { Attached Heat Flux } \\
\text { Sensors." Microelectronics } \\
\text { Journal, vol. 30, no. 11, } \\
\text { 1999, pp. 1163-1168. }\end{array}$ & $\begin{array}{c}\text { HFS sensor development looking at different low } \\
\text { thermal resistance materials. The goal of the study } \\
\text { was to develop a sensor able to overcome the } \\
\text { distortion of heat flux paths, which is common with } \\
\text { surface heat flux measurement devices. A } \\
\text { conductive composite material was employed for } \\
\text { fabrication of heat flux sensors on aluminum } \\
\text { substrate. }\end{array}$ \\
\hline $\begin{array}{l}\text { Lienhard, John H., and } \\
\text { John H. Lienhard. A Heat } \\
\text { Transfer Textbook. Dover } \\
\text { Publications, Inc., } 2019 .\end{array}$ & $\begin{array}{l}\text { Textbook to reference fundamental heat transfer } \\
\text { principles }\end{array}$ \\
\hline $\begin{array}{l}\text { Niedermann, R., et al. } \\
\text { "Heat Flux Measurements } \\
\text { for Use in Physiological } \\
\text { and Clothing } \\
\text { Research." International } \\
\text { Journal of Biometeorology, } \\
\text { vol. 58, no. 6, Apr. 2013, } \\
\text { pp. 1069-1075. }\end{array}$ & $\begin{array}{l}\text { This study addresses concerns regarding heat flux } \\
\text { sensor calibration and tested four different } \\
\text { methods of calibration: hot plate, double hot plate, } \\
\text { nude cylinder and a cylinder covered with a spacer } \\
\text { material. Differences were found between the } \\
\text { manufacturer calibration and the calibration used } \\
\text { for the study. These differences were especially } \\
\text { evident when forced convection was involved as } \\
\text { the main heat transfer mechanism. The authors } \\
\text { concluded that the calibration method should be } \\
\text { chosen according to the intended purpose of use. }\end{array}$ \\
\hline
\end{tabular}




\begin{tabular}{|c|c|}
\hline $\begin{array}{l}\text { Pullins, Clayton A., and } \\
\text { Tom E. Diller. "In Situ High } \\
\text { Temperature Heat Flux } \\
\text { Sensor } \\
\text { Calibration." International } \\
\text { Journal of Heat and Mass } \\
\text { Transfer, vol. 53, no. 17- } \\
\text { 18, 2010, pp. 3429-3438. }\end{array}$ & $\begin{array}{l}\text { Successful characterization of temperature } \\
\text { dependence of the sensor output from } 100-900^{\circ} \mathrm{C} \\
\text { with acceptable uncertainty limits. Results showed } \\
\text { that the primary cause of the HFS output } \\
\text { temperature dependence is due to the change in } \\
\text { thermal conductivity with changing temperature. }\end{array}$ \\
\hline $\begin{array}{l}\text { Shenoy, Shyam Krishna, } \\
\text { and Thomas E. Diller. } \\
\text { "Heat Flux Measurements } \\
\text { from a Human Forearm } \\
\text { under Natural Convection } \\
\text { and Isothermal } \\
\text { Jets." International Journal } \\
\text { of Heat and Mass Transfer, } \\
\text { vol. 123, 2018, pp. 728- } \\
737 .\end{array}$ & $\begin{array}{l}\text { Heat transfer from a human forearm was studied } \\
\text { using a cylinder and a large jet similar to a building } \\
\text { HVAC vent outlet using HFS and IR camera. The } \\
\text { authors used Fluxteq sensors (PHFS-01 thin film } \\
\text { heat flux sensor with an embedded T-type } \\
\text { thermocouple). The results showed that at low heat } \\
\text { flux levels typical of body conditions, the heat flux } \\
\text { sensor gave lower measurement uncertainty than } \\
\text { the IR camera. }\end{array}$ \\
\hline $\begin{array}{l}\text { Singh, Sachin K., et al. } \\
\text { "Measurement Issues } \\
\text { Associated with Surface } \\
\text { Mounting of Thermopile } \\
\text { Heat Flux } \\
\text { Sensors." Applied Thermal } \\
\text { Engineering, vol. } 114,19 \\
\text { Dec. } 2016, \text { pp. } 1105-1113 .\end{array}$ & $\begin{array}{l}\text { Close examination of the intrusion due to surface } \\
\text { mounting thermopile sensors. Good explanation of } \\
\text { thermopile sensor physics. Authors found that } \\
\text { matching the impedance of the sensor and heat } \\
\text { conduction medium is important for minimizing the } \\
\text { intrusive effects. }\end{array}$ \\
\hline $\begin{array}{l}\text { Taler, Dawid, et al. } \\
\text { "Measurement of Heat Flux } \\
\text { Density and Heat Transfer } \\
\text { Coefficient." Archives of } \\
\text { Thermodynamics, vol. 31, } \\
\text { no. 3, Jan. 2010, pp. 3-18. }\end{array}$ & $\begin{array}{l}\text { Presents the solution to a problem of determining } \\
\text { the heat flux density and the heat transfer } \\
\text { coefficient based on temperature measurements at } \\
\text { three locations on a flat sensor that is temperature } \\
\text { dependent. }\end{array}$ \\
\hline $\begin{array}{l}\text { Vatell Corporation } \\
\text { (2001). Differential } \\
\text { Thermopile Heat Flux } \\
\text { Transducer. } 6278051 .\end{array}$ & $\begin{array}{l}\text { Introduces a thermopile HFS that can } \\
\text { simultaneously measure heat flux and temperature } \\
\text { at the measurement location. Previous HFS would } \\
\text { have to add a thermocouple or some other } \\
\text { temperature measurement instrument to the } \\
\text { measurement surface, which introduces thermal } \\
\text { contact resistance and could disturb the } \\
\text { measurement. }\end{array}$ \\
\hline
\end{tabular}




\begin{tabular}{|c|c|}
\hline $\begin{array}{l}\text { Vega, Thomas, et al. } \\
\text { "Partitioning Measurements } \\
\text { of Convective and } \\
\text { Radiative Heat } \\
\text { Flux." International Journal } \\
\text { of Heat and Mass Transfer, } \\
\text { vol. 84, 2015, pp. 827-838. }\end{array}$ & $\begin{array}{l}\text { New measurement techniques are presented to } \\
\text { simultaneously determine the radiative and } \\
\text { convective components in a mixed-mode heat } \\
\text { transfer environment. Sensitivity of the separated } \\
\text { irradiation heat flux values to the gas temperature } \\
\text { was evaluated. }\end{array}$ \\
\hline $\begin{array}{c}\text { Vettori, Robert L, and } \\
\text { David W Stroup. } \\
\text { "Measurement Techniques } \\
\text { for Low Heat Flux } \\
\text { Exposures to Fire Fighters } \\
\text { Protective } \\
\text { Clothing." National Institute } \\
\text { of Standards and } \\
\text { Technology, June } 2001 .\end{array}$ & $\begin{array}{l}19 \mathrm{HFS} \text { tested in six different configurations and } \\
\text { exposed to three different levels of heat flux from a } \\
\text { natural gas fired radiant panel. Three levels of heat } \\
\text { flux were } 1.2,2.5 \text {, and } 5 \mathrm{~kW} / \mathrm{m}^{\wedge} 2 \text { (low flow). This } \\
\text { experiment demonstrates heat flux measurements } \\
\text { and their correlation to expected heat flux values. } \\
\text { The water-cooled Schmidt-Boelter total heat flux } \\
\text { gauge yielded the closest to predicted heat flux }\end{array}$ \\
\hline
\end{tabular}




\section{CURRICULUM VITAE}

NAME:

CONTACT INFORMATION:

DOB:

EDUCATION \&TRAINING
Catherine Berghuis

1172 East Broadway, Louisville, KY 40204

Work: 502-452-5643

Cell: 603-667-6752

catherine.berghuis@gmail.com

March 19, 1994

M.S. Mechanical Engineering (exp. 05/2020)

University of Louisville

2017-2020

B.E. Mechanical Engineering

Dartmouth College

2016-2017

B.A. Engineering Sciences

Dartmouth College

2012-2016

\section{WORK EXPERIENCE:}

GE Appliances, Louisville, Kentucky

July 2017-

Present

Edison Engineering Development Program Member

- $4^{\text {th }}$ Rotation: Refrigeration, Master's Thesis

Present

Jan. 2019- 
- Studying methods of quantifying heat leak into refrigerated cabinet

- Built standalone sealed systems capable of cooling cabinet and determining heat leak via in flow measurement devices

- Validating use of heat flux sensors for measurement of heat leak through cabinet walls

- $3^{\text {rd }}$ Rotation: Range, Gas New Product Integration (NPI) July 2018Jan. 2019

- Designed oven camera housing to allow for ease of assembly and reduction of high temperatures

- Lead weekly cross functional meeting between mechanical, software and electronics teams for oven camera subsystem

- $2^{\text {nd }}$ Rotation: Computer Aided Engineering

Jan. 2018July 2018

- Performed impact, buckling, excessive stress/strain and thermal analysis using Abaqus and Hypermesh software

- Created rotational program on-boarding procedure to guide new hires on practical use of structural analysis software

- 1st Rotation: Refrigeration, Ice and Beverage Filtration July 2017Jan. 2018

- Developed test fixture with Arduino data acquisition system and 3D printed parts to digitize measurement system of hydraulic test equipment

- Assisted NPI team with filter testing to meet project deadlines

Build Health International, Fond-des-Blancs, Haiti Project Engineering Intern

June- Sept. 2016

- Consulted with project supervisor on installation of two mile water pipeline to supply local hospital

- Spent final week of work term as stand-in project supervisor for the construction of a surgical center

Dartmouth Machine Shop, Hanover, NH Teaching Assistant

- Machined, designed, and built parts using lathes, mills, laser cutters and other shop equipment

- Instructed students on engineering projects involving machining, thermoforming, and laser cutting 
Suffolk Construction, Boston, MA

July- Sept. 2015

Intern

- Proof-read blueprints to eliminate dimensional errors using AutoCAD software

- Contributed to weekly mechanical engineering subcontractor meetings

TECHNICAL SKILLS:

- Certified Solidworks Professional

- Rapid prototyping

- Machine tools

- Data acquisition

- Sensor Development

- Root cause analysis

COMPUTER SKILL \& LANGUAGES:

Proficient: LabVIEW, Arduino, MATLAB, Creo/ProE, Solidworks, Minitab, Engineering Equations Solver, MS Excel, MS Word

Familiar: Git, $\mathrm{C}++_{+}$Abaqus, HyperMesh 